\title{
Emotion Socialization via Mother-Child Conversations about Past Emotional Events
}

Kristina M. Kania

Follow this and additional works at: https://researchrepository.wvu.edu/etd

\section{Recommended Citation}

Kania, Kristina M., "Emotion Socialization via Mother-Child Conversations about Past Emotional Events" (2014). Graduate Theses, Dissertations, and Problem Reports. 5931.

https://researchrepository.wvu.edu/etd/5931

This Dissertation is protected by copyright and/or related rights. It has been brought to you by the The Research Repository @ WVU with permission from the rights-holder(s). You are free to use this Dissertation in any way that is permitted by the copyright and related rights legislation that applies to your use. For other uses you must obtain permission from the rights-holder(s) directly, unless additional rights are indicated by a Creative Commons license in the record and/ or on the work itself. This Dissertation has been accepted for inclusion in WVU Graduate Theses, Dissertations, and Problem Reports collection by an authorized administrator of The Research Repository @ WVU.

For more information, please contact researchrepository@mail.wvu.edu. 
Emotion Socialization via Mother-Child Conversations about Past Emotional Events

Kristina M. Kania, M.S.

\author{
Dissertation submitted to the \\ Eberly College of Arts and Sciences \\ at West Virginia University \\ in partial fulfillment of the requirements \\ for the degree of \\ Doctor of Philosophy \\ in \\ Psychology
}
Elisa Krackow, Ph.D., Chair Melissa Latimer, Ph.D. Cheryl McNeil, Ph.D. Julie Hicks Patrick, Ph.D. Constance Toffle, Ph.D.
Department of Psychology
Morgantown, West Virginia 2014

Keywords: Negative Affect; Mother-Child Conversations; Emotion Socialization; Qualitative 


\section{ABSTRACT \\ Emotional Socialization via Mother-Child Conversations about Past Emotional Events Kristina M. Kania, M.S.}

This study examined how mothers $(N=24)$ socialized emotions in their 7 - to 10 -year-old children during conversations about past positive and negative events. Mothers completed the Positive and Negative Affect Schedule (Watson, Clark, \& Tellegen, 1988) to rate the extent to which they experienced negative and positive affect. Conversations were coded for content, themes, mothers' and children's narrative strategies, life lessons, and statements that foster selfesteem. These patterns are discussed across mothers and children. Mothers and their children were collaborative in their discussions of past emotional events. That is, they tended to emphasize similar narrative processes during their conversations, regardless of emotional valence. Conversations also were coded for mothers' approach of emotions and event details, which then were correlated with mothers' affect levels. There were no significant findings for happy conversations. Mothers with higher (i.e., a little) negative affect tended to socialize their children to be less detail-focused when discussing past negative events. Maternal affect was only related to mothers' amount of speaking during happy conversations, with mothers with higher positive affect using fewer conversational exchanges. Overall, the strategies that mothers in this dissertation used during the conversations with their children tend to enhance children's social competence development (e.g., modeling, coaching, reacting; Denham, 1998). The children in this dissertation displayed skills that are associated with success in multiple socioemotional domains (e.g., identify and discuss causes and consequences for their and others' emotions; Fivush, Reese, \& Haden, 2006). These data were collected as part of a faculty member's ongoing project. 


\section{ACKNOWLEDGEMENTS}

There are many individuals I would like to acknowledge for their guidance and support. Without them, I would not be where I am today. First, I would like to express my infinite love and appreciation for my parents and for my friends from home, in graduate school, and on internship. Your wisdom, words of encouragement, hugs, and humor kept me going when times were difficult. You reminded me of the light at the end of the tunnel and motivated me to reach my ultimate professional goal. I would also like to thank my committee chair and members, Drs. Elisa Krackow, Melissa Latimer, Cheryl McNeil, Julie Hicks Patrick, and Constance Toffle, for their time, guidance, and support with this project. You challenged me to grow professionally and personally during this experience. Last, but certainly not least, I would like to express my gratitude for my internship and fellowship supervisors. I will never forget your roles in helping me reach my goal of becoming a clinical psychologist. 


\section{TABLE OF CONTENTS}

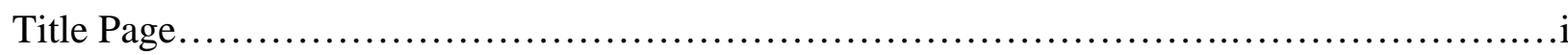

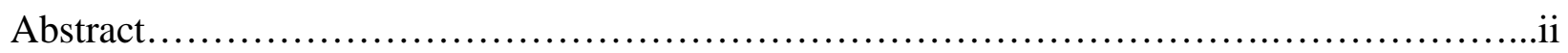

Acknowledgements.................................................................ii

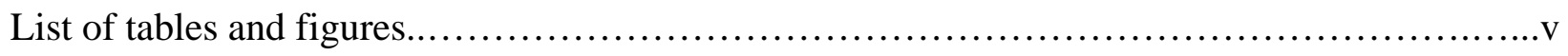

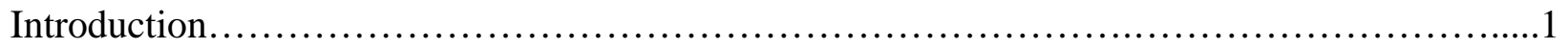

Method

Participants............................................................... 31

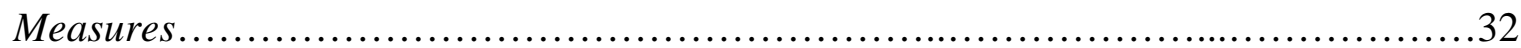

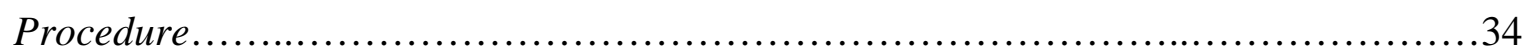

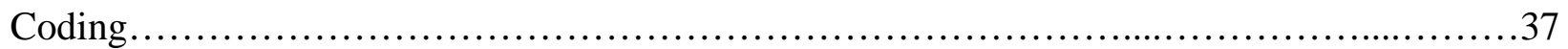

Results........................................................................46

Discussion....................................................................... 70

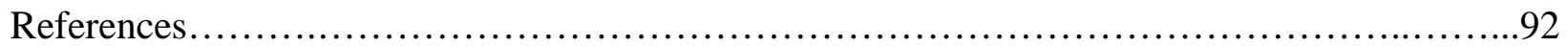

Tables......................................................................... 105

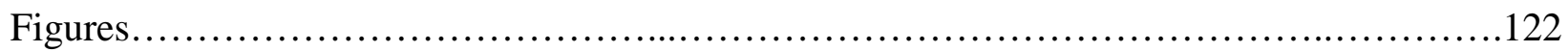




\section{LIST OF TABLES AND FIGURES}

\section{TABLES}

Table 1. Descriptive characteristics of conversations.................................. 105

Table 2. Coding system codes, definitions, and examples from this study..................106

Table 3. Inter-rater reliability for the coding system, as calculated by Cohen’s kappa..........109

Table 4. Name and number of topics discussed by mother-child dyads, per emotion conversation.

Table 5. Name and number of themes discussed by mother-child dyads, per emotion conversation.

Table 6. Order of maternal processes used, per emotion conversation.......................112

Table 7. Mean use of maternal conversational processes by emotion event...................113

Table 8. Order of children's processes, per emotion conversation..........................114

Table 9. Mean use of children’s conversational processes by emotion conversation...........115

Table 10. Themes of life lessons mothers conveyed, per emotion conversation................116

Table 11. Themes of statements mothers used that are related to improving children's self-

esteem, per emotion conversation....................................................118

Table 12. Mean use of maternal approach statements, per emotion conversation..............119

Table 13. Correlations among negative affect (NA) and positive affect (PA) on the PANAS and use of approach statements, per emotion..........................................120

Table 14. Correlations among negative affect (NA) and positive affect (PA) on the PANAS, and number of maternal conversational exchanges, per emotion.

\section{FIGURES}

Figure 1. Mean Maternal Exchanges by Emotion Conversation. 
Figure 2. Mothers’ Use of Statements that Approach Emotion, Emotion Resolution, and Event

Detail during Happy Conversations.................................................123

Figure 3. Mothers' Use of Statements that Approach Emotion, Emotion Resolution, and Event

Detail during Sad Conversations...................................................124

Figure 4. Mothers’ Use of Statements that Approach Emotion, Emotion Resolution, and Event

Detail during Scared/Worried Conversations.........................................125

Figure 5. Mothers’ Use of Statements that Approach Emotion, Emotion Resolution, and Event

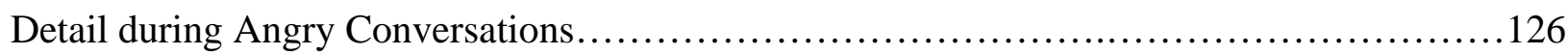


Emotion Socialization via Mother-Child Conversations about Past Emotional Events

Emotional development is a major component of general child development. One important question to ask is what factors affect children's emotional development. More specifically, it is important to understand processes by which children begin to understand, express, and cope with their emotions. Emotional development occurs in part through parentchild interactions, whereby parents teach or socialize emotions in their children (Castro, Halberstadt, Lozada, \& Craig, 2014; Fivush, 1991a).

Sociocultural theory (Vygotsky, 1978) provides an explanation for one mechanism through which maternal emotional expressiveness during mother-child conversations transmits to the child's personal emotional understanding and regulation. According to Vygotsky's (1978) theory, learning must occur for children to be able to develop processes they use when interacting with others in their environment. Through interactions with adults, children internalize these processes and incorporate them into their own behavioral repertoire. Applying Vygotsky’s (1978) theory to emotion socialization specifically, children's ability to regulate emotions originates from mother-child conversations about emotion. This learning is transmitted in conversations by mothers scaffolding children's emotional understanding and regulation abilities to narrow the discrepancy between the child's actual developmental level and the child's level of potential development (i.e., zone of proximal development; Vygotsky, 1978). However, a mother who is unable to regulate her own emotions may not be able to model and guide her child to allow the child to narrow that discrepancy between the child's actual and potential developmental levels. For example, rather than approaching and processing emotions with her child to encourage increased regulation of emotions, she may avoid discussing emotions entirely, thereby restricting her child's emotional understanding. 
Denham's (1998) model of emotion socialization provides a large portion of the conceptual framework for this dissertation. The model theorizes that parental modeling of emotions, discussion of emotions, and reactions to their children's emotions all impact the extent to which children understand and express emotions. Denham (1998) suggests that children will not gain much insight into emotion if parents do not discuss emotions, limit their own emotional expression or react negatively to their children's expression of emotions. Additionally, parents model and coach their children on how to regulate their emotions when their experiences are under- or overwhelming for them. Emotion regulation is significantly associated with others' impressions of one's social competence, which has many implications for the child's academic and social success. As children age and develop more effective coping skills, they require less guidance from their parents on how to regulate their emotions (Denham, 1998; Eisenberg, Fabes, Murphy, Maszk, Smith, \& Karbon, 1995). In sum, parents play a key role in helping their children develop their own understanding of emotions in addition to shaping their children to be viewed positively by others, including teachers and peers. Fivush's work serves as the other primary component of the conceptual framework on which this dissertation is based. Like Denham, Fivush also suggests that children learn how to express and modulate their emotions during verbal and nonverbal interactions with adults (Fivush, Brotman, Buckner, \& Goodman, 2000). Fivush's work is based largely on Vygotsky's (1978) sociocultural theory. More specifically, Fivush's theories are based on the fact that personal narratives develop externally via interactions with others and later become part of the individual (Fivush, 1991a). Therefore, this dissertation is largely guided by Denham, Fivush, and Vygotsky's theories and concepts. 


\section{Empirical Support for Model of Emotion Socialization}

There is general support for Denham's model of emotion socialization (Denham et al., 2003; Denham \& Kochanoff, 2002; Denham, Mitchell-Copeland, Strandberg, Auerbach, \& Blair, 1997). However, evidence supporting portions of Denham's (1998) model theorizing that emotion socialization occurs specifically in the context of parent-child conversation comes from Dunn, Brown, and Beardsall (1991). The researchers examined how individual differences in children's conversations about emotions with their mothers and siblings influence their subsequent ability to identify emotions in others. Two 1-hour sessions were conducted in the children's homes when they were 3 and 6 1/2 years old. At age 3, mother-child conversations were coded for discussions of feeling states. Researchers specifically coded: 1) mothers' and 2) children's references to feeling states, 3) details about turn taking, 4) arguments, 5) references to emotional antecedents during conversations that referred to feeling states, 6) the average length of time the child spoke, and 7) the total number of times turn taking occurred in these motherchild conversations (Dunn et al., 1991). When the children were $6 \frac{1}{2}$ years-old, the researchers administered the Rothenberg (1970) test of social sensitivity as the tool for measuring the children's ability to identify others' emotions (Dunn et al., 1991).

Mothers who discussed emotions more with their children at age 3 had children who were better able to identify others' emotions at age $6 \frac{1}{2}$ than children whose mothers used fewer emotional expressions in conversations at age 3. In general, 3-year-old children and mothers whose families discussed numerous emotions were more likely to discuss antecedents and consequences to emotions than were 3-year-old children and mothers whose families engaged in these feeling state discussions less frequently (Dunn, Brown, \& Beardsall, 1991). At age 6 1/2, these children also made more accurate inferences about the emotions of the adults in the 
Rothenberg (1970) test of social sensitivity compared to those children who had fewer feeling state discussions at age 3 (Dunn et al., 1991). In sum, early childhood conversations influence children's later understanding of others' emotions.

In addition, maternal expression of emotion has been found to predict children's subsequent use of those expressions (Bauer, Stark, Lukowski, Rademacher, \& Abbema, 2005). If a mother tends to focus on one emotion over another when discussing past experiences, the child then learns that the more commonly discussed emotion is more important than the less discussed emotion (Fivush et al., 2000). These findings emphasize the importance of maternal modeling of appropriate emotional expression. In sum, maternal discussion and expression of emotions when a child is young develops the child's ability to understand and express emotions as the child gets older.

\section{Emotion Socialization across Development}

Parental emotion socialization begins when the child is an infant, by providing eye contact and facial expressions as they speak to the infant and by responding to the infant's display of emotions (Leaper, 2002). Parents shape their children's emotional expressions at this age, in part, by attending to the infant more when the infant is happy or calm and removing joint attention when the infant is frequently dysregulated. During toddlerhood, parents shape their children by developing their understanding that they have emotions that may be different from others', that they have control over the expression of their emotions, and that they can have prosocial emotions (Leaper, 2002). By the preschool years, children have developed emotional scripts (Widen \& Russell, 2010). These scripts are formed through experience with emotions. Children initially develop broad emotion categories (e.g., positive, negative). With experience with the causes and consequences of each emotion, children learn to separate the various 
emotion categories into more specialized emotions (e.g., angry, sad) and apply labels to them (Widen \& Russell, 2010). These scripts help the child determine the types of events that map onto major emotions (e.g., death of a loved one maps onto sadness). Also at this age, children begin to understand display rules (Misailidi, 2006). Display rules govern the specifics (e.g., when, where, with whom) of expressing emotion, influencing children's emotional expression during their conversations with their mothers. Display rules fit into two categories: prosocial and self-protective (Gnepp \& Hess, 1986). Prosocial display rules serve to benefit others while selfprotective display rules serve to enhance benefit or reduce loss to the self. As mothers model and discuss emotional expression during interactions with their children, children learn the specifics of when, how, and to whom to express or conceal their emotions.

During middle childhood, children continue to look to their parents for support; however, children begin relying on peers to gain additional support. Parents may begin decreasing the intensity of their emotion regulation guidance, while still ensuring their children's adherence to the family's core values (Leaper, 2002). Parents typically decrease their emotion regulation guidance even further when their children become adolescents and, instead, begin increasing their guidance with helping their adolescents reach specific goals, such as graduating, or avoiding certain behaviors, such as risky sexual behavior (Leaper, 2002). Emotion socialization does not end at the conclusion of adolescence. Rather, families continue to interact and provide support and guidance to their children, especially during times of change (e.g., marriage, having children, dealing with parental mortality; Leaper, 2002). In sum, emotion socialization is a lifetime process of transactions between children, their parents, and others. 


\section{General Processes and Exact Strategies of Emotion Socialization via Conversations}

To date, two studies have examined the general processes mothers use during conversations with their children about past events and the functions of those processes (Marin, Bohanek, and Fivush, 2008; Wang \& Fivush, 2005). In the first study by Marin et al. (2008), middle-class, predominantly Caucasian families with 9- to 12-year-old children discussed one recent negative event. The conversations were coded for the processes used during the conversations: initiations (e.g., new information is presented), collaborations (e.g., agreement and elaboration on statements), and non-collaborations (e.g., disagreement and revision of statements). They also coded the function of the statements into expression (e.g., what the emotion is) or explanation (why the emotion was experienced). Additionally, they coded conversations as either negative or positive and either specific or general. The difference between specific and general emotions was that specific conversations directly stated the emotion (e.g., happy), whereas general conversations indirectly approached the emotion. For example, stating that the child had fun suggests it was a positive experience, but it does not state a specific emotion, such as happiness. Both specific and general emotions are captured in the coding in this dissertation under the approach emotion category. Two years after the family discussion, the children completed the Rosenberg self-esteem inventory (RSI; Rosenberg, 1965) and the Self-perception profile for children (SPPC; Harter, 1985).

Marin et al. (2008) found that the parental initiation, collaboration, and discussion of specific negative emotions were associated with higher child self-reporting of social and academic competence. As conversations are, by definition, exchanges of information, it is important to note that children also influence conversations. Children whose parents have thoroughly discussed emotions and the reasons for those emotions are better able to contribute to 
conversations about emotions (Wareham \& Salmon, 2006). Therefore, it may be that children who have higher social and academic competence influence their parents' verbal behavior during conversations about emotions.

The second study that examined the processes mothers use during conversations with their children found that mothers in the United States, compared to Chinese mothers, talk frequently about the antecedents of children's emotions (e.g., approach emotions) and about reducing negative emotions (e.g., approach emotion resolution) by focusing on how the problem is now resolved (Wang \& Fivush, 2005). In turn, the children in the United States often speak about the antecedents to their emotions. The researchers stated that when mothers focus on emotions and resolution of negative emotions, it is likely that their children will develop emotional understanding and unique social and personal identities, also referred to as an autonomous self (Wang \& Fivush, 2005).

In sum, the narrative processes mothers use during conversations with their children affect their children's later social and emotional functioning. This dissertation examines the general processes mothers use to socialize emotions in their children during conversations about past positive and negative events. In addition, this dissertation breaks down the general processes into exact strategies, such as what questions the mothers are asking to elicit certain information about emotions and event details.

Empirical evidence (e.g., Bohanek, Fivush, Zaman, Lepore, Merchant, \& Duke, 2009) and technique (e.g., grounded theory) drive the coding for the mother's processes and exact strategies used during the mother-child conversations in this dissertation. First, the focus will be on the empirical evidence for general processes. In Bohanek and colleagues' (2009) study, they coded spontaneous family narratives during dinnertime. They coded each utterance into four 
processes: request, provide, confirm, and negate. The function of each code was: a) request— to ask for information, b) provide — to present new information, c) confirm — to validate or repeat a previous utterance, and d) negate - to negotiate the facts of the event (Bohanek et al., 2009). These codes map loosely onto the codes used in this dissertation. The difference is that the codes in this dissertation further divide Bohanek et al.'s (2009) codes to gather more in-depth information.

Fivush, Berlin, Sales, Mennuti-Washburn, and Cassidy (2003) also coded for narrative process in conversations between mothers and their preschool children. Although the sample in this dissertation consists of 7- to 10-year-old children, research on preschoolers is relevant because emotion socialization waxes and wanes and changes form over the course of a child's development (Leaper, 2002). Fivush et al. (2003) coded for style (e.g., elaborations, evaluations, and repetitions) and content (e.g., factual, emotion, attribution, cause, and resolutions). This dissertation utilizes some of the same codes, but again extends beyond the content and focuses on the process. In sum, although the coding schemes in the two aforementioned studies are not identical to the one used in this dissertation, they provide guidance for the theoretical coding done according to grounded theory

As for grounded theory, coding moves from content and themes to that of process of the narrative (Charmaz, 2014). Although it is recommended that grounded theory be guided primarily by the researcher's interpretation of the data and how the researcher makes sense of the data, empirical evidence guides how codes are grouped together into larger codes. This recommendation is in line with constructivist assumptions and objectives and explains that coding is subjective in that the researcher's views influence the codes that are created (Charmaz). In addition to grounded theory, the coding for the exact strategies the mothers used during the 
conversations with their children in this dissertation is influenced by the work of Marin et al. (2008). They coded for the processes mothers used and the functions of those processes. As conversations are transactional and bi-directional, children's general conversational processes are also coded in this dissertation. As is the case with the maternal process codes, the children's process codes also are based on empirical evidence (e.g., Fivush et al., 2003) and technique (i.e., grounded theory).

\section{Conversation Valence and Emotion Socialization in Mother-Child Conversations}

In addition to the important impact of maternal narrative processes, the mood or tone of the event discussed in a mother-child conversation about the past (positive v. neutral v. negative) has been shown to vary. Although mothers in relevant studies are commonly instructed to discuss an event in the recent past, they are not typically restricted to a particular conversational tone. Even without these restrictions, the majority of the mother-child discussions chosen by mothers are positive (Farrant \& Reese, 2000; Reese \& Brown, 2000) or positive and neutral in nature (Burch, Austin, \& Bauer, 2004). Burch et al. (2004) found that children provided more information for the negative events discussed than for the positive or neutral events.

Additionally, children tended to describe their feelings and ideas for causality of emotions more when discussing negative versus positive events (Burch et al., 2004). Other important questions to address relate to the processes by which mothers discuss positive versus negative life events with their children and how that narrative structure affects children's development.

\section{Content and Themes of Mother-Child Conversations}

A majority of the mother-child discourse studies do not discuss the topics of the conversations. Three known exceptions exist in the literature, with two of those being from the same data set. One example in which content and themes have been reported in mother-child 
conversations is a study by Bohanek, Marin, Fivush, and Duke (2006) that shares the same data set with Marin et al. (2008). Bohanek et al.’s (2006) sample consisted of middle-class families with children between the ages of 9 and 12 years old. In this study, families discussed one positive and one negative past shared event with the main goal of the study examining the transmission of self-esteem in mother-child conversations. For the positive events, the topics discussed were: vacations (78\%), new sibling (8\%), sporting event $(8 \%)$, visits with relatives $(5 \%)$, and ceremonies $(1 \%)$. The topics discussed during the negative event conversations were: death of a family member or friend (30\%), death of a pet $(20 \%)$, illness or injury $(13 \%)$, accident/disaster (13\%), family conflict (8\%), moving (8\%), problem during vacation ( $8 \%)$, and parents' well-being (1\%). Bohanek et al. (2006) found three narrative styles used among the families in this study: coordinated, individual, and imposed. These styles match up to three of Baumrind's (1971) parenting styles: authoritative, permissive, and authoritarian. Families with a coordinated perspective or authoritative parenting style encourage and validate children's contributions to conversations and integrate their contributions into the overarching conversation. Those with an individual perspective or permissive parenting style allow children to voice their opinions, but do not attempt to shape those opinions to match or please others. Finally, families who take an imposed perspective or an authoritarian parenting stance do not encourage children to express their thoughts or emotions and may even punish the child for doing so, and they assert that children should willingly accept the opinions of authority figures (Baumrind, 1971; Bohanek et al., 2006).

A second example that explicitly states topics discussed during mother-child conversations is the study by Wiley, Rose, Burger, and Miller (1998) in the autonomous self literature. Their sample consisted of $2 \frac{1}{2}$ - to 3 -year-old children and their families. The families 
were informed that the researchers were interested in examining how children learn to communicate. The authors explicitly list the topics of conflict from these conversations, which included: whether the child dropped or threw a toy, whether the child cried or not after an event component, and whether the child threw up yesterday or a while ago. Together, these are the topics to which one can compare the topics discussed in this dissertation.

In contrast to content, themes are more commonly reported, especially in the moral development literature. One example of such a study is from Woolgar, Steele, Steele, Yabsley, and Fonagy (2001). The themes they report as being discussed in their study are: physical punishment, verbal punishment, other exclusion, shame, affection, positive maternal representations, maternal disciplining representations, dishonesty, guilt/reparation, and physical aggression. Another example is the review chapter by Smetana, Campione-Barr, and Metzger (2006) that focuses on adolescent development, with parent-child issues as just one portion of the chapter. The authors discuss themes of parent-adolescent relationships, such as conflict, distancing, separation, closeness, and warmth. Related to conflict, distancing, and separation, Smetana et al. (2006) discuss the literature on the pattern of conflict between parents and their children over time, how conflict with parents affects child's well-being and independence, and the role of demographic variables in parent-adolescent conflict. The authors discuss various factors related to each other and group them into the categories of closeness and warmth. For example, they discuss how patterns of these constructs change with the child's age, the effects of these constructs on children's well-being and social skills, and how these constructs look different with mothers versus fathers (Smetana et al., 2006). Overall, themes are created by grouping the content of the conversations into larger clusters that make conceptual sense and by 
assigning meaning to those clusters. In general, these studies provide examples of how topics in this dissertation can meaningfully be grouped into themes.

An important question to ask is why these topics are being discussed by mothers and their children. People are more likely to recall experiences that were unique for them, as opposed to experiences that are more routine or typical in their lives (McCabe \& Peterson, 1990). Children often have a difficult time pinpointing details of specific events if those events have occurred on numerous occasions and, instead, tend to rely on their general event knowledge during autobiographical recall (Hudson \& Nelson, 1986). Additionally, the way in which the event is unique for the person influences which details they recall later (Hudson \& Krackow, 1990). In sum, the content and themes commonly seen in mother-child conversations represent events that are atypical and exceptional in some way to the children.

\section{Maternal Life Lessons}

Mothers often use conversations with their children about past events to teach lessons, to give advice, and to help children develop emotion regulation skills (Kulkofsky, Wang, \& Koh, 2009). Kulkofsky et al. (2009) examined conversations of Chinese mother-child dyads and European American mother-child dyads. The children had a mean age of $4 \frac{1}{2}$ years and all came from middle-class families, with the majority of the mothers having at least a college degree. Mother-child dyads engaged in free play, before reminiscing about two specific, shared, novel events (i.e., one positive emotion event, one negative emotion event that were counterbalanced across groups) that took place within the previous two months. Kulkofsky et al. (2009) instructed the dyads to discuss the conversations as they typically would and did not place any length restrictions on the conversations. 
As part of the study, mothers completed an open-ended question on why they typically share their memories with their children. These responses then were coded for seven functions, including teaching/problem solving and emotional regulation. Kulkofsky et al. (2009) found that mothers that reported believing these functions are important were more likely to use these strategies during their conversations with their children about shared past emotional events. Additionally, the European American mothers were more likely to use these specific strategies than were the Chinese mothers. The researchers suggested this was likely because sharing memories is the preferred method of teaching in European American cultures because it is an enjoyable method of teaching. The researchers stated that, in comparison, teaching in Chinese cultures is viewed as requiring more formal methods of delivery (Kulkofsky et al., 2009). Therefore, culture influences the emphasis on and methods mothers use to teach life lessons to their children.

Not only do mothers teach life lessons and give advice when reminiscing about shared memories, but they also use this strategy when discussing their children's peers (Laird, Pettit, Mize, Brown, \& Lindsey, 1994). Laird et al. (1994) examined conversations between mothers and their children via six interviews with the mothers on the telephone. The children were either in preschool, with a mean age of 5 years, or in elementary school, with a mean age of almost 6 years. All families were professional and from a small city, with the majority of the participants being Caucasian. The mothers were asked about conversations they had with their children within the past 48 hours regarding situations with the children's peers. If coding was not able to be completed based on what the mother freely offered the interviewer, the interviewer used standard prompts to gain the information (e.g., did you provide advice?). Interviews were coded 
on seven factors based on the mother's report, including whether the child asked for help and whether the mother offered advice (Laird et al., 1994).

The researchers found that mothers gave advice in $27 \%$ of the conversations with their children, an average of 1.5 times per family (Laird et al., 1994). Advice giving ranged from none to seven times per family, with $28 \%$ of the mothers never giving advice, $33 \%$ giving advice once, and $23 \%$ giving advice at least three times. When advice was given, mothers provided the life lesson almost exclusively in the context of peer relationships. More specifically, there were three primary areas of focus for the lessons conveyed by the mothers: how to contact a peer, how to keep a friendship going, and how to manage bullying or conflict. The researchers reported that the frequency of maternal advice giving in their study predicted children's peer acceptance, as measured by peer reports. That is, it may be that advice giving, in a positive mother-child relationship, develops young children's social competence. Mention of a positive relationship is important in that it has been shown that advice giving or 'coaching' is less effective when mother-child relationships are strained (Mize \& Pettit, 1997).

The next question to be asked regards the structure of mother-child conversations in which mothers provide life lessons. Conversations in which the mother is focused on giving advice or conveying a lesson qualitatively differ from those in which the mother is attempting to bond with the child. Kulkofsky (2011) examined conversations about past events between mothers and their 4-year-old children. Almost half of the mothers had at least a college degree and half of the dyads were Caucasian, while the other half of the dyads was Hispanic. The dyads were instructed to read a picture book together, and then discuss a novel, shared, event that occurred within the past 2 months. After that task, mothers were told to have two conversations with their children: one with a focus on bonding with the child and the other with a focus on 
teaching a lesson. The order of these conversations was counterbalanced. The conversations were video recorded and the length of the conversations was not dictated by the researcher.

Conversations were coded for social content (i.e., talk about others), evaluative content (i.e., evaluate the experience), and didactic talk (i.e., appropriate behavior, morals).

Kulkofsky (2011) found that mothers used more didactic talk and focused more on the child when they were told to focus on teaching a lesson, whereas they used more social content and focused more on the mother when they were told to focus on bonding with their children. Additionally, when the focus was on teaching a lesson, mothers focused less on autonomy, evaluating experiences, and specific events than when the focus was on bonding. Maternal elaboration and child elaborations or repetitions did not differ between the two types of conversations (i.e., bonding, teaching a lesson; Kulkofsky, 2011). In sum, during conversations that contain maternal life lessons, mothers tend to focus on rules and morals, while keeping the conversations focused on the child.

In addition to the quality of the mother-child relationship, a child's age also may impact the effectiveness of parental advice giving. Interestingly, higher levels of parental advice giving in older children have been associated with poorer child social competence ratings. McDowell, Parke, and Wang (2003) looked at the relation among parental advice giving style and content and children's social competence and psychological functioning in a sample of $3^{\text {rd }}$ graders and their parents. Advice content was coded as the number of statements in which the parents offered advice to their children. Advice quality was coded as the degree to which the advice was specific, reasonable, or feasible. Their sample consisted of primarily Caucasian, lower- to middle-class families, with parents who had at least a high school degree. 
In their study, the children and their parents discussed social situations that were presented to them by the researchers at Time 1 and were video recorded (McDowell et al., 2003). At Time 1 and at a 1-year follow-up, peers and teachers rated the children's social competence and the child completed self-reports of depression and loneliness. More specifically, teachers completed measures using a 5 -point likert scale $(1=$ not at all like this child, $5=$ very much like this child) rating the child's likability and behavioral attributes at school. The child's peers completed sociometric interviews and nominated peers they liked or disliked spending time with and peers who fit certain descriptions (e.g., prosocial behavior, aggression). The child completed Asher, Hymel, and Renshaw's (1984) 16-item self-report measure on loneliness and Kovacs' (1981) Children's Depression Inventory.

The researchers found that more frequent and higher quality parental advice giving during conversations about difficult social situations was related to poorer peer and teacher ratings of the child's social competency (McDowell et al., 2003). Also, children who reported higher levels of loneliness and depression received poorer social ratings by teachers and peers. Finally, the children who received a higher quantity of parental advice at Time 1 reported higher levels of depression and loneliness at Time 2 (McDowell et al., 2003). McDowell and Parke (2009) replicated the finding that higher levels of and better quality advice are associated with worse child social competence ratings by others.

These findings together suggest that it could be that more advice and shaping are necessary when children are younger, and that children would typically benefit from a reduction in parental intrusiveness as they get older and develop more skills. However, the literature is not clear on the age at which parental advice becomes less useful. Also, the direction of the relation between quantity of parental advice and child's social standing is unclear. It could be that when 
children have a poor social standing, the parents then try to remediate that during their conversations about social events by providing more advice. Alternatively, it could be that children have a poor social standing because of the high frequency with which their parents provide advice, which does not allow the child to solve difficult social situations on their own. Therefore, increased levels of loneliness and depression in these older children could be a cause or a result of a poor social standing.

Overall, cultural norms play a role in the prevalence and helpfulness of advice giving during parent-child conversations. This relation depends on the parent's emphasis on and preference for informal or formal teaching strategies. Also, conversations in which the focus is on giving advice differ in content and structure from those that have a different focus (e.g., bonding). Finally, maternal life lessons and advice giving are helpful depending on the child's age and existing level of social competence. Younger children with less-developed social competence tend to benefit more from higher levels of and better quality advice from parents, whereas those in later childhood tend to see depreciating effects on their social competence ratings from others. However, further research is needed to clarify the age at which maternal life lessons become less useful.

\section{Maternal Statements to Foster Self-Esteem}

Parent-child conversations about the past help develop a child's sense of self (Fivush \& Nelson, 2006). In particular, parent-child talk about emotions allows children to evaluate their past, to understand that they existed in the past and can exist in the future, and to understand that their internal states, which include internal representations of beliefs, cognitions, and emotions, do not remain stable. Additionally, children learn to differentiate their internal states from those of others. Children typically begin developing a sense of self in their preschool years (Fivush \& 
Nelson, 2006). Vygotsky's (1978) sociocultural theory of development supports the importance of social interaction and language on developing a child's theory of mind. Discussing the past helps the child learn that memories are symbols of the past, and not actually the result of the event repeating itself (Fivush \& Nelson, 2006). Therefore, they learn that others may have different memories about events than they do, which extends into an understanding of separateness of one's mind from others' minds (Fivush \& Nelson, 2006). In sum, parent-child conversations allow children to develop a sense of self over time and compared to others. It is only following a developed sense of self that one can develop a sense of worth and self-esteem, which both impact social competence.

Mothers converse with their children not only to bond or to give advice, but also to foster their self-esteem. Marin, Bohanek, and Fivush (2008) examined how self-esteem is affected by parent-child discourse using a sample of middle-class, primarily Caucasian families with children between 9 and 12 years old. The detailed procedure for their study was described previously in this paper. The researchers found that the expression of, and especially the explanation of specific, not general, negative emotions during the family conversations were related to higher levels of the children's self-esteem ratings and levels of competency (Marin et al., 2008). Those families that were open to and supportive of the child's expressions and evaluations of their negative emotions were found to have children with higher levels of selfesteem. Discussing negative emotions in an evaluative way helps children learn how to cope with negative emotions, thereby increasing their self-esteem and perceived competency at managing those emotions. Additionally, Marin et al. (2008) discovered that families that thoroughly discussed and explained specific, not general, positive emotions in the context of past negative emotional events also had children with higher levels of self-esteem and social 
competence (Marin et al., 2008). Therefore, discussing positive emotions only to try to detract from the negativity of a situation is not effective at improving children's self-esteem and social competence; however, integrating the specific positive and negative emotions about a situation is more effective at achieving those goals.

Although discussion and explanation of both specific negative and positive emotions is important in fostering children's self-esteem, the reasons they each are important are different. Reese, Bird, and Tripp (2007) suggested that the reason discussing specific negative and positive emotions in a conversation is associated with higher self-esteem in children is because it possibly allows children to integrate their own strengths and weaknesses and develop a stronger sense of self. Alternatively, they suggested it could be that parents feel that it is less damaging to discuss their children's weaknesses/negative emotions when their children already have high selfesteem. To capture this, this dissertation codes for mothers who recast their children's weaknesses as strengths. Reese et al. (2007) also suggested that discussing specific positive emotions in the context of past events is likely beneficial in that it is not only teaching children to assess their pasts positively, but could also generalize to children appraising themselves in a more positive manner overall. Therefore, it is the explaining of specific emotions and the validating of children's emotional experiences, both positive and negative, that are associated with higher levels of children's self-esteem. This dissertation accounts for this by coding for maternal support of children's expression and evaluation of emotions. This dissertation also codes for person and process praise. Person praise is praising the child and process praise is praising the child's behavior (Kamins \& Dweck, 1999). Together, these codes elucidate the processes by which mothers are praising their children. 
A child's sex may impact how mothers try to foster self-esteem in their children. For example, Bohanek et al. (2006) examined children's sex differences in the effect of family discourse on child self-esteem. Their sample consisted of middle-class, primarily Caucasian families, with children between 9 and 12 years old. Families were asked to discuss one specific positive and one specific negative shared event that occurred within the past 2-3 years. There were no time constraints placed on the conversations and the order in which the conversations were discussed was counterbalanced across families. Conversations were audio recorded, transcribed, and then coded into three types of narrative styles: coordinated perspective (e.g., children and parent both integrating their contributions to the narratives), individual perspective (e.g., a focus on the child's perspective without integrating family members' views), and an imposed perspective (e.g., a focus on the parent's perspective, while changing the child's contributions to fit parent's views). Children completed the Rosenberg Self-Esteem scale (RSE; Rosenberg, 1965) and another measure that is irrelevant to this dissertation.

Bohanek, Marin, Fivush, and Fuke (2006) found that a coordinated perspective during family discussions of shared past events was significantly associated with higher levels of selfesteem for girls, but not for boys. Bohanek et al. (2006) suggest that it is likely that, due to their age and developmental levels, the boys in their study may have self-esteem more closely tied to factors outside of the family (e.g., school) and that their self-esteem is not tied to social connectedness until later in life.

Finally, self-esteem is a culturally-defined concept. Therefore, it is important to note any cultural differences on the emphasis on statements that foster self-esteem in children during discourse with a parent or caregiver. Most of the comparisons in mother-child discourse have examined differences between European American and Eastern Asian cultures. In a comparison 
of European American and Chinese mothers, Miller, Fung, and Mintz (1996) found that the European American mothers in their study tended to cast a positive light on their children and fostered self-admiration in their children, whereas the Chinese mothers were more likely to foster self-criticism and self-evaluation in their children. European American mothers in their study stated that they felt that their children required their attention to develop self-esteem. This finding could be influenced by the differences in emphasis on the self (e.g., European American) versus the community (e.g., Chinese), whereby independent goals tend to be more valued in the first and goals for the group tend to be more valued in the latter (Miller et al., 1996).

In sum, the content, style, and effectiveness of maternal statements that foster self-esteem vary based the emotional valence of the event, the sex of the child, the age of the child, and the cultural influences on the family. Therefore, the literature on the impact of those individual differences on mother-child conversations is reviewed next.

As mentioned previously, parental emotion socialization is an ever-evolving process. Therefore, all of the parent-child conversation findings discussed previously may look different at different points in time depending, in part, on the child's age and skill level.

\section{Individual Differences Affecting Mother-Child Conversations}

Child's sex. Examining the effect of child's sex on emotion socialization via parent-child conversations, Fivush et al. (2000) asked parents to talk about past events with their preschoolage children, focusing on four separate occasions during which the child felt happy, angry, sad, and scared. Those four emotions are used throughout the parent-child discourse literature, as they are the most commonly experienced emotions (Fivush et al., 2000). The literature shows that older children are more skilled at role-taking with their peer groups if they have mothers who discussed the causes of emotional responses with them when they were young. Therefore, 
Fivush et al. (2000) coded for attributions and causes of the emotion. They also looked for social-relational conversation themes versus autonomous themes, as the literature shows that mothers use the former type of theme more commonly with daughters and the latter theme more commonly with sons (Fivush, 1991b). The researchers examined conversation lengths for each emotion, the number and type of utterances about emotional components of the events, and the number of emotion words used (Fivush et al., 2000).

Fivush et al. (2000) found, in part, that mothers spoke more, used more emotion words, and discussed causes of emotions more than did fathers with their 3-year-old children; however, both mothers and fathers gave more causes for sadness to their daughters than their sons. Females may learn from this that sadness is more important than other emotions. In turn, this could lead to females discussing and focusing more on sadness, which potentially could increase their likelihood for developing depression (Fivush et al., 2000). Alternatively, males may be learning that other emotions are more important than sadness, which could put them at a disadvantage for learning how to healthfully cope with sadness (Fivush et al., 2000). In line with previous research, the researchers found that mothers and fathers used more social-relational themes during conversations with their daughters, and more autonomous themes when discussing emotions with their sons. Female children tended to be more focused on relationships and showed more empathy for others during the conversations than did male children. Additionally, female children, compared to male children, used more emotion words when discussing events that evoked fear. Also, as previously discussed, Bohanek, Marin, Fivush, and Duke (2006) found sex differences in family discussions of shared past events, in that incorporating children's comments and emotions into a conversation is significantly associated with higher levels of self- 
esteem for girls, but not for boys. To summarize, child's sex influences parents' focus on certain emotions and themes and the conversational processes and strategies that parents use.

In a study examining the effect of child's sex on emotion socialization via specifically mother-child conversations, Fivush and Wang (2005) analyzed conversations between mothers and their 3-year-old children. The mothers were informed to discuss one negative event (e.g., worst event for child) and one positive event (e.g., best event for child). The researchers found no differences in the way mothers discussed emotions with their sons and daughters during either of the conversations, but the lack of difference was particularly noticeable during the negative conversations. The researchers stated that the lack of sex differences during mother-child conversations about highly emotional events stands in contrast to the literature on mothers-child conversations about every day experiences with their children (Fivush \& Wang, 2005). That is, during discussions of every day events, mothers tend to discuss emotional attributions or causes more with their daughters than with their sons (Wang, 2001). In sum, it may be that mothers only socialize their daughters to discuss emotions during every day events, but socialize both their daughters and sons to discuss emotions when talking about highly emotional, especially negative, events (Fivush \& Wang, 2005). Overall, it may be that child's sex influences mothers' approach of emotions only during less emotional conversations.

In sum, the sex of the child plays a role in determining the tone of mother-child conversations (e.g., sad, happy angry, scared/worried), the theme of the conversations (e.g., social-relational, autonomous), and the general processes mothers use (e.g., emotion clarification).

Family income and maternal education. The literature suggests that mothers who have low education levels and low socioeconomic statuses (SES) do not use the type of narrative 
structure or style that has been associated with improving children's social and emotional competence (Raikes \& Thompson, 2008). More precisely, these mothers are less likely to elaborate on their children's emotion statements and are less likely to validate their children's emotional experiences than are their more educated and higher SES counterparts (Raikes \& Thompson, 2008). Additionally, lower-income mothers have been found to value negative affect more than higher-income mothers during conversations with their children about emotional events (Miller \& Sperry, 1987). Also, Reese and Newcombe (2007) found that mothers with lower education levels have sparser and less evaluative conversations with their children about the past. In sum, low SES and maternal education level negatively impact a mother's ability to effectively socialize emotions in her children.

Maternal positive and negative affect. Empirically-derived theories and models of depression suggest that high negative affect (NA) and low positive affect (PA) are contributors to the onset and maintenance of depressive symptoms (e.g., Tripartite model; Clark \& Watson, 1991). Therefore, although this dissertation does not examine depression directly, the depression literature is relevant, as this dissertation does examine how varying levels of negative and positive affect influence mother's narrative styles with their children.

Although distinct constructs, high negative affect (NA, e.g., distress, displeasure) and low positive affect (PA, e.g., sadness, weariness) indicate emotion dysregulation (i.e., problems regulating intense, negative, and shifting emotional states; Bradley et al., 2011). Individuals with high NA and low PA tend to experience recurrent depressive symptoms over their lifetime (Burcusa \& Iacono, 2007), likely due to the fact that these individuals tend to think more negative thoughts (Beck, 1967), experience higher levels of life stress (Krackow \& Rudolph, 2008), and ruminate about their depressive symptoms without further processing those emotions 
(Nolen-Hoeksema, 1991). Given this, it may be that people with depression exhibit these same tendencies in conversations with their children about emotional events, thereby socializing emotions differently than nondepressed mothers. One goal of this dissertation is to examine the relation between maternal negative and positive affect levels and maternal conversational style (e.g., use of statements that approach emotion directly or indirectly, approach negative emotion resolution, and approach event details).

From early adolescence through adulthood, women are twice more likely than men to experience depressive symptoms (Nolen-Hoeksema, 1990). Additionally, research indicates that children of mothers with high NA and low PA develop depressive symptoms at rates higher than their peers (e.g., Goodman \& Gotlib, 1999). Specifically, Goodman and Gotlib's (1999) model proposes that a child's overall functioning (e.g., social-emotional) is negatively impacted by the presence of high maternal NA and low maternal PA through four mechanisms: (1) genetics; (2) neurobiology; (3) negative maternal cognitions, affect, and behavior including verbal behavior; and (4) life stress. This dissertation focuses on the maternal affect and behavior mechanisms in Goodman and Gotlib's (1999) model.

Children's social-emotional functioning is one area of functioning that can be negatively impacted by maternal affect by way of maternal verbal behavior (e.g., emotional expressiveness) with the child. In support of this idea, Denham's (1998) model suggests that mothers socialize emotions in their children by expressing their own emotions and encouraging their children to express their emotions, specifically through mother-child conversations (Dunn, Brown, \& Beardsall, 1991). As previous research has suggested that having a pattern of high negative affect with or without low positive affect is indicative of problems regulating one's own emotions, it is imperative to examine whether and how different levels of negative and positive affect impact a 
mother's ability to socialize emotions in others, such as during conversations with her child. This is particularly important because children's social-emotional well-being, understanding, and regulation are consistently predicted by maternal processing of emotions during mother-child conversations (Bohanek, Fivush, Zaman, \& Lepore, 2009). Children may experience emotion dysregulation or poor emotional understanding as a result of their mothers' lack of discussion about emotions, their limiting of their own emotional expressions, or their negative reactions to their children's expression of emotions (Denham, 1998).

Evidence for interactional (e.g., emotional socialization) differences related to maternal affect exists in the literature. For example, mothers with depression have been found to use fewer words (Breznitz \& Sherman, 1987). Additionally, a sample of mothers with an anxiety disorder, who, on average, also exhibited comorbid depressive symptoms tended to use more emotional avoidance statements (i.e., change subject from or ignore mention of emotions) during conversations with their children compared to mothers without a diagnosis of an anxiety disorder and on average an absence of co-occurring depressive symptoms (Suveg, Zeman, FlannerySchroeder, \& Cassano, 2005). In another study, in addition to generally using fewer words and more emotional avoidance statements with their children, mothers with depression more commonly conveyed expressions of negative affect during their interactions with their children than did nonclinical comparison mothers (Campbell, Cohn, \& Meyers, 1995). In another study, depressed mothers have been shown to be more negative and less positive than community mothers without depression, even when the goal of the activity is to help or teach their children (Ewell Foster, Garber, \& Durlak, 2008). For example, depressed mothers make more critical comments during conflicts with their children and provide less praise to their children than do nondepressed mothers (Ewell Foster et. al, 2008). Additionally, mothers with depression have 
been shown to be less active, to show fewer positive facial expressions, and to engage in less play than community mothers without depression during research tasks (Field, Sandberg, Garcia, Vega-Lahr, Goldstein, \& Guy, 1985).

Although there is a different pattern of negative affect and positive affect between depression (i.e., high NA, low PA) and anxiety (i.e., high NA, high PA), the presence of high negative affect suggests emotion dysregulation, which is likely to alter the way in which mothers socialize emotions in their children. The Positive and Negative Affect Schedule (PANAS) is used in this dissertation because of its ability to measure NA and PA. In sum, it is particularly important to strengthen emotion regulation skills in children of mothers with emotion dysregulation (e.g., high NA), as child emotion regulation skills mediate the link between maternal psychopathology and child psychopathology. This link places children with emotionally dysregulated mothers at a higher risk for developing psychopathology themselves (Suveg, Shaffer, Morelen, \& Thomassin, 2011).

This dissertation examines the relationship of maternal negative and positive affect with mothers' narrative styles by coding for mothers' use of statements that approach emotions, emotion resolutions, and event details. This coding system was developed by Krackow (2014). This information could inform early intervention parenting treatments on how to improve mothers' modeling and teaching of emotion regulation for their children during joint conversations about past emotional events.

More specifically, although the codes used in this dissertation were developed independently, they map onto coding in the existing literature. Marin et al. (2008), coded statements that approached emotion directly as 'expression' statements and reported that their function was to discuss the emotional state or behavior. These statements also have been coded 
as 'attributions' and 'emotion' statements and their definitions were any mention of an emotion or attributing an emotion to a person, such as the child (Fivush et al., 2003; Fivush et al., 2000).

Under Marin, Bohanek, and Fivush's (2008) coding system, the researchers coded statements that approached emotion indirectly as 'explanation' statements and Fivush et al. (2003) and Fivush et al. (2000) coded these statements as 'causes.' They defined these statements or questions as having the function of discussing the cause of an emotional state or behavior. In sum, this code has empirical evidence to support it. Although these two categories were separated in previous studies, their results provide no support for separating these statements into two categories. Therefore, they were combined in this dissertation.

The approach emotion resolution code used in this dissertation also has empirical support for its use. For example, Fivush et al. (2003) coded these statements as 'resolutions' and stated their purpose as being to resolve the negative affect experienced. Researchers have gotten significant findings using this code. As for the approach event detail code used in this dissertation, previous research supports the idea of separating event details from emotions altogether. For example, Fivush et al. (2000) coded these statements as 'event talk,' while Fivush et al. (2003) coded them as 'factual statements.' They define these statements as those in which there is a mention or question about the actions, objects, or descriptions of the event without mentioning emotion. In sum, previous research findings support the use of these three codes.

\section{Statement of the Problem}

Although there are multiple studies that examine mother-child conversations, more information is needed on the process by which mothers socialize emotions in their children during conversations about children's past positive and negative emotion events. This dissertation employs the creation of a new coding system to determine how mothers approach 
emotions, emotion resolutions, and event details in conversations with their children. While the coding system in this dissertation is based on previous research (e.g., Bohanek, Fivush, Zaman, \& Lepore, 2009), this coding system codes for more statements than are included in the previous system and the statements that are coded for in this dissertation are operationally defined. Additionally, children's processes are coded for in this dissertation to account for the bidirectional relationship of conversations. Finally, no other study, to date, has addressed all of these research questions in a single study. Coding systems were created based on grounded theory, a general research method that provides guidance on data collection and analysis to develop a theory. Coding systems also were based on existing literature to address the topic and content of the conversations, the general processes and exact strategies mothers use during the conversations, the life lessons and advice mothers convey during the conversations, and the statements the mothers use during the conversations that are associated with fostering their children's self-esteem. In all, this dissertation is the most extensive study to date in this area.

Although previous studies have described mother-child conversations, to date, no studies have examined how maternal affect specifically relates to the socialization of children's emotions within conversations about past positive and negative events. To address this gap in the literature, the graduate student examined data, which were collected as part of the faculty member's ongoing project (Elisa Krackow, PI). The faculty member's study was designed to examine how mothers who report having varying levels of negative and positive affect discuss past emotional events (i.e., socialize emotions) with their 7 - to 10-year-old children. In addition, although a few emotion socialization studies have included school-aged children (e.g., Bohanek et al., 2009), the majority of previous research on mother-child conversations has been conducted with mothers of preschool-age children. Therefore, this dissertation extends the literature by 
examining whether there are any differences in the ways in which mothers socialize emotions in their children as the children get older.

\section{Research Questions (RQ) and Hypotheses (H)}

The following research questions (RQ) and hypotheses (H) are addressed by this study. RQ1-7 are addressed by qualitative analyses. H1-3 are addressed by quantitative analyses.

RQ1: What processes do mothers use to discuss children's past emotional events? That is, how do mothers discuss children's past emotional events?

RQ2: What processes do children use to discuss their past emotional events with their mothers? That is, how do children discuss their past emotional events?

RQ3: What exact strategies do mothers use to elicit information from their children during conversations about children's past emotional events?

RQ4: What topics do mothers discuss with their children during conversations about children's past emotional events?

RQ5: What themes emerge from the conversations about children's past emotional events between mothers and their children?

RQ6: What life lessons or pieces of advice do mothers provide to their children during conversations about children's past emotional events?

RQ7: What statements do mothers make to their children during conversations about children's past emotional events that are associated with fostering self-esteem in their children?

RQ8: Does maternal negative affect relate to mother's discussion of emotions and event details during conversations with their children about past positive and negative emotional events?

RQ9: Does maternal positive affect relate to mother's discussion of emotions and event details during conversations with their children about past positive and negative emotional events? 
H1: As negative affect increases, mothers will use fewer statements that approach emotions directly or indirectly.

H2: As negative affect increases, mothers will use fewer statements that attempt to help resolve children's negative emotions.

H3: As negative affect increases, mother will use fewer statements that discuss event details in both the negative event conversations and the positive event conversation.

Hypotheses 1 through 3 are supported by the finding that mothers with higher negative affect compared to mothers with low negative affect use emotional avoidance statements more frequently when conversing with their children (Suveg, Zeman, Flannery-Schroeder, \& Cassano, 2005). Also, individuals with higher negative affect tend to perseverate without further processing their emotions (Nolen-Hoeksema, 1991), which supports the idea that these mothers may exhibit this same tendency in conversations with their children about emotional events.

\section{Method}

\section{Participants}

Participants were 24 mothers (Mage $=39.65, S D=7.29$, age range 27.42 to 51.08 ) and their 7- to 10-year-old children (Mage $=9.23, S D=1.06)$ from West Virginia and Pennsylvania. The majority of the children were male $(n=16)$ and Caucasian $(n=21)$, with the other children identifying as Asian ( $\mathrm{n}=1)$, African American $(\mathrm{n}=1)$, and Biracial $(\mathrm{n}=1)$. None of the children were diagnosed with learning disabilities, $\mathrm{AD} / \mathrm{HD}$, or severe speech problems. The mothers were primarily Caucasian $(\mathrm{n}=20)$, with the others identifying as Asian $(\mathrm{n}=2)$, African American $(\mathrm{n}=$ 1), and Biracial $(\mathrm{n}=1)$. The majority of the mothers had at least a college degree $(\mathrm{n}=19)$, with the other mothers reporting receiving a terminal high school diploma $(n=3)$ or associates degree $(\mathrm{n}=2)$. Most mothers $(\mathrm{n}=20)$ reported working outside of the home while the remaining 
mothers $(n=4)$ reported being stay-at-home mothers. The majority of mothers $(n=20)$ reported being married to the child's father. Two of the remaining mothers reported being married, but not to the child's father, and the final two mothers reported never having been married. Family income ranged from under $\$ 29,000$ per year to over $\$ 90,000$, with 11 mothers reporting annual income of over $\$ 90,000$. Participants were recruited via newspaper advertisements that informed mothers that the purpose of the study was to examine how mothers talk with their children about children's experiences.

\section{Measures}

Positive and Negative Affect Schedule (Watson, Clark, \& Tellegen, 1988). The Positive and Negative Affect Schedule (PANAS) is a 20-item self-report questionnaire. The PANAS consists of two major scales: Positive Affect (PA) and Negative Affect (NA). According to Watson et al. (1988), high PA represents a high level of enthusiasm and enjoyment, while low PA represents sadness and weariness. In contrast, high NA represents increased distress and displeasure, whereas low NA represents calmness. NA and PA are said to be distinct scales, yet they have a weak negative association with each other $(r=-.24$; Crawford $\&$ Henry, 2004). Watson et al. (1988) reported that the NA and PA scales share $1 \%$ to $5 \%$ of their variance. Crawford and Henry (2004) reported that the covariance between NA and PA for the women in their sample was -.24. The NA and PA constructs relate to the tripartite model by Clark and Watson (1991). The tripartite model shows that although high NA is associated with both depression and anxiety, depression is able to be distinguished from anxiety by the presence of low PA, or sadness (Clark \& Watson, 1991). The PANAS can be administered for different time frames. Individuals are asked to rate the extent to which they experienced specific moods for this moment, today, during the past few days, the past week, the past few weeks, the past 
year, or in general. Individuals rate their mood on a 5-point Likert scale ranging from $1=$ "very slightly or not at all" to $5=$ "very much." Crawford and Henry (2004) examined the PANAS's psychometric properties in a sample from the general adult population. They found that the women in their sample scored significantly higher than men on the NA scale, but significantly lower than men on the PA scale. The mean score for women on the PA scale was $M=30.6, S D$ $=7.9$, range 10-50, while their mean score on the NA scale was $M=16.7, S D=6.4$, range 10-42. Both scales have strong internal consistency, with $\alpha=.89$ for PA and $\alpha=.85$ for NA (Crawford \& Henry, 2004). Additionally, Watson, Clark, and Tellegen (1988) found that the scales were reliable, regardless of the time frame referenced in the instructions. Finally, the PANAS has acceptable convergent and divergent validity (Watson, Clark, \& Tellegen, 1988).

As there are no commonly accepted cut-off scores for this measure, higher scores indicate higher levels of a certain affect and lower scores indicate lower levels of that affect. In this dissertation, reliability, as estimated by Cronbach's alpha, of mothers overall was .81 for general positive affect and .82 for general negative affect. A one-sample t-test was run to determine whether the mean PANAS scores from Crawford and Henry's (2004) study was different from the means in this dissertation. Mean negative affect score $(M=15.8, S D=4.6)$ is lower for mothers in this dissertation, but the difference is not statistically significant, $t(23)=-.95, p=.35$. In comparison to Crawford and Henry's (2004) study, the mean positive affect score ( $M=36.8$, $S D=5.4)$ in this dissertation is higher, with a statistically significant mean difference of 6.2 , $95 \% \mathrm{CI}[3.9$ to 8.4$], t(23),=5.6, p<.001$. Therefore, although the mothers in this dissertation had significantly higher positive affect than those in Crawford and Henry's (2004) study, the mothers in both studies had comparable negative affect ratings. 
Demographic questionnaire. This questionnaire includes questions regarding mothers' age, ethnicity, marital status, education level, employment status, and family income as well as child's age, sex, ethnicity, and cognitive diagnoses (e.g., ADHD). Maternal education level was categorized into less than high school, high school diploma, some college (i.e., "associates degree from community college"), 4-year college degree, and higher education (i.e., "master's degree”, “JD/MD/Ph.D.”). Income in this study was grouped into four categories in part based on available U.S. Census bureau information that makes conceptual sense: below poverty line (below $\$ 29,999$ on demographic questionnaire), lower class $(\$ 30,000$ - $\$ 59,999$ on demographic questionnaire), middle class (\$60,000 - \$89,999 on demographic questionnaire), and upper class $(\$ 90,000+$ on demographic questionnaire). Child's sex was not listed on the demographic questionnaire. Rather, the researcher noted the child's sex during the child's participation in the study.

\section{Procedure}

This study was approved by the West Virginia University (WVU) Institutional Review Board (IRB). Participants were recruited via newspaper advertisements that informed mothers that the purpose of the study was to examine how mothers talk with their children about children's experiences. Data from 14 participants were collected in the lab and 10 were collected in the home with the experimenter running the study on the phone, often on speaker phone. If participants did not use a speaker phone, they put the phone down during the conversations in a manner that the researcher could hear the conversation occurring. All participants had a set appointment time to complete the study. One difference was that the consents and questionnaires were completed via Survey Monkey, whereas in person questionnaires were completed via hard copy. Another difference is that the researcher was able to view mother-child 
dyads via a closed-circuit television in the lab, but the researcher could not view the dyads who participated in their homes; therefore, it is likely that this difference shaped participants' behavior. Audio recorders were mailed to participants with stamped envelopes for return. Following completion of the study, the participants mailed the tape recorders back to the researcher. Regardless of location, the researcher guided the mothers and children through the study in the same manner.

First, mothers completed a consent form and children completed an assent form. Following this, mothers completed parent and child demographic forms. Next, mothers completed the Positive and Negative Affect Schedule (PANAS) to rate the extent to which they experienced specific affective states generally, on average and during the past few weeks. Mothers then completed a depression measure not being included in this study. Next using Fivush et al.'s (2000) methodology, mothers and children were instructed to agree upon four past emotional events (i.e., happy, angry, sad, and scared/worried) to discuss in a random order. The criteria for the events to be chosen were: 1) the mother and child must have experienced the events together (i.e., shared events); 2) the child had to have a good memory of the events, according to the mother and child; and 3) the events must be distinctive autobiographical events that occurred on a single occasion (e.g., not birthdays or holidays). Mothers and children were asked to discuss each event until the conversations became strained. At the conclusion of the emotional event discussions, the mother completed a form that asked for a brief description of each event by emotion (e.g., sad; death of family dog) and the date that the event occurred.

Each family was paid $\$ 30-40$ for their participation, with the home families paid $\$ 40$ due to use of their resources (phones and computers). The conversations were transcribed verbatim by an undergraduate research assistant or the faculty member and all transcriptions were checked 
either by the person who transcribed or by another individual to ensure accuracy. The faculty member has listened to the majority of these audio recordings to ensure transcription accuracy. The majority of the data were collected as part of the faculty member's (Elisa Krackow, PI) ongoing study; however, to gain a thorough understanding of the procedural aspect of this study, the graduate student was present for the collection of data from $3(12.5 \%)$ mother-child dyads and listened to the remaining $21(87.5 \%)$ audio recordings of the procedure. No publications exist from these data.

Each mother-child dyad recorded the approximate date that each event originally occurred. Conversations ranged from occurring 3 months to $1 \frac{1 / 2}{2}$ years prior to these discussions occurring (See Table 1). Regardless of the timing of events, the events needed to be remembered well.

Length of conversation can be calculated based on number of exchanges that occur during a conversation or the length of time that passes during the conversation. An exchange is defined as the statement(s) or question(s) one person makes before the other person in the conversation speaks. For example, one exchange would be a mother asking "How did you feel? Were you sad?" Another example of an exchange would be the child responding, "Yes, I felt sad."

First, the number of maternal exchanges per emotional conversation was calculated (See Table 1). Next, a one-way ANOVA was conducted to compare the effect of the independent variable (i.e., the order of the emotion conversation: happy, sad, scared/worried, and angry in all orders discussed by participants in this dissertation) on the dependent variable (i.e., total number of maternal conversational exchanges). There was not a significant effect of order of emotion conversation on total number of maternal exchanges $(F(3,20)=2.4, p=.09)$. 
Next, the number of child exchanges per emotional conversation was calculated (See Table 1). Finally, the exact length of time that passed during each conversation was calculated, based on a random sampling of $25 \%$ of the conversations (See Table 1), with the total conversations, on average, lasting approximately 33 minutes.

\section{Coding}

Coding was conducted on verbatim transcriptions of the conversations. The faculty member and graduate student independently coded $25 \%$ of the transcripts for content, themes, mothers' and children's processes, mothers' self-esteem statements, mothers' life lessons conveyed, and three additional categories on which maternal negative and positive affect were examined (See Table 2). The student coded the remainder of the transcripts and served as master coder. As such, when discrepancies existed, the graduate student's code was used. Simple agreement was $100 \%$ for what the content was, what the themes were, and the specific processes mothers used. For the presence of a life lesson and for the specific processes children used, simple agreement was $84 \%$. Cohen's $\kappa$ was run to determine if there was agreement between the two raters on the presence or choice of a specific code for each conversational exchange, accounting for chance. Agreement ranged from moderate to almost perfect (See Table 3). Kappa was calculated for the presence or absence of all of the codes, with an additional kappa calculation for the specific life lessons mothers conveyed.

There are various accepted methods of measuring validity in qualitative research. For example, Thomson (2011) cites various researchers whom have coined a few of the numerous terms for these methods, such as Maxwell's (1992) terms of descriptive validity, theoretical validity, and dependability. The codes in this dissertation meet descriptive validity, as the transcriptions were created verbatim from what the participants said and information was not 
omitted from or added to those transcriptions. Additionally, the graduate student was able to determine important aspects of the conversations, such as tone of voice, by listening to the audio recordings and attending a few sessions. This ensures that the data remain true to what the participants said. As for theoretical validity, each code used in this dissertation becomes combined with other codes to create larger, meaningful constructs. These constructs ultimately join together to form overarching theories that expand upon previous theories in the literature. Finally, this dissertation meets the criteria for dependability because the methods, procedures, and coding processes are all explained to the reader to allow for replication in the future. Thomson (2011) suggests that new theories emerge through qualitative research that can later be tested through quantitative research.

Qualitative analysis is sometimes based on grounded theory, a general research method that provides guidance on data collection and analysis to lead to a theory. Grounded theory requires that researchers complete coding in two stages (e.g., Charmaz, 2014). First, the researcher reviews the data (e.g., transcript) and defines the codes. Second, coding can be completed line by line on a transcript, referred to as line-by-line grounded theory coding. Line by line coding expands upon general topical qualitative coding (e.g., content) by attempting to explain what is happening in the narrative (e.g., the process; Charmaz, 2014). This theoretical coding (e.g., process) will be discussed under the coding category of processes and exact strategies.

Content and themes. The student was informed on content analysis by previous research, such as Bohanek, Marin, Fivush, and Duke (2006) and Marin, Bohanek, and Fivush (2008). Each of the four emotion conversations (e.g., happy, sad, scared/worried, and angry) was read and the graduate student assigned one topic per conversation for each of the mother-child 
conversations. Examples of the types of negative and positive events discussed in Bohanek et al.'s (2006) study include death of a friend or family member and family vacations.

Guided by research, such as Braun and Clarke (2006), thematic analyses were conducted from the content that was discovered in the first analysis. A walk-through of an example is provided at the conclusion of this paragraph. First, the content from the conversations was organized into meaningful groups. Content was placed into multiple groups, if the content fit into various themes. Next, themes were reviewed to determine if there were enough data to support them and if multiple themes could form a larger, overarching theme. The transcriptions were reviewed again to determine whether any themes were originally missed. Themes were then reviewed to determine whether they meaningfully reflect those in the existing literature. Finally, themes were thought about in terms of how each one is important to the mother-child conversations and how the combination of the themes is important to the mother-child conversations. For example, discussions about storms and flooding were placed into a content category of severe weather. Severe weather was then placed into a larger category with conversations about siblings getting lost or being afraid on a roller coaster, for example, and was given the thematic label of safety, as that was the main concern on the child during those events. Examples of themes from the literature include not lying to friends and persevering for the good of others (Narvaez, Gleason, Mitchell, \& Bentley, 1999). Examples of themes from this dissertation, other than safety are: social inclusion, novel experiences, and negotiating interpersonal conflict (See Table 2).

Maternal processes and exact strategies. Mother-child conversations in this dissertation first were coded for the general processes that the mothers used to structure the conversations and move the conversations forward. Each mother's exchange was coded according to 10 codes. 
Direct quotes from the mothers in this dissertation follow the definition of each code (See Table 2).

1) Clarification on what the emotion is - any statement or question that contained emotion words or behavior in relation to the child experiencing the emotion (e.g., “How'd that make you feel?").

2) Clarification on why the child's emotion occurred - any statement or question that attributed cause to child's emotion state or behavior or that explains the emotion state or behavior in more detail (e.g., "What made you angry about that?").

3) Eliciting of information - any statement or question with the function of getting the child to present new information without mentioning emotion (e.g., "Did he stop sitting with you at school?’).

4) Core issue - any statement or question that addressed the main reason the child experienced an emotion (e.g., "Is that part of the reason you were sad probably?").

5) Discussion of own emotion - any statement that contained emotion words or behavior in relation to the mother experiencing the emotion (e.g., "I enjoyed it.").

6) Shared reaction - any statement that contained emotion words or behavior in relation to the mother and child both experiencing the same emotion in response to an event component (e.g., "We had a lot of fun.").

7) Reduce negative emotion - any statement that attempts to resolve the negative emotions the child experienced or any question that asks about when or if the child stopped feeling the negative emotion (e.g., "No, you're not gonna see him, but you might when you go to heaven one day, huh?"). 
8) Adding information - any statement that contains new details or expands upon the conversation without addressing emotions (e.g., "Yeah and then dad and I told you guys we were gonna move.").

9) Lesson - any statement or question that functions to convey a life lesson or give advice to the child (e.g., "You have to talk about things that make you sad to deal with things.").

10) Negative comment - any statement or question that functions to reprimand or ridicule the child (e.g., "Is that what it looked like with the big scaredy you were?").

The codes in this dissertation were created after the graduate student became familiar with the data and used technique and empirical evidence to group codes into meaningful categories. After each exchange was coded for process, a summary statement was created to describe the overall process each mother used during each emotional conversation. For example, during a conversation about a sad event, one mother clarified details about the child's emotion, clarified whether the child's negative emotion was reduced, and then focused on resolving the child's negative emotion.

In this dissertation, the processes were coded on a more in-depth level to examine exactly what the mothers were asking to elicit information from their children. The exact questions were then grouped together in a way that makes conceptual sense to form more general questions for descriptive purposes (See Table 2). For example, under the process coding of clarification of why an emotion occurred, there were several questions asked, such as "what is it that your sibling does that makes you angry?" and "were you happy because you were learning things?" that were then combined into the more general question of "why did you feel that emotion?" This 
coding provides more descriptive information on what mothers are doing to socialize emotions in their children during joint conversations about the past.

Children's processes. Mother-child conversations in this dissertation were coded for the general processes that the children used to structure the conversations and move the conversations forward. Each child's exchange was coded according to the 10 codes that emerged from the data, some of which are different from the 10 maternal process codes (See Table 2). Direct quotes from the children in this dissertation follow the definition of each code.

1) Clarification on what child's emotion is - any statement or question that contained emotion words or behavior in relation to the child experiencing the emotion (e.g., "Basically, I was happy the whole trip.").

2) Clarification on why child's emotion occurred - any statement or question that attributed cause to child's emotion state or behavior or that explains the emotion state or behavior in more detail (e.g., “Because she's my girlfriend and I don't like her hanging out with other dudes.").

3) Eliciting of information - any statement or question with the function of getting the mother to present new information without mentioning emotion (e.g., "What's after that month?").

4) Eliciting of advice - any statement or question with the function of getting the mother to present advice for a given situation (e.g., "Wouldn't you do that?").

5) Reduce negative emotion - any statement that shows the child's negative emotions have or have not been resolved or the child is attempting to resolve the negative emotions the child experienced (e.g., "At least we got home safe.”). 
6) Adding information - any statement that contains new details or expands upon the conversation without addressing emotions, including those that serve to correct or confirm the mother's statements (e.g., "Lots of stuff had to be thrown away because it got soaked in the basement.").

7) Lesson - any statement or question that functions to show the child has learned a lesson (e.g., "Because taking a bath when it's raining, especially that hard, is really dangerous.").

8) Thanking the mother-any statement that functions to thank the mother for her support, advice, or compliment (e.g., “Thank you!”).

9) Discussion of others' emotions - any statement or question that functions to discuss another person's emotion state or behavior (e.g., "And he gets mad if he doesn't and he'd go over and (name) and (name) would just blame it on me.").

10) Negative comment — any statement or question that functions to reprimand or ridicule another person (e.g., "Yeah, that little pest came along.").

These codes were created after the graduate student became familiar with the data and used technique and empirical evidence to group codes into meaningful categories. After each exchange was coded for process, a summary statement was created to describe the overall process each child used during each emotional conversation. For example, during a conversation about an event that scared/worried a child, one child clarified his emotions, clarified why he experienced those emotions, added event details, and then discussed negative emotion reduction.

Life lessons. Mothers giving advice or conveying life lessons is commonly examined in the mother-child discourse literature (e.g., Kulkofsky, Wang, \& Koh, 2009; Laird, Pettit, Mize, Brown, \& Lindsey, 1994). In this dissertation, the mothers' statements were reviewed and 
marked as having or lacking advice giving or lesson conveying (See Table 2). A statement was marked as containing a lesson or piece of advice if there was mention of a) proper behavior, b) rules, or c) morals, which Kulkofsky (2011) labeled as 'didactic talk.' Statements were also marked as containing this information if the mother was d) asking the child to generate solutions to an issue, or the mother was e) providing solutions to the child.

When a statement was denoted as containing a life lesson, the overall purpose of the lesson was determined. Once the purposes were determined for each statement, they were grouped into larger categories that make conceptual sense and fit the literature. Those categories are: managing interpersonal conflict, mood management, safety, perseverance, and negotiating scheduling/keeping appointments. An example of a life lesson given during one of the motherchild conversations in this dissertation is: "You have to talk about things that make you sad to deal with things." This lesson/advice was then grouped into the larger category of mood management. The purpose of this coding is essentially to examine one of the strategies mothers use during emotional conversations with their children in more depth to learn what mothers are conveying to their children during these conversations.

Self-esteem. Self-esteem also is commonly examined in the mother-child discourse literature (e.g., Miller, Wang, Sandel, \& Cho, 2002; Reese, Bird, \& Tripp, 2007). Although researchers sometimes directly query mothers about self-esteem (e.g., Miller et al., 2002), there is typically an initial period during which researchers give the mothers time to determine whether mothers use these statements spontaneously. In this dissertation, self-esteem was never mentioned to the mother-child dyads. This means that all statements that mothers used that are associated with fostering self-esteem in their children in this dissertation were used spontaneously, making the use of statements more ecologically valid. In the literature, when self- 
esteem is examined in the context of parent-child conversations, child's self-esteem is typically correlated with parental narrative structure, rather than coding for specific statements that foster children's self-esteem (e.g., Marin, Bohanek, \& Fivush, 2008). This dissertation is innovative in that specific maternal statements that are related to fostering self-esteem in children are coded.

The literature and conventional wisdom suggest that the following processes foster children's self-esteem: a) supporting the child's expression and evaluation of their emotions (Marin et al., 2008), b) praising the child (i.e., person praise) and the c) child's behavior (i.e., process praise; Kamins \& Dweck, 1999), and d) recasting their children's areas of weakness as strengths (Miller et al., 1996). Therefore, the maternal statements that are associated with fostering self-esteem in this dissertation were coded according to the four aforementioned processes (See Table 2).

Maternal exchanges were coded for three additional categories on which quantitative analyses were performed (See Table 2). They are as follows:

Approach emotion. A mother was coded as approaching emotion, as opposed to avoiding emotion, when she asked how a child felt, if a child felt a certain way, or when she summarizes or reflects how the child felt. The key point is that it must be a mention to the child's emotion. Emotion itself could be either direct, such as stating "I felt happy," or indirect by discussing crying, which implies sadness. Examples from this dissertation are: "How did that make you feel?" and "It makes you upset?"

Statements also were coded as approaching emotion when the mother, directly or indirectly, obtains information and reasons about why the child experienced the emotion or about the circumstances in which the child experienced the emotion, such as somatic symptoms. These clarifications can be in the form of a question or a statement. For example, a direct emotion 
clarification question asked by a mother in this dissertation is: "Why did that make you feel scared?" Examples of indirect emotion clarification questions asked by a mother in this dissertation are: "Do you ever have a stomachache when you are sad?" and "How'd that make your stomach feel?"

Approach emotion resolution. Approach emotion resolution statements and question are used when the mother's goal is to reduce the negative emotion or obtain information about whether a negative emotion is reduced. Examples from this dissertation are: "But that helped make it so it wasn't so sad." and "Ok you got scared going through the water, but what did mommy do to help you get through that?"

Approach event detail. Approach event detail was coded as such when a statement or question was used with the main goals either of providing more information about what happened during the event or of obtaining further information about the event itself. It is not coded as an event detail if there is mention of emotion. Examples from this dissertation are: "And then what would happen?" and "We gave them all of the emails."

\section{Results}

First, the six qualitative analyses are presented on how mothers in this dissertation socialized emotions in their children during conversations about past emotional events and the one qualitative analysis on how children in this dissertation discuss past emotional events with their mothers. Next, the quantitative analyses are presented on how mothers' use of statements that approach emotions and event details is associated with maternal negative and positive affect levels on the Positive and Negative Affect Schedule (PANAS; Watson et al., 1988). 


\section{Qualitative analyses}

Content. Each of the four emotion conversations (e.g., happy, sad, scared/worried, angry) was coded for topics. The results are divided by emotion (See Table 4 for descriptives).

For the happy emotion conversations, the topics discussed by mothers and their children, in order from most frequent to least frequent, were: going on a vacation or trip, extracurricular activities, feeling good at something/talent, making new friends, birth of a sibling, getting a new pet, being recognized at school for displaying appropriate behavior, making it through a religious rite of passage, and going to work with the parent.

For the sad emotion conversations, the topics discussed by mothers and their children, in order from most frequent to least frequent, were: death of a pet or pet running away, being separated from a loved one, moving to a new geographical location, the death of a friend/family member, losing a friend or being left out by friends, getting injured or in an accident, losing a sporting event, losing a belonging, not being able to go someplace, not wanting to express emotion, and having a television show interrupted.

For the scared/worried emotion conversations, the topics discussed by mothers and their children, in order from most frequent to least frequent, were: bad weather, getting injured or almost drowning or fear of drowning, the parents' well-being, being home alone, the first day of school, a haunted house, having a sibling get lost, having surgery, getting blood work done, having a pet run away, going on a roller coaster, a parent not picking the child up from a place, almost missing a flight, car breaking down, and performance in a sporting event.

Finally, for the angry emotion conversations, the topics discussed by mothers and their children, in order from most frequent to least frequent, were: not being allowed to do something, having an argument with a friend, being bossed around, losing a sporting event, having a 
belonging broken, relationship jealousy, and having a promise broken, being blamed for something the child did not do, and getting injured.

Across emotions, the most frequently discussed topics were vacation, extracurricular activities, death or running away of a pet, separation from loved ones, bad weather, injury or threat of injury, not being allowed to do something, and arguments with friends.

Themes. To gain a more in-depth understanding of the topics being discussed by the mothers and their children, themes of the content for each of the four emotion conversations were analyzed. The results are divided by emotion (See Table 5 for descriptives). One motherchild dyad topic could include multiple themes, so the sample size may not equal 24 for each emotion conversation. For example, one mother-child dyad discussed moving to another geographic location. As this was the first time the child moved and the child was moving away from friends and family, this topic was coded as having two themes: separating from loved ones and novel experiences.

For the happy emotion conversations, there was an average of 5 themes $(S D=6.2)$. Those themes, in order from most frequent to least frequent, were: novel experiences with loved ones, social inclusion, talent, loving/caring for someone, transitions, earning privileges, having mixed feelings, and rite of passage shared with loved ones.

For the sad emotion conversations, there was an average of 2.7 themes $(S D=2.5)$. Those themes that emerged, in order from most frequent to least frequent, were: death/loss of a loved one, separation from loved ones, negotiating interpersonal conflict, transitions, novel experiences, safety, losing at something, losing a belonging, having privileges restricted, reminiscing, expressing emotions, and having fun interrupted. 
There was an average of 3.5 themes $(S D=7.1)$ during the scared/worried conversations. The themes that emerged from the scared/worried emotion conversations, in order from most frequent to least frequent, were: safety, loss of a loved one, missing out on an opportunity, novel experiences, having mixed feelings, transitions, pressure to perform well, and fear of letting others down.

Finally, for the angry emotion conversations, there was an average of 4.8 themes $(S D=$ 7.1). The following themes, in order from most frequent to least frequent, emerged: negotiating interpersonal conflict, having privileges restricted, damage to property, negotiating scheduling, identifying emotions, and stressful experiences.

Overall, there was an average of 3.8 themes $(S D=5.4)$. The most commonly discussed themes were novel experiences with loved ones, social inclusion, talent, death or separation from loved ones, safety, negotiating interpersonal conflict, and having privileges restricted. Research supports why these might be the most common themes of mother-child conversations of schoolaged children, which is discussed later in this paper.

Maternal process. After examining the function of each exchange during the motherchild conversations, that is, the goal of the mother's conversational exchange, the graduate student analyzed the processes the mothers used to structure each of the four emotion conversations. The results are reported divided by emotion (See Table 6).

First, the average number of times each process was used by mothers was calculated (See Table 7):

For the happy conversations, mothers primarily engaged in eliciting information, followed in descending order of use by adding information, clarifying what the child's emotion is, clarifying why the child experienced the emotion, reducing the child's negative emotion, 
discussing their own emotions, conveying a lesson, then discussing a shared reaction . The mothers did not address core issues and did not make negative comments.

For the sad conversations, the most common process the mothers used was eliciting information, followed in descending order of use by reducing the child's negative emotion, adding information, clarifying what the child's emotion is, clarifying why the child experienced the emotion, discussing a shared reaction, discussing their own emotions, conveying a lesson, addressing a core issue, then making a negative comment.

For the scared/worried conversations, mothers primarily engaged in eliciting information, followed in descending order of use by reducing the child's negative emotion, adding information, clarifying why the child experienced the emotion, clarifying what the child's emotion is, discussing their own emotions, addressing a core issue and conveying a lesson, discussing a shared reaction, then making a negative comment.

For the angry conversations, the most common process the mothers used was eliciting information, followed in descending order of use by adding information, reducing the child's negative emotions and clarifying why the child experienced the emotion, clarifying what the child's emotion is, conveying a lesson, addressing a core issue and discussing their own emotions, then making a negative comment. Mothers discussed no shared reactions.

The following descriptions of the temporal order of the processes mothers used are based on the summary statements from each mother on the order of the narrative processes they used. During the happy emotion conversations, the mothers typically began the conversations by asking the children how they felt about the event being discussed. Following that, mothers tended to clarify why the child felt that emotional response to the event. Mothers then elicited more event details from the children to put the situation into context. Following that, the mothers 
often complimented and/or validated their children's statements. To conclude the conversations, mothers typically added information they remembered about the event before discussing their own emotional reactions to the event and their shared reactions with the child. In sum, when mothers discussed happy events with their children, their focus was on clarifying their children's emotions and event details, while also discussing their own emotions.

Although similar to the happy emotion conversations, there were slight differences in the processes mothers used during the negative (e.g., sad, scared/worried, angry) emotion conversations and even between the separate negative emotion conversations regarding the temporal order of and emphasis placed on each process.

Looking specifically at the sad emotion conversations, mothers tended to initiate the conversations by eliciting event details to provide context to the conversation. Next, mothers asked how the children felt about the events before requesting an explanation for why they felt that way. Mothers then tended to add their own details about the event and/or revise the child's statements about the event. Commonly, mothers then made statements to reduce the sadness that the child was experiencing or asked questions about when the child started and stopped feeling sadness. Finally, mothers discussed their own emotional reactions and their shared reactions with the child before concluding with an examination of the core issue of why the child experienced sadness during the event being discussed. One mother included a lesson for how to better manage sadness in the future. To summarize, during sad conversations with their children, mothers primarily tended to clarify their children's emotions and worked towards alleviating some of their children's sadness.

During the scared/worried emotion conversations, mothers began the conversations typically by eliciting event details to gain context. Then, mothers clarified how the children felt 
about the event. Next, mothers tended to add their own event details and/or revise the children's statements. Interestingly, mothers attempted to reduce the fear/worry the child reported having or asked when the child started/stopped feeling that way before asking why the child felt scared or worried. The mothers tended to get at the core issue of why the child felt fear or worry at this point, which is earlier than during the sad emotion conversations. Mothers then discussed their own emotional reactions and their shared reactions with the child before conveying a lesson for the future. Finally, one mother also made a negative comment about her child for being a "scaredy" cat during the event. In sum, during scared/worried conversations with their children, mothers tended to focus primarily on their alleviating their children's fear or worry and on helping the child learn something from the situation to help in the future.

Finally, during the angry emotion conversations, mothers typically started the conversation by eliciting event details to gain context. Mothers then got at how and why the child felt during the event. Following that, mothers made statements to reduce the child's anger or asked when the anger started and stopped for the child. Mothers then tended to add their own event details and/or revise the child's statements. To conclude the conversations, mothers provided lessons for how to handle situations differently in the future and got at the core issue of why the children were angry about the events. One mother made a negative comment about the child during the angry emotion conversation. To summarize, when discussing the angry conversations with their children, mothers tended to focus on the context of the situation before attempting to alleviate any leftover anger, and ended the conversations by trying to get the children to learn something from those events that could be useful in the future.

Overall, the processes the mothers used were reliably consistent across all four emotion conversations. What was subtly different was the order in which the mothers used these 
processes and the emphasis on each process, particularly between positive and negative emotion events. Understanding the general processes that mothers used to elicit information about their children's emotional experiences, it then is important to examine exactly how the mothers were getting at that information.

Exact strategies. For that purpose, the processes were broken down further to examine the exact strategies that mothers were using to elicit information from their children during each of the four emotion conversations. These strategies were formed from an analysis of each maternal exchange. The results are reliable across each of the emotion conversations; therefore, they are reported in a combined manner. Mothers were consistently asking several questions, with wording variations. The examples listed after each general question are verbatim questions asked by mothers in this dissertation that addressed the same point as the overarching, general question.

1. Who was involved? (e.g., "Do you remember who they are?" and "Who was it?"). This strategy maps onto the maternal process code of eliciting information, as the function of these questions was to learn about an event detail and not the child's emotion.

2. What happened? (e.g., "What happened?" and "What else was fun about it?" and "What did you do?" and "What could you do differently in the future?"). This strategy maps onto the maternal process code of eliciting information, as the function of these questions was to learn about an event detail and not the child's emotion.

3. Where did it happen? (e.g., "Where were you?" and "Do you remember where you went?"). This strategy maps onto the maternal process code of eliciting information, as the function of these questions was to learn about an event detail and not the child's emotion. 
4. When did it happen? (e.g., "Was that back in X grade?" and "When was that?"). This strategy maps onto the maternal process code of eliciting information, as the function of these questions was to learn about an event detail and not the child's emotion.

5. Why did you feel that way? (e.g., "Is that what really bothered you?" and "Why were you sad?" and "What were you worried about?" and "Why do you think you felt that way?"). This strategy maps onto the maternal process code of clarifying why the child experienced the emotion.

6. How did you feel? (e.g., "How does that make you feel?" and "Did that make you happy?" and "Were you upset?" and "What did you think?"). This strategy maps onto the maternal process code of clarifying what emotion the child experienced.

To summarize, mothers used a variety of different, more elaborate questions than the 'five w' questions (i.e., who, what, where, when, and why) and the sixth 'h' question (i.e., how). However, all of their questions got at the same points as those six basic questions. Each category of questions maps onto one of the maternal process codes based on its function.

Children's processes. After examining the function of each exchange during the motherchild conversations, the graduate student analyzed the processes the children used to structure each of the four emotion conversations. The results are reported divided by emotion (See Table 8).

First, the average number of times each process was used by the children was calculated (See Table 9):

For the happy conversations, children primarily added information, followed in descending order of use by clarifying their emotion, clarifying why they experienced the 
emotion, eliciting information, discussing others' emotions, then making a negative comment and reducing their negative emotions. Children did not elicit advice, discuss lessons, or thank their mothers.

For the sad conversations, the most common process the children used was adding information. This process was followed in descending order of use by clarifying their emotion, clarifying why they experienced the emotion, reducing their negative emotion, eliciting information, eliciting advice and discussing others' emotions, then discussing a lesson. Children did not thank their mothers or make a negative comment.

For the scared/worried conversations, children primarily added information, followed in descending order of use by clarifying their emotion, clarifying why they experienced the emotion, reducing their negative emotion, discussing a lesson, eliciting information, eliciting advice, then thanking the mother and discussing others' emotions. Children did not make a negative comment.

For the angry conversations, the most common process the children used was adding information. This process was followed in descending order of use by clarifying their emotion, clarifying why they experienced the emotion, eliciting information, eliciting advice and reducing their negative emotion, making a negative comment, then thanking the mother and discussing others' emotions. Children did not discuss lessons.

The following descriptions of the temporal order of processes children used are based on the summary statements from each child on the order of the narrative processes they used. During the happy emotion conversations, the children typically began the conversations by clarifying how they felt. Then, children tended to discuss why they felt that emotion. Following this, the children typically added and elicited event details, and discussed others' emotions. One 
child discussed a reduction in negative emotion and one other child made a negative comment about another person. In sum, during the happy conversations, children primarily focused on what their emotions were, why they felt those emotions, and adding event details.

Although similar to the happy emotion conversations, there were slight differences in the processes children used during the negative (e.g., sad, scared/worried, angry) emotion conversations. There also were subtle differences between the separate negative emotion conversations regarding the temporal order of and emphasis placed on each process.

During the sad emotion conversations, the children first clarified how they felt and why they felt that emotion. Next, children tended to elicit and add event details. Following this, children discussed a reduction in their negative emotions before eliciting advice from their mothers. Conversations sometimes included discussion of others' emotions and discussion of a lesson the child learned. In sum, during the sad conversations, children primarily focused on what their emotions were, why they felt those emotions, and adding event details.

During the scared/worried emotion conversations, the children first clarified how they felt and why they felt that emotion. Next, children tended to add event details. Following this, children typically spoke about a reduction in their negative emotions. After that, they elicited event details, discussed lessons they learned, and then elicited advice from their mothers. One child discussed others' emotions and another child thanked his mother. In sum, during the scared/worried conversations, children primarily focused on what their emotions were, why they felt those emotions, discussion of their negative emotions being reduced, and adding event details.

Finally, during the angry emotion conversations, the children first clarified how they felt and why they felt that emotion. Next, they tended to add and elicit event details before eliciting 
advice from their mothers. After this, children often discussed reduction in their negative emotions, discussed others' emotions, and sometimes ended the conversation by thanking their mothers. In sum, during the angry conversations, children primarily focused on what their emotions were, why they felt those emotions, and adding event details.

Overall, the processes the children used were reliably consistent across all four emotion conversations. What was subtly different was the order in which the children used these processes and the emphasis on each process, particularly between positive and negative emotion conversations. Generally, children's processes matched mothers' processes throughout each conversation. That is, mothers typically led the conversations and children's replies matched the function of their mothers' statements. For example, during the happy emotion conversations, mothers tended first to ask how and why their children felt an emotion, while the children tended first to discuss how they felt and why. Next, mothers typically elicited event details and children typically added event details. This then switched and children then elicited event details and mothers added event details. Following this, mothers typically discussed their own emotions and children discussed others' emotions. Although subtly different, the same pattern emerged across the other three emotion conversations (i.e., sad, scared/worried, angry).

Life lessons. Another strategy mothers implemented during conversations with their children was using life lessons or advice giving. The transcriptions of the mother-child conversations were analyzed to examine the specific life lessons mothers were conveying to their children throughout the conversations. Following that, summary statements were created for each of the specific life lessons mothers conveyed (e.g., working hard pays off, it is important to appropriately handle conflict with others). Next, those summary statements were compared across emotions and the similar statements were grouped into overall themes of the core issue 
each statement was addressing (e.g., perseverance, managing interpersonal relationships). The lessons are presented by emotional event and are presented in order of summary statement, (example of exact quote from mother in this dissertation), and overall theme with explanation (See Table 10).

During the happy emotional events, six mothers provided lessons. The lessons conveyed during these conversations were:

a) Working hard pays off (e.g., "And well you got that because you had made all As."). This lesson fits into the overarching theme of perseverance because the mother is conveying the idea that the child must work hard to earn good grades even when it is challenging; therefore, it is important to persevere to earn things.

b) It is nice to be helpful to others (e.g., “...that's kind of a nice situation for her because you can go over and play with the cats and socialize the cats...that's very helpful to her.") This lesson fits into the overarching theme of managing interpersonal relationships because the mother is conveying the idea that assisting others can help maintain positive relationships with others.

c) Your emotions can affect others (e.g., "I love seeing you happy."). This lesson fits into the overarching theme of managing interpersonal relationships because the mother is conveying the idea that it is important to manage one's own emotions because they can affect the individuals around you in a manner that would improve or harm the relationship.

d) Difficult situations can improve (e.g., “... and each time you go and you build from that and you learn something new."). This lesson fits into the overarching theme of 
perseverance because the mother is conveying the idea that if you continue to approach challenging situations, they become less challenging for you over time.

During the sad emotional events, 14 mothers provided lessons. The lessons conveyed during these conversations were:

a) It is acceptable to grieve and honor deceased individuals (e.g., "We still cry when we sing grandpa's favorite songs, and that's fine, right?"). This lesson fits into the overarching theme of mood management because the mother is conveying the idea that expressing emotions is an appropriate part of dealing with difficult situations.

b) Good things can come from difficult situations (e.g., “...you think something bad is going to happen again, but that's not always going to be the case. Sometimes it might be something good, probably most of the time something good. Rarely is it something bad."). This lesson fits into the overarching theme of perseverance because the mother is conveying the idea that expecting the worst in a situation is not helpful because it does not encourage you to push through to see positive outcomes that you might have missed otherwise.

c) Death has different circumstances (e.g., “...it was just sad. Because even though she was old, it wasn't her time to go yet."). This lesson fits into the overarching theme of mood management because the mother is conveying the idea that it is typical to feel sad following the death of a loved one, but you should prepare to feel sadder possibly when that death is unexpected and to prepare coping strategies accordingly.

d) Give people the benefit of the doubt, unless there is reason not to (e.g., "...I am glad you weren't very sad after that because accidents can just happen.”). This lesson fits into the overarching theme of managing interpersonal relationships because the 
mother is conveying the idea that it is important to judge the intentionality of a person who hurts you (e.g., accidental or purposeful) and resolve the issue accordingly.

e) Your emotions can affect others (e.g., "I just get emotional when you cry."). This lesson fits into the overarching theme of managing interpersonal relationships because the mother is conveying the idea that it is important to understand that your emotional expressions can influence your interactions with others.

f) There are methods to reduce your sadness (e.g., "....when you do feel sad, try to think of something else to try to get your mind off of what is making you sad...or talk about why you are sad.”). This lesson fits into the overarching theme of mood management because the mother is conveying the idea that there are coping strategies you can use when you feel sad to make yourself feel better.

g) It is important to express your emotions (e.g., "You have to talk about things that make you sad to deal with things."). This lesson fits into the overarching theme of mood management because the mother is conveying the idea that discussing your emotions is one strategy you can use to make yourself feel better when you feel sad. During the scared/worried emotional events, 13 mothers provided lessons. The lessons conveyed during these conversations were:

a) You can trust your parents to keep you safe (e.g., "Do you think that we would let you get on something that would hurt you?"). This lesson fits into the overarching theme of managing interpersonal relationship, in that the child has to determine who he or she can trust.

b) Difficult situations can improve (e.g., "You tend to be afraid of things that you don't know how to do, don't you? I can tell until you learn how to get it then you say 'hey 
that wasn't bad after all,' huh?'). This lesson fits into the overarching theme of perseverance because the mother is conveying the idea that it is important to push through intimidating situations, as it can improve your confidence.

c) It is important to take steps for your safety (e.g., "I wanted you to have nice swimming lessons so that if anything ever happens if you are in the pool or the ocean or a lake or anywhere that you don't panic.”). This lesson fits into the overarching theme of safety because the mother is conveying the idea that there are measures you can take to protect yourself.

d) There are methods to reduce your fear (e.g., "That does always help when you are worried and you start succeeding and start doing better, so then you can stop worrying so much.”). This lesson fits into the overarching theme of mood management because the mother is conveying the idea that there are strategies you can use to improve your mood.

e) It is important to express your emotions (e.g., "Right, well we didn't know. Right and I agree. I wasn't 100\% comfortable doing that either, so now we know, so let's not do it again until you're older.”). This lesson fits into the overarching theme of mood management because the mother is conveying the idea that discussing your emotions is one method that can improve your mood.

f) It is normal to experience some worry (e.g., "It is a little bit healthy sometimes to have that level of nerves."). This lesson fits into the overarching theme of mood management because the mother is conveying the idea that you can expect to feel anxious sometimes and not to let that prevent you from continuing forward in life. 
During the angry emotional events, 17 mothers provided lessons. The lessons conveyed during these conversations were:

a) It is important to appropriately handle conflict with others (e.g., "Well, not ignored when he hit you. What should you have done instead of yelling?"). This lesson fits into the overarching theme of managing interpersonal relationships because the mother is conveying the idea that it is important to deal with conflict appropriately to maintain friendships.

b) It is important to adhere to schedules (e.g., "I know, but if you both agree to be there at a certain time, you have to be there."). This lesson fits into the overarching theme of negotiating scheduling because the mother is conveying the idea that it is important to schedule your life wisely and adhere to that to maintain professionalism and relationships.

c) Difficult situations can improve (e.g., "You did so well. Do you realize we just have to do what we have to do and we can still do it?"). This lesson fits into the overarching theme of perseverance because the mother is conveying the idea that it is important to push through challenging situations to build confidence.

d) Give people the benefit of the doubt, unless there is a reason not to (e.g., "But isn't that possible? Let's just, you know, assume we're gonna give him the benefit of the doubt.”). This lesson fits into the overarching theme of managing interpersonal relationships because the mother is conveying the idea that it is important to trust others if you want to maintain relationships.

e) It is important to express your emotions (e.g., "I made you angry? I'm sorry. You make me angry sometimes, too."). This lesson fits into the overarching theme of 
managing interpersonal relationships because the mother is conveying the idea that it is important to maintain open communication with others to ensure any issues are resolved.

f) There are consequences for aggression (e.g., "You kept telling your teacher he kept hurting you and nothing was getting done and we talked to the principal. He was not allowed to come a certain amount of space towards you and we did not have any more issues with him hurting you."). This lesson fits into the overarching theme of managing interpersonal relationships because the mother is conveying the idea that it is not acceptable to hurt others, as it will fracture relationships and possibly result in other negative consequences.

Overall, five major themes emerged from the life lessons mothers in this dissertation provided to their children. Those themes were how to manage interpersonal relationships, how to negotiate scheduling, how to manage mood, how to promote safety, and how to persevere through challenging times. These life lessons map onto the topics and themes discussed by the mother-child dyads. Interpersonal conflict and safety were two of the most commonly discussed themes throughout all of the conversations.

Self-esteem. Each of the four emotion conversations was analyzed for statements the mothers used that are associated with fostering self-esteem in their children. These statements then were assigned a label based on content (e.g., social inclusion). Finally, these statements were then grouped into meaningful categories based on their function that map onto the coding system described in the methods section (i.e., person praise, process praise, recasting the focus from a weakness to a strength, supporting the child's expression and evaluation of emotions). 
The majority of these statements occurred during the happy emotion conversations. The results are divided by emotion (See Table 11). Thirteen separate mothers used statements that are associated with fostering their children's self-esteem during their conversations. Six mothers provided statements across different emotion conversations.

For the happy emotion conversations, eight separate mothers made comments that are associated with fostering their children's self-esteem. The statements were:

a) Social inclusion/competence (e.g., "You've made lots of new friends. You are part of a group.”). This label maps onto the code person praise.

b) Personality (e.g., "And he had a lot of personality. He had a big personality kinda like you...”). This label maps onto the code person praise.

c) Good grades in school (e.g., "You got that because you had made all A's. It made me happy..."). This label maps onto the code process praise.

d) Strengths (e.g., "I remember you didn't like to take naps because you had too much energy, but you were good at circle time. So you were the one who was good that day. You got to go first as a reward. That's a pretty cool thing, huh?”). This label maps onto the code recasting the focus from a weakness to a strength.

e) Religious rite of passage (e.g., "Yeah dad and I were real proud of you that day. I told you it was the best present I could have gotten.”). This label maps onto the code process praise.

f) Memory and description of an event (e.g., "Good job. Good memory. Your memory is definitely better than mommy's.”). This label maps onto the code person praise.

g) Talent at a sporting event (e.g., "You played well. You got batted in so you got to score one of those runs that helped win the game, so that was very exciting... When it 
really mattered, you did what you had to do and you won."). This label maps onto the code process praise.

h) Validating emotions (e.g., "I love seeing you happy. I love seeing you smile. It is so pretty."). This label maps onto the code supporting the child's expression or evaluation of emotions.

i) Appropriate behavior (e.g., "You were very good while you were there. You were well behaved and a good helper.”). This label maps onto the code process praise.

During the sad emotion conversations, five separate mothers made a total of five comments that are associated with fostering their children's self-esteem.

a) Social inclusion/competence (e.g., “...you've made lots of new friends, so it's all worked out for the best.") and ("Yeah, you and [friend] are big buddies. I know they miss you."). This label maps onto the code person praise.

b) Perseverance (e.g., "Well that's a good way of working that out. So you met some new friends and you kind of moved past that."). This label maps onto the code process praise.

c) Validating emotions (e.g., "But at the time it wasn't silly or stupid. It really hurt your feelings.") and ("No, it's not fine if it makes you sad."). This label maps onto the code supporting the child's expression or evaluation of emotions.

For the scared/worried emotion conversations, four separate mothers made six statements that are associated with fostering self-esteem in their children.

a) Bravery (e.g., "'Cause you were such a star, so that wasn't as scary.”). This label maps onto the code process praise. 
b) Personality (e.g., "You're so witty. Where do you get that stuff?"). This label maps onto the code person praise.

c) Perseverance (e.g., "You were really strong for him...you were doing so good. I was so proud of you. What's great about it is that it didn't keep you from [activities] and that's great because some people let their emotions...they get too scared...but you felt strong and you did it. High five.”). This label maps onto the code process praise.

d) Appropriate behavior (e.g., “...we thought maybe we'd try it for one time because you were responsible.”). This label maps onto the code process praise.

Finally, for the angry emotion conversations, three separate mothers made three statements that are associated with fostering self-esteem in their children.

a) Talent at a sporting event (e.g., "Because you did so well...”). This label maps onto the code process praise.

b) Validating emotions (e.g., “...you can't allow people to be yucky to you.”). This label maps onto the code supporting the child's expression or evaluation of emotions.

c) Reducing blame (e.g., It wasn't your fault, but people thought that you did it on purpose. So he got mad. I guess he just wasn't willing to take the blame for his own actions."). This label maps onto the code recasting a weakness as a strength.

In sum, across the 13 mothers who made relevant statements, they used all of the strategies highlighted in the literature that are associated with fostering their children's selfesteem: supporting the child's expression and evaluation of their emotions, praising the child (i.e., person praise), praising the child's behavior (i.e., process praise), and recasting the children's areas of weakness as strengths. This underscores the fact that the mothers in this dissertation use strategies that suggest they value self-esteem in their children. 


\section{Positive and Negative Affect}

The scores for each scale on the Positive and Negative Affect Schedule (PANAS) convert to percentiles, with scores converting to the $25^{\text {th }}$ percentile $(\mathrm{PA}=26, \mathrm{NA}=12), 50^{\text {th }}$ percentile $(\mathrm{PA}=32, \mathrm{NA}=15), 75^{\text {th }}$ percentile $(\mathrm{PA}=37, \mathrm{NA}=18)$, and $99^{\text {th }}$ percentile $(\mathrm{PA}=47, \mathrm{NA}=35)$ (Crawford \& Henry, 2004).

First, preliminary analyses were conducted on mothers' affect on the PANAS. For maternal ratings of negative affect recently (i.e., over the past few weeks), $M=18.6, S D=6.3$, range $10\left(12^{\text {th }}\right.$ percentile $)$ to $33\left(98^{\text {th }}\right.$ percentile $)$. For negative affect generally, $M=15.8, S D=$ 4.6, range $11\left(18^{\text {th }}\right.$ percentile) to $30\left(96^{\text {th }}\right.$ percentile $)$. For maternal ratings of positive affect recently (i.e., over the past few weeks), $M=36.8, S D=5.1$, range $25\left(21^{\text {st }}\right.$ percentile) to 48 $\left(>99^{\text {th }}\right.$ percentile). For positive affect generally, $M=36.8, S D=5.4$, range 24 ( $18^{\text {th }}$ percentile) to $46\left(98^{\text {th }}\right.$ percentile).

Next, two Spearman rank-order correlation coefficients were computed to assess the relationship between positive affect generally, on average on the PANAS and positive affect over the past few weeks on the PANAS and between negative affect generally, on average on the PANAS and negative affect over the past few weeks on the PANAS. There was a positive correlation between the two negative affect ratings on the PANAS, $r s(22)=.70, p<.001$, twotailed. There was also a positive correlation between the two positive affect ratings on the PANAS, $r s(22)=.57, p<.01$, two-tailed. In general, the results suggest that this sample of mothers tended consistently to rate themselves as having either higher or lower positive and negative affect over the past few weeks and in general, on average. Therefore, the analyses are only conducted on mothers' ratings over the negative and positive affect in general. 


\section{Positive and Negative Affect and Approach Statements}

To determine what relationship, if any, maternal affect has with mothers' use of statements that approach emotions and event details, Spearman rank-order correlations were computed. The results are reported divided by: positive emotion, negative emotions combined, and separately by sad emotion, scared/worried emotion, and angry emotion.

First, the average number of times mothers approached each of the three categories is reported divided in the same way the correlations are reported (See Table 12 and Figure 1).

Spearman rank-order correlations were computed to explore the relationship between positive and negative affect ratings in general, on average on the PANAS and totals for happy (See Table 13) conversation codes (e.g., approach emotion directly or indirectly, approach emotion resolution, and approach event details). There were no statistically significant findings for the happy conversation codes.

Spearman rank-order correlations also were computed to explore the relationship between positive and negative affect ratings in general, on average on the PANAS and totals for sad, scared/worried, and angry conversation codes (See Table 13): approach emotions, approach negative emotion resolution, and approach event details. There was one statistically significant finding, with a moderate correlation, in agreement with Hypothesis 3. Mothers who reported higher (i.e., a little) negative affect in general used fewer statements that approached event details during negative event conversations combined, $r s(22)=-.479, p=.018$. This suggests that mothers with a little negative affect are not focused on details when discussing past negative events with their children.

To gain a better understanding of whether a particular emotion conversation was driving that initial result, Spearman rank-order correlations were then computed to explore the 
relationship between positive and negative affect ratings in general, on average on the PANAS and the separate negative (i.e., sad, scared/worried, angry) conversation codes (e.g., approach emotion directly or indirectly, approach emotion resolution, and approach event details).

During the sad event conversations, there were no significant findings.

During the scared/worried conversations, there was one significant finding, which supports Hypothesis 3. Mothers who reported higher (i.e., a little) negative affect in general used fewer statements that approached event details, $r s(22)=-.595, p=.002$.

Finally, during the angry conversations, there was one significant finding, which supports Hypothesis 3. Mothers with higher (i.e., a little) negative affect generally used fewer statements that approached event details, $r s(22)=-.595, p=.002$.

Overall, there were no significant findings for mothers' use of approach statements during the happy conversations, but there was support for Hypothesis 3 , in that mothers with higher (i.e., a little) negative affect tended to be less focused on details during scared/worried and angry conversations.

\section{Positive and Negative Affect and Maternal Conversational Exchanges}

Next, to determine if maternal affect was related to mothers' amount of speaking about any given emotional event, Spearman rank-order correlation coefficients were computed to assess the association between maternal affect on the PANAS with the number of maternal conversational exchanges per emotion conversation (e.g., happy, sad, scared/worried, angry; See Table 14 and Figures 2-5). There was one significant findings for mothers' affect ratings on the PANAS generally and the number of their conversational exchanges during happy conversations. That is, mothers who rated themselves as having higher positive affect generally used fewer conversational exchanges during happy conversations $\left(r_{s}(23)=-.41, p<.05\right)$. 


\section{Summary of Positive and Negative Affect Findings}

To summarize all of the positive and negative affect findings together, mothers with a little negative affect tend to be less focused on event details during conversations about past negative events. There were no significant findings for happy conversations or for positive affect ratings. There also were no significant findings for mothers' use of statements that approach emotions directly or indirectly or that attempt to resolve their children's negative findings during any of the emotional conversations. Maternal affect ratings only influenced the number of maternal conversational exchanges during the happy conversations.

\section{Discussion}

\section{The Current Study}

This dissertation examined how mothers socialize emotions in their children during conversations about children's past positive and negative events. That is, this dissertation first qualitatively examined seven variables: 1) the content of the conversations mothers had with their children (e.g., moving away, making a friend); 2) the themes of the conversations mothers had with their children (e.g., safety, negotiating interpersonal conflict); 3) the process mothers used to elicit emotions in their children (e.g., clarify how child felt, reduce negative emotion of child); 4) the process children used to discuss emotions with their mothers (e.g., state how they felt, elicit advice); 5) the exact strategies the mothers used to elicit emotions in their children (e.g., who? what?); 6) the life lessons the mothers conveyed to their children during the conversations (e.g., how to persevere); and 7) the statements the mothers used that are associated with fostering their children's self-esteem. Next, this dissertation quantitatively examined whether mothers with varying levels of negative and positive affect on the Positive and Negative Affect Schedule (PANAS) differed in the number of their conversational exchanges and their 
approach of emotions, resolution of negative emotions, and event details in their conversations with their children.

\section{Content}

First, the specific common content of the conversations was analyzed. The most common content discussed was vacation, extracurricular activity, death or run away pet, separation from loved one, bad weather, injury or threat of injury, not being allowed to do something, and arguments with friends. Previous studies focus on whether topics are categorized as socialrelational or autonomous in nature (e.g., Fivush, 1991b). In this dissertation, the topics discussed primarily were social-relational in nature, in that most children discussed events that involved their interactions with others (e.g., vacation, extracurricular activity, arguments with friends). Therefore, the mothers in this dissertation selected opportunities to teach their children about their emotions in relation to others' emotions, thus developing their children's sense of self as similar to and distinct from others.

It is important to understand why particular topics were commonly discussed during the mother-child conversations in this dissertation. The literature shows that topics are typically discussed when they stand out in a person's memory. That is, an event typically stands out in a person's memory when it deviates from a routine or is distinctive in some way (Hudson \& Krackow, 1990; Hudson \& Nelson 1986). Events or event components that are more typical in nature are those that are typically mentioned less frequently over time (Hudson \& Fivush, 1991a). Due to possible interference by general event schema (Hudson \& Nelson, 1986), mothers in this dissertation were instructed to discuss novel events. Therefore, it is less likely that children's general event schemata were interfering with their memories for specific events. Cultural norms likely also play a role in the topics that were discussed between mothers 
and their children, as children's emotional appraisals and expression are influenced by cultural norms (Cole, Bruschi, \& Tamang, 2002; Hudson, 1991) via display rules (Misailidi, 2006) and emotion scripts (Widen \& Russell, 2010). The children in this dissertation were likely relying on their emotion scripts, which emerge during the preschool years, to choose which events to discuss for each emotion. Additionally, the mothers in this study were all middle- to upper-class, educated women, which can influence their cultural norms. In sum, the topics of the motherchild conversations in this study were likely chosen not only due to their uniqueness, but also were influenced by the participants' cultural norms regarding emotional appraisal and expression.

\section{Themes}

Looking more closely at the content of the mother-child conversations in this dissertation, deeper themes emerged. Out of the 25 themes that emerged from the data, the most common themes were novel experiences, social inclusion, death or separation from loved ones, safety, negotiating interpersonal conflict, and having privileges restricted. Individually, each of the themes is important. As mentioned in the results, each theme maps onto the content that was discussed, suggesting these are the most salient events for the 7 - to 10 -year-old children in this sample, and possibly in general. The themes all are developmentally appropriate and consistent with literature on common issues during that period of life. For instance, when a child is in elementary school, they are often exposed to novel experiences, such as field trips or family vacations. It is also typical that school-aged children will become curious and ask about death, such as the death of a class pet or of an older family member (Bering, Blasi, \& Bjorklund, 2005). Additionally, bullying and interpersonal conflict are common realities for school-aged children in the United States (Nansel, Overpeck, Pilla, Ruan, Simons-Morton, \& Scheidt, 2001). Finally, 
parents and teachers commonly use behavioral interventions for school-age children, such as restricting privileges (i.e., negative punishment) to reinforce appropriate behavior (Rudolph \& Radey, 2011). In sum, these themes are particularly salient for school-aged children and make sense that they would be commonly discussed in this dissertation.

Looking at the function of the themes overall, it is consistent with Vygotsky's (1978) theoretical views and Fivush's (1991a) results. More specifically, one of the main functions of discourse is the development of the self, including autonomy and preparation for the future, in terms of interpersonal effectiveness and competence. Mothers model narrative skills for their children, especially those that are culturally relevant. The types of questions mothers ask their children when having children recall an event affects the information that children report when recalling the event at a later time, suggesting that children internalize their mothers' narrative styles to some degree (Fivush, 1991a). Mothers teach their children not only how to discuss past events, but also why it is socially helpful to do so. The content and structure of conversations are guided by specific cultural frameworks for storytelling. Mothers include evaluative information in their conversations, which guide the child in learning how to think about their past experiences and also how to view themselves (Fivush, 1991a). Therefore, the themes in this dissertation may have emerged, in part, due to the mothers' modeling of culturally important narrative skills.

\section{Maternal Processes}

It is not only important to know what was being discussed by the mother child dyads, but also the process the mothers used to elicit these emotions in their children in this dissertation. More specifically, mothers elicit emotions in their children particularly by asking the child what their emotion was and why the child experienced that emotion. Patterns emerged across mothers for each of the four emotion discussions; however, the negative emotions (e.g., sad, angry, 
scared/worried) generally espoused the same patterns, which were slightly different from that of the happy, or positive, emotion. For that reason, the processes were combined into two categories (i.e., negative emotions and happy emotions) for the sake of the discussion. The processes seen in this dissertation more closely map onto Marin, Bohanek, and Fivush's (2008) coding system of initiations (e.g., add new information, convey advice or lessons), collaborations (validate child's statement), and non-collaborations (revise child's statement, make negative comment about child) than onto the more primitive elaborative versus repetitive coding system that was used by Fivush (1993). The sequential data on which the information below is based is presented in the results section when the order of the processes the mothers used was detailed.

For the negative conversations, mothers typically added or elicited emotion and event details, trying to get at the core issue behind the child's negative emotional reaction (i.e., sadness, fear/worry, anger) to the event. Mothers also tended to focus on trying to reduce some of the child's negative emotions or to ask about whether the child's negative emotions were reduced. For example, a mother in this dissertation said "But that helped make it so it wasn't so sad." Mothers also attempted to make the experiences learning opportunities for how to better manage similar events in the future. On two occasions, mothers made negative comments to the child or about the child either blaming them for the event or suggesting the child should not feel the negative emotion.

The processes mothers used to elicit information during the happy conversations were basically the same as the ones they used during the negative conversations; however, the order in which mothers used the methods and their emphasis on the methods were different. More specifically, during discussions of happy events, mothers typically first focused on gathering more information of their children's emotions and the context in which they experienced these 
emotions. During the positive event discussions, mothers spent more time complimenting or validating their children's emotions than they did during the negative event discussions. There was less of an emphasis on turning these conversations into learning opportunities for the child.

A key difference between the happy and negative emotion conversations was that the mothers were attempting to maximize positive emotions in the first conversations and minimize negative emotions in the latter conversations. Additionally, mothers did not try to get at the core issue of what made the child happy or to convey as many lessons or pieces as advice as they did during the negative conversations. Overall, the mothers tended to use similar methods to elicit information and emotions from their children during the conversations, with a difference in temporal order and prominence of certain methods.

\section{Exact Strategies}

On a more micro level, the exact strategies mothers used to guide the conversations about both past negative emotional events and positive emotional events with their children were analyzed. During this examination, most mothers were found to be using the same strategies, which was to ask numerous questions. The most commonly asked questions were a variation of the following: a) how did you feel?; b) why did you feel that way?; c) when did you start/stop feeling that emotion?; d) who was a part of this event with you?; e) where did this event occur?; and f) what happened during the event or what did you learn from the event?

Mothers in this dissertation are asking these questions to better understand their children's emotional experiences. Mothers also provided their insights into why the child may have experienced that particular emotion. Through this process, mothers also implied how emotions are natural and acceptable as long as they do not impair the child. Finally, mothers empowered their children that they have the ability to handle situations that evoke that emotion 
in the future. The exact strategies used in this dissertation expand upon the function coding used by Marin, Bohanek, and Fivush (2008). The way that mothers structure these conversations for their children socializes the children to think about their emotions in a manner consistent with the maternal structure.

In sum, the mothers in this dissertation were modeling how to evaluate their pasts and their emotions, which is associated with the child's development of self-concept (Fivush \& Nelson, 2006). It makes sense, given that mothers begin socializing emotions in their children during conversations early in children's lives that mothers would continue to use these questions to structure conversations as their children become older and more skilled at using that language. The mothers in this dissertation were teaching their children to view themselves positively when reminiscing about happy times by complimenting the child about handling a situation well, for example. Additionally, the mothers were teaching their children to provide constructive feedback to themselves when situations did not go well for the child by asking questions that got at what could have gone differently. This helps the child develop insight and new skills for how to better handle that situation in the future.

\section{Children's Processes}

As conversations are bidirectional, it is also important to know the process the children used to discuss these emotional events with their mothers. Patterns emerged across children for each of the four emotion discussions, with only subtle differences in the temporal order and emphasis on each process. The processes seen in this dissertation map onto Fivush et al.'s (2003) coding system of elaborations (e.g., add event details code in this dissertation), evaluations, repetitions, and facts (e.g., adding information code in this dissertation), emotions (e.g., clarification of what emotion is code in this dissertation), attributions and causes (e.g., 
clarification on why emotion occurred code in this dissertation), and resolutions (e.g., reduce negative emotion code in this dissertation). However, the codes in this dissertation are more extensive than those previously used in the literature to get a more fine tuned examination of how children are discussing past emotional events with their mothers.

During all of the emotion conversations, the relations between children's and mothers' contributions to the conversations were concurrent. More specifically, the patterns that emerged in what mothers were doing also emerged in what children were doing during these conversations. That is, the mother-child dyads in this dissertation were collaborative in their discussions about past emotional events. As mothers were asking how and why their children experienced an emotion, children were responding to those questions. As one conversational partner elicited event details, the other partner responded with event details. When children discussed others' emotions, mothers tended to discuss their own emotions or the emotional reactions they shared with their children. Mothers' and children's discussions of reductions in children's negative emotions also matched. Finally, as children elicited advice, mothers responded by conveying lessons, to which children responded by discussing what lesson they learned from the event. In sum, regardless of whom it was who initiated a line of conversation (e.g., eliciting advice, eliciting event details), the other conversational partners' responses followed suit (e.g., conveyed lessons, added event details).

To tie these findings to the literature, families who are more collaborative (e.g., integrate and validate children's statements about emotions and event details) during conversations about specific negative emotional events, have children who report higher social competence (Marin, Bohanek, \& Fivush, 2008). Functionally, families who express and explain specific negative emotions during their conversations have children who report higher social competence, and 
families who explain specific positive emotions have children who report higher self-esteem (Marin et al., 2008).The children in this dissertation had their emotional and event detail statements integrated cohesively into the conversations with their mothers. Additionally, the children were able to both express and explain specific emotions they experienced during these events. Therefore, even though this was not assessed in this dissertation, it is likely that these children would report higher social competence and self-esteem levels.

The children in this dissertation were able to express and explain others' emotions in addition to their own. This ability can help a child successfully negotiate peer conflict and engage in other prosocial behaviors (Denham et al., 2003). In turn, these behaviors can lead to that child being viewed more favorably by peers and authority figures. In turn, this can make it more likely that the child will continue to experience positive interactions with others. In turn, this can lead to the child feeling more socially competent, thus continuing the cycle (Denham et al., 2003).

In sum, the children and mothers in this dissertation had the same goals for the conversations, as evidenced by their use of processes in relatively the same order and with relatively the same emphasis on each process. The fact that mother-child dyads in this dissertation were high SES families makes this finding more probable. That is, higher SES mothers use strategies that are associated with better child emotional development outcomes (Raikes \& Thompson, 2008).

\section{Life Lessons}

Next, the opportunities that mothers used to convey lessons or advice were examined more closely. The most common lessons conveyed were those about managing interpersonal relationships including conflict, managing mood disturbances, persevering through challenging 
situations, promoting safety, and managing and negotiating scheduling. More specifically, mothers tended to encourage the child to reflect on the interpersonal conflicts they had and to create alternative solutions to the problems. Mothers then typically provided advice to the child on how to handle the situation differently or they praised the child for independently generating an appropriate alternative solution to manage the conflict.

When discussing how to manage interpersonal relationships, mothers provided general rules and norms to guide the child through issues and impressed upon the child the importance of respect and trust. For the lessons on managing mood disturbances (e.g., anxiety, sadness), mothers tended to give advice on what might help the child's mood stabilize (e.g., talk to others, distraction techniques) and asked the child to generate other solutions. During the lessons on perseverance, mothers normalized their children's emotions and turned the focus to the positive outcomes that result from hard work. When promoting future safety, mothers tended to encourage their children to reflect on what they thought kept them safe in the past and gave advice on how to fine tune their approach in the future. Finally, when discussing managing and negotiating scheduling, mothers again espoused societal norms and expectations to advise the child on how to be responsible and respectful.

In sum, individuals' values are influenced by their demographic variables and the expectations and norms of the families and cultures in which they are embedded. The mothers in this dissertation reflected these values when promoting certain lessons or advice to their children. Therefore, mother-child conversations are one method via which these unwritten rules are passed down through generations. 


\section{Self-Esteem}

Another strategy that mothers use to develop children's social and emotional competence is the use of terms that are intended to foster children's self-esteem. Self-esteem analyses are commonly done throughout the child narrative literature (Cho, Sandel, Miller, \& Wang, 2005;

Miller, Wang, Sandel, \& Cho, 2002). When children's statements are confirmed and assimilated into family conversations, the children's levels of self-esteem tend to be higher (Bohanek, Marin, Fivush, \& Duke, 2006). Also, mothers who openly explain and display emotions, especially specific negative emotions, tend to have children who have higher levels of self-esteem (Bohanek et al., 2006; Marin, Bohanek, \& Fivush, 2008). Of course, the role of self-esteem in caregiver-child narratives varies across and within cultures (Cho et al., 2005). Research has found that European American parents place a greater emphasis on fostering self-esteem in their children through discourse and discipline than parents in other cultures (Miller \& Fung, 2012). Therefore, it is expected that these statements would be prevalent among this sample.

Statements that foster self-esteem are those that: a) support the child's expression and evaluation of their emotions (Marin, Bohanek, \& Fivush, 2008), b) praise the child (i.e., person praise) and the c) child's behavior (i.e., process praise; Kamins \& Dweck, 1999), and d) recast the child's areas of weakness as strengths (Miller, Fung, \& Mintz, 1996). Because self-esteem is one component of the development of the self that can be strengthened during mother-child conversations, it was important to examine statements that contributed to self-esteem in this dissertation.

The statements that are associated with fostering self-esteem in this dissertation were found in both the positive and negative conversations. During the happy emotion conversations, these statements reflected the child's good behavior, talent at sports or academics, being socially 
competent and well-liked, having a good memory, making a religious rite of passage, and validating the child's emotions. In the negative emotion conversations, these statements regarded valuing the child's emotions, instilling self-respect in the child via validating their emotions, social inclusion and competence, good behavior, talent at sports, praising the child for making it through a challenging situation, and reducing the child's perception of blame and guilt. These labels mapped onto all of the codes supported in the literature for how mothers improve selfesteem in their children: person praise, process praise, recasting a weakness as a strength, and supporting the child's expression and evaluation of emotions. This suggests that mothers in this dissertation were making statements that are associated with strengthening their children's selfawareness, improving their children's social connections with others, teaching their children effective ways to cope with their emotions, and tightening the association between their children's autobiographical memory and their development of the self.

Overall, the statements in this dissertation that were associated with those that foster self-esteem are similar to those in the existing literature. Instilling self-esteem is important, as it impacts a child's social and emotional competence (Marin, Bohanek, \& Fivush, 2008). The literature suggests that verbal approval and support from significant others has a strong tie to child's self-esteem (Reese, Bird, \& Tripp, 2007). More specifically, parents' mentioning and evaluating their children's positive emotions is linked to higher child self-esteem, independent of the emotional valence of the conversation. It is suggested that as the parents teach the children to evaluate the past more positively, the children also begin to evaluate themselves more positively, thereby improving their self-esteem (Reese et al., 2007).

In sum, the function of each of the statements mothers used to that are associated with fostering self-esteem in their children in this dissertation was the same - to teach their children 
to evaluate life experiences and themselves more positively. Although not measured in this dissertation, research suggests that mothers who use these statements more frequently likely have children with higher self-esteem. This analysis expanded upon our current knowledge of how mothers foster the development of the self and self-esteem by examining the exact statements used, the themes of those statements, and how those map onto the pre-existing coding system of person praise, process praise, supporting the child's expression and evaluation of emotions, and recasting a weakness as a strength.

Recent research suggests the effectiveness of using praise differs by type of praise used (e.g., person versus process praise) and by pre-existing self-esteem status in the child (e.g., low versus high; Brummelman, Thomaes, Overbeek, de Castro, van den Hout, \& Bushman, 2014). Parents have been found to use more person praise and less process and other praise with children who have low self-esteem, while doing the opposite for children with high self-esteem. Although parents' intentions are well-meaning and an attempt to reduce the child's insecurities, research shows that using person praise with a child who has low-self esteem actually lowers their self-esteem further (Brummelman et al., 2014). A possible explanation for this finding is that children with low self-esteem may base their self-worth on these statements made by significant others (i.e., conditional regard) and feel significant disgrace following a failure (Kamins \& Dweck, 1999). This dissertation did not measure children's self-esteem, so this type of analysis is not possible; however, this is an area that would be interesting to examine in future studies. Based on the literature, however, it could be hypothesized that the mothers who used more of these statements felt that their children had low self-esteem and they were trying to improve that. 


\section{Positive and Negative Affect and Approach Statements}

After examining what the mothers were doing overall, the results were analyzed based on maternal affect levels (i.e., positive, negative) on the Positive and Negative Affect Schedule (PANAS). More specifically, the question being examined was do varying levels of maternal affect relate to mothers' use of statements that approach emotions and event details. Maternal exchanges were coded as either: 1) approach emotions; 2) approach emotion resolution; or 3) approach event details.

Interestingly, there were no significant findings during mother-child conversations about happy past events. Maternal affect did not relate to how mothers approached emotions or event details during happy conversations. It may be that differences due to maternal affect levels are only found when discussions are about negative emotions, as that is when emotionally dysregulated individuals have been found to ruminate. Discussing positive emotions may buffer the mother-child interaction from the effects of a little negative affect and may even serve to reduce some of the mother's negative affect (Leckman-Westin, Cohen, \& Stueve, 2009). Additionally, higher negative affect is characteristic of both depression and anxiety. Therefore, it could be that the mothers in the current sample were too heterogeneous in their symptomatology to lead to the results that are commonly seen among depressed mothers in the existing literature (i.e., emotion dysregulation is associated with lower levels of processing emotions regardless of emotion type of conversation; Leckman-Westin et al., 2009). Further, the mothers in the current sample were not given diagnostic interviews to determine whether they met criteria for a psychiatric disorder. Therefore, it could be that the results commonly found in the literature are not found until the severity of the symptoms meets the clinical threshold for disorder. Additionally, maternal depression, and therefore high negative affect, has been linked more 
strongly to negative rather than positive parenting behaviors (Lovejoy, Graczyk, O’Hare, \& Neuman, 2000). In sum, higher levels of maternal negative affect do not have strong associations with positive parenting, including socializing positive emotions in children.

There were several findings during mother-child conversations about negative past events, however. Generally, mothers with higher (i.e., a little) negative affect approached event details less frequently than mothers with higher positive affect. This suggests that mothers with higher (i.e., a little) negative affect (i.e., a little emotion dysregulation) are less focused on event details when discussing negative past events with their children. These results support Hypothesis 3.

Hypotheses 1 and 2 were disconfirmed, as there were no significant differences in mothers' use of statements that approached emotions directly or indirectly or that reduced negative emotions. Another study that did not find that mothers approached emotions less during negative emotion conversations was the study by Fivush et al. (2003). They actually found the opposite to be true, in that mothers with higher negative affect approached emotions more during negative conversations overall. Fivush et al. (2003) suggested that the mothers were teaching their children how to cope with their negative emotions by evaluating the source of their emotions. In sum, it may be that the mothers in this dissertation did not have sufficiently high enough negative affect levels to see an effect in either direction.

Hypothesis 3 partially was confirmed by the results. Mothers with higher (i.e., a little) negative affect were less likely to approach event details, but only during negative emotional conversations. This finding replicates Fivush et al.'s (2003) finding with mothers generally, but this dissertation extends this finding to a sample of mothers with a little negative affect. Additionally, this finding replicates Breznitz and Sherman's (1987) finding with mothers with 
high negative affect, but this dissertation extends this finding to a sample of older children.

Fivush et al. (2003) suggested that when mothers discuss event details about past negative events, they teach their children that those emotions do not define them. Therefore, mothers with higher (i.e., a little) negative affect in this dissertation may be socializing their children not to believe that their negative emotions are an integral part of who they are.

\section{Positive and Negative Affect and Maternal Conversational Exchanges}

Finally, maternal affect on the PANAS was correlated with the number of conversational exchanges mothers engaged in during each emotional conversation (e.g., happy, sad, scared/worried, angry). In sum, there was only one significant association between maternal affect ratings and number of conversational exchanges used during any of the emotion conversations. That is, mothers with higher positive affect tended to use fewer conversational exchanges when discussing happy emotion conversations.

Looking at the mother-child conversation literature, when given no restrictions, the majority of the mother-child discussions chosen by mothers are positive (Farrant \& Reese, 2000; Reese \& Brown, 2000) or positive and neutral in nature (Burch, Austin, \& Bauer, 2004). In comparison of positive and negative conversation valence, previous studies have found that mothers tend to discuss negative events at greater length than positive or neutral events (Sales, Fivush, \& Peterson, 2003). In all of those studies, however, maternal affect was not assessed. Looking at the mother-young child literature that assesses maternal affect, mothers with high negative affect, compared to mothers with low negative affect, have been found to use fewer words during conversations with their children (Breznitz \& Sherman, 1987). The findings in this dissertation do not support that finding with a sample of mothers with a little negative affect and with a sample of older children. It may be that the mothers in this dissertation did not have 
sufficiently high levels of negative affect to see these results. Interestingly, mothers with higher positive affect engaged in fewer conversational exchanges when discussing positive emotions. It may be that these mothers felt that there was less to question about why the child experienced happiness and did not need the time to resolve any negative emotions.

\section{Limitations of the Current Study}

The limitations of this dissertation are now acknowledged. First, the sample was fairly homogenous, in that the participants were mostly Caucasian, upper-class, well-educated women, although the lab sample was composed of mothers and children who live in an Appalachian community. As mentioned previously in the document, emotion socialization is influenced by cultural and demographic (e.g., SES, education) variables. Therefore, caution should be used in generalizing these results from the lab.

Another limitation of this study is that the sample size is small (i.e., $N=24$ ). It is known that sample size affects the amount of sampling errors in statistical tests and makes it more difficult to detect effects. Having low statistical power also decreases the chances of statistically significant results denoting true effects. Although the sample size in this dissertation was a limitation for those reasons, small sample sizes are not uncommon in the mother-child conversation literature (e.g., Fivush et al., 2000, $N=21$; Marin, Bohanek, \& Fivush, 2008, $N=$ 24; Miller, Wang, Sandel, \& Cho, 2002, $N=16$ ). Having a smaller sample size makes it more approachable to conduct more in-depth examinations of what occurs in the conversations.

Another limitation of this dissertation is that the conversations were only recorded at one time point. This does not allow to analyses of how maternal verbal behavior is related to child's verbal behavior or well-being over time. Although this is a limitation, examining conversations at one point in time is common in the parent-child conversation literature (e.g., Bohanek, Marin, 
Fivush, \& Duke, 2006; Wang \& Fivush, 2005). Additionally, child well-being cannot be examined in relation to maternal conversational processes and strategies or maternal affect because child outcomes were not assessed in this dissertation.

This dissertation is also limited in that it only examines the processes mothers use to socialize emotions in their children. Children interact with numerous other individuals on a regular basis whom also socialize emotions in the children. These individuals include fathers (Fivush et al., 2000), extended family members including grandmothers (Cho et al., 2005), teachers (Ahn, 2005), siblings and peers (Eisenberg, Cumberland, \& Spinrad, 1998). Future studies would benefit from examining how these other individuals socialize emotions in children.

Finally, another limitation of this dissertation is related to the demand characteristics of mother-child dyads who participated in the lab versus in their homes. As mentioned previously, participants were not video recorded; however, the researcher watched the mother-child dyads who participated in the lab via a closed-circuit television. The mother-child dyads who participated in their homes could not been seen by the researcher. Therefore, it is possible that the mothers who were participating in their homes were using non-verbal facial and body gestures to direct their children's behaviors in a manner that will present the dyad in a positive light without the researcher having awareness of this fact. This is supported by Orne's (1962) work on "good subjects" wanting to portray themselves positively and provide the researcher with the information the subject thinks the researcher wants based on their perceived demand characteristics of the particular experiment. Although the procedure was the same for motherchild dyads in the lab and in home, one could reasonably expect the dyads to behave differently when the researcher is and is not present. The faculty member made the decision to begin collecting data in participants' homes to gain a broader sample of participants. 


\section{Theory}

The findings of this study are strongly supported by the work of Susanne Denham and Robyn Fivush. Based on average use of maternal processes in this dissertation, the mothers, particularly those with low negative affect, focused primarily on the event details during the discussions with their children. Next, mothers worked to reduce or assess whether their children's negative emotions were reduced. Finally, the mothers turned their focus to the details of their children's emotions (e.g., what the emotion was, why that emotion was experienced). Taken together, the data allow for the creation of a theory. Theory derivation from the data is the basis of grounded theory qualitative analysis. Based on the mothers' primary focus on event details in this dissertation, it can be theorized that mothers of children in the 7-10 year age group teach their children to define themselves more so by their actions in the past than by their emotions. This theory can be explained further in terms of Fivush et al.'s (2003) and Denham's (1998) findings.

These findings map onto Fivush et al.'s (2003) theory of children's emotional selfunderstanding. More precisely, when mothers focus on the event details and emotional expression during those conversations, it provides an opportunity for the child to define themselves, which is what Fivush and colleagues (2003) label as self-in-relation. As children develop an understanding of how they share their emotional experiences with others, they can develop insight into how they relate to others interpersonally. Differently, when mothers focus on reducing their children's negative emotions, it allows the child to develop an understanding of how they typically manage their mood, which is what Fivush and colleagues (2003) refer to as coping. That is, parents may highlight the various ways in which their children manage their negative emotions (e.g., crying and talking to someone when sad, venting when angry), which 
helps the child further develop their emotional insight. Finally, when mothers focus on the details of their children's emotions (e.g., what, why), children begin to view themselves as a certain type of person, which is what Fivush and colleagues (2003) named self-defining. More specifically, Fivush et al. (2003) stated that parents decide which emotions to highlight and which to overshadow during discussions with their children and these decisions influence how children view themselves emotionally (e.g., often happy, rarely angry). Discussing situation-specific and emotion-specific details with children allows them to develop a more complete understanding of their emotional identities and may better prepare them to manage emotional events in the future.

Additionally, the narrative processes that mothers in this dissertation used during the conversations with their children all are in line with Denham's (1998) model of children's understanding and expression of emotion. First, mothers expressed their own emotions (e.g., “...it scared me;" and “...got me all excited.”) to their children, which maps onto Denham's (1998) modeling component. Next, mothers discussed emotions generally with their children, which maps onto Denham's (1998) coaching component. Finally, mothers responded to their children's expressions of emotion, which maps onto Denham's (1998) reaction to children's expression of emotion component. The result of the mothers engaging in these three skills is that their children develop interpersonal effectiveness skills, whereby the children learn to become socially competent and develop emotion regulation abilities. Social competence is derived from the ability to apply one's understanding of emotions and emotional expression during interpersonal situations while regulating one's emotions (Denham et al., 2003). A person is viewed by others as being more socially competent when their emotional expressions are primarily happy. Additionally, the understanding of emotions provides individuals with the guidance necessary to successfully negotiate interpersonal conflict, which was a key theme in the 
conversations of this dissertation. Finally, individuals who are better able to regulate their emotions, meaning they are able to control their experience of their emotions, are viewed by others as being more emotionally and socially competent (Denham et al., 2003). Therefore, during conversations with their children, mothers are using strategies that either enhance or hinder their children's social competence development.

Overall, the mothers in this dissertation used processes that tend to enhance children's social competence development (Denham, 1998) and their insight into their roles in interpersonal relationships (e.g., self-in-relation; Fivush et al., 2003). The mothers' use of effective modeling and discussion of emotions and emotion regulation and their primarily positive responses to their children's emotions is likely influenced by the fact that the mothers in this dissertation were well-educated, high SES women (Raikes \& Thompson, 2008). The children in this dissertation were able to identify their emotions and discuss causes and consequences of their emotions. Additionally, they were able to recognize and discuss others' emotions. These abilities are associated with success in multiple socioemotional domains (Fivush, Reese, \& Haden, 2006). As conversations are transactional by nature, both the mothers and children in this dissertation engaged in strategies that are associated with well-developed emotion and social competence.

\section{Conclusions}

As mentioned previously, parenting practices, including emotion socialization, are influenced by parental cohort effects and children's age or developmental skills (Demo, 1992; Morris, Silk, Steinberg, Myers, \& Robinson, 2007). Therefore, caution should be taken when attempting to generalize these findings to mothers of different cohorts and of different aged children. It is possible that the results in this dissertation are representative only of mothers in the same age range with children in the same age range. Also, it is important to remember that the 
children in this dissertation have had been socialized by many different individuals, such as family, other adults, and peers throughout their lives and this dissertation only captured one moment in time with one individual speaking to the child.

Mothers with higher (i.e., a little) negative affect in this dissertation, compared to mothers with high positive affect, were less likely to focus on the facts of the events being discussed. In general, mothers who use statements that approach and process emotions have children with more developed social-emotional competence. Children whose mothers focus more on emotions and less on event facts teach their children that those emotions are part of their selfdefinition (Fivush et al., 2003). The mothers in this dissertation did not vary in their use of statements that approach emotions based on their reported affect levels. Even when the mothers were not divided into higher and lower affect levels, mothers tended to approach event details more frequently than emotions and emotion resolutions, regardless of the emotion conversation. Therefore, it may be that the mothers in this dissertation were conveying the idea to their children that their emotions are not necessarily an integral part of who they are.

The qualitative analyses in this dissertation provided rich information to add to the existing literature about how mothers are socializing positive and negative emotions in their children when discussing past emotional events. This dissertation extended the literature by examining the role of maternal affect on mother-child discourse about past emotional events and by broadening the age range (e.g., preschool age) of the children typically discussed in the mother-child conversation literature to include older children. 


\section{References}

Ahn, H. J. (2005). Child care teachers' strategies in children's socialization of emotions. Early Child Care Development \& Care, 175(1), 49-61. doi: 10.1080/0300443042000230320

Asher, S. R., Hymel, S., \& Renshaw, P. D. (1984). Loneliness in children. Child Development, 55(4), 1456-1464. doi: 10.2307/1130015

Bauer, P. J., Stark, E. N., Lukowski, A. F., Rademacher, J., Van Abberna, D. L., \& Ackil, J. K. (2005). Working together to make sense of the past: Mothers' and children's use of internal states language in conversations about traumatic and nontraumatic events. Journal of Cognition \& Development, 6(4), 463-488. doi:10.1207/s15327647jcd0604_2

Baumrind, D. (1971). Current patterns of parental authority. Developmental Psychology Monograph, 4(1, Pt. 2), 1-103. doi: 10.1037/h0030372

Beck, A. T. (1967). Depression: Clinical, experimental, and theoretical aspects. New York: Harper \& Row.

Bering, J. M., Blasi, C. H., \& Bjorklund, D. F. (2005). The development of 'afterlife' beliefs in religiously and secularly schooled children. British Journal of Developmental Psychology, 23(4), 587-607. doi: 10.1348/026151005X36498

Bohanek, J. G., Fivush, R., Zaman, W., \& Lepore, C. E. (2009). Narrative interaction in family dinnertime conversations. Merrill-Palmer Quarterly 55(4), 488-515. doi: $10.1353 / \mathrm{mpq} .0 .0031$

Bohanek, J. G., Marin, K. A., Fivush, R., \& Duke, M. P. (2006). Family narrative interaction and children's sense of self. Family Process, 45(1), 39-54. doi: $10.1111 / \mathrm{j} .1545-5300.2006 .00079 . x$

Bower, G. H. (1981). Mood and memory. American Psychologist, 36(2), 129-148. 
Bradley, B., DeFife, J. A., Guarnaccia, C., Phifer, J., Fani, N., Ressler, K. J., \& Westen, D. (2011). Emotion dysregulation and negative affect: Association with psychiatric symptoms. Journal of Clinical Psychiatry, 72(5), 685-691. doi: 10.4088/JCP.10m06409blu

Braun, V., \& Clarke, V. (2006). Using thematic analysis in psychology. Qualitative Research in Psychology, 3(2), 77-101. doi: 10.1191/1478088706qp063oa

Breznitz, Z., \& Sherman, T. (1987). Speech patterning of natural discourse of well and depressed mothers and their young children. Child Development, 58(2), 395-400. doi:10.1111/1467-8624.ep7253726

Brummelman, E., Thomaes, S., Overbeek, G., Orobio de Castro, B., van den Hout, M. A., \& Bushman, B. J. (2014). On feeding those hungry for praise: Person praise backfires in children with low self-esteem. Journal of Experimental Psychology: General, 143(1), 914. doi:10.1037/a0031917

Burch, M. M., Austin, J., \& Bauer, P. J. (2004). Understanding the emotional past: Relations between parent and child contributions in emotionally negative and nonnegative events. Journal of Experimental Child Psychology, 89(4), 276-297. doi:10.1016/j.jecp.2004.07.006

Burcusa, S. L., \& Iacono, W. G. (2007). Risk for recurrence in depression. Clinical Psychology Review, 27(8), 959-985. doi: 10.1016/j.cpr.2007.02.005

Campbell, S. B., Cohn, J. F., \& Meyers, T. (1995). Depression in first-time mothers: Motherinfant interaction and depression chronicity. Developmental Psychology, 31(3), 349-357. doi:10.1037/0012-1649.31.3.349 
Castro, V. L., Halberstadt, A. G., Lozada, F. T., \& Craig, A. B. (2014). Parents' emotion-related beliefs, behaviours, and skills predict children's recognition of emotion. Infant and Child Development. Advance online publication. doi: 10.1002/icd.1868

Charmaz, K. (2014). Constructing grounded theory ( $2^{\text {nd }}$ ed.). Thousand Oaks, Ca: Sage.

Cho, G. E., Sandel, T. L., Miller, P. J., \& Wang, S. (2005). What do grandmothers think about self-esteem? American and Taiwanese folk theories revisited. Social Development, 14(4), 701-721. doi: 10.1111/j.1467-9507.2005.00325.x

Clark, L. A., \& Watson, D. (1991). Tripartite model of anxiety and depression: Psychometric evidence and taxonomic implications. Journal of Abnormal Psychology, 100, 316-336.

Cole, P. M., Bruschi, C. J., \& Tamang, B. L. (2002). Cultural differences in children's emotional reactions to difficult situations. Child Development, 73(3), 983-996.

Crawford, J. R. \& Henry, J. D. (2004). The Positive and Negative Affect Schedule (PANAS): Construct validity, measurement properties and normative data in a large non-clinical sample. British Journal of Clinical Psychology, 43(3), 245-265. doi:10.1348/0144665031752934

Demo, D. H. (1992). Parent-child relations: Assessing recent changes. Journal of Marriage and Family, 54, 104-177. doi: 10.2307/353279

Denham, S.A. (1998). Emotional development in young children. New York: Guilford Press.

Denham, S. A., Blair, K. A., DeMulder, E., Levitas, J., Sawyer, K., Auerbach-Major, S., \& Queenan, P. (2003). Preschool emotional competence: Pathway to social competence. Child Development, 74(1), 238-256. doi:10.1111/1467-8624.00533

Denham, S., \& Kochanoff, A. T. (2002). Parental contributions to preschoolers' understanding of emotion. Marriage \& Family Review, 34(3-4), 311-343. doi:10.1300/J002v34n03_06 
Denham, S. A., Mitchell-Copeland, J., Strandberg, K., Auerbach, S., \& Blair, K. (1997).

Parental contributions to preschoolers' emotional competence: Direct and indirect effects. Motivation and Emotion, 21(1), 65-86. doi:10.1023/A:1024426431247

Dunn, J., Brown, J., \& Beardsall, L. (1991). Family talk about feeling states and children's later understanding of others' emotions. Developmental Psychology, 27(3), 448-455. doi: $10.1037 / 0012-1649.27 .3 .448$

Eisenberg, N., Cumberland, A., \& Spinrad, T. L. (1998). Parental socialization of emotion. Psychological Inquiry, 9(4), 241-273.doi: 10.1207/s15327965pli0904_1

Eisenberg, N., Fabes, R. A., Murphy, B. C., Maszk, P., Smith, M., \& Karbon, M. (1995). The role of emotionality and regulation in children's social functioning: A longitudinal study. Child Development, 66(5), 109-128.

Ewell Foster, C. J., Garber, J., \& Durlak, J. A., (2008). Current and past maternal depression, maternal interaction behaviors, and children's externalizing and internalizing symptoms. Journal of Abnormal Child Psychology, 36(4), 527-537. doi: 10.1007/s10802-007-9197-1

Farrant, K., \& Reese, E. (2000). Maternal style and children's participation in reminiscing: Stepping stones in children's autobiographical memory development. Journal of Cognition \& Development, 1(2), 193-225. doi:10.1207/S15327647JCD010203

Field, T., Sandberg, D., Garcia, R., Vega-Lahr, N., Goldstein, S., \& Guy, L. (1985). Pregnancy problems, postpartum depression and early mother-infant interactions. Developmental Psychology, 21(6), 1152-1156. doi:10.1037/0012-1649.21.6.1152

Fivush, R. (1991a). The social construction of personal narratives. Merrill-Palmer Quarterly, $37(1), 59-81$. 
Fivush, R. (1991b). Gender and emotion in mother-child conversations about the past. Journal of Narrative and Life History, 1, 325-341.

Fivush, R. (1993). Emotional content of parent-child conversations about the past. In C.A. Nelson (Ed.), The Minnesota Symposium on Child Psychology: Memory and affect in development (pp. 39-77). Hillsdale, NJ: Lawrence Erlbaum Associates, Inc.

Fivush, R., Berlin, L. J., Sales, J. M., Mennuti-Washburn, J., \& Cassidy, J. (2003). Functions of parent-child reminiscing about emotionally negative events. Memory, 11(2), 179-192. doi: $10.1080 / 09658210244000351$

Fivush, R., Brotman, M. A., Buckner, J. P., \& Goodman, S. H. (2000). Gender differences in parent-child emotion narratives. Sex Roles, 42(3/4), 233-253.

Fivush, R., \& Nelson, K. (2006). Parent-child reminiscing locates the self in the past. British Journal of Developmental Psychology, 24(1), 235-251. doi: 10.1348/026151005X57747

Fivush, R., Reese, E., \& Haden, C. A. (2006). Elaborating on elaborations: Role of maternal reminiscing style in cognitive and socioemotional development. Child Development, 77(6), 1568-1588. doi: 10.1111/j.1467-8624.2006.00960.x

Fivush, R., Sales, J. M., Goldberg, A., Bahrick, L., \& Parker, J. (2006). Weathering the storm: Children's long-term recall of Hurricane Andrew. Memory, 12(1), 104-118. doi: $10.1080 / 09658210244000397$

Fivush, R., \& Wang, Q. (2005). Emotion talk in mother-child conversations of the shared past: The effects of culture, gender, and event valence. Journal of Cognition and Development, 6(4), 489-506. doi: 10.1207/s15327647jcd0604_3

Gnepp, J., \& Hess, D. L. R. (1986). Children's understanding of verbal and facial display rules. Developmental Psychology, 22(1), 103-108. doi: 10.1037/0012-1649.22.1.103 
Goodman, S. H., \& Gotlib, I. H. (1999). Risk for psychopathology in the children of depressed mothers: A developmental model for understanding mechanisms of transmission. Psychological Review, 106(3), 458.

Harter, S. (1985). The self-perception profile for children, Unpublished Manual, University of Denver, Denver, CO.

Hudson, J. A. (1991). Learning to reminisce: A case study. Journal of Narrative and Life History, 1(4), 295-324.

Hudson, J. A., \& Fivush, R. (1991a). As time goes by: Sixth graders remember a kindergarten experience. Applied Cognitive Psychology, 5, 347-360. doi: 10.1002/acp.2350050405

Hudson, J. A., \& Fivush, R. (1991b). Planning in the preschool years: The emergence of plans from general event knowledge. Cognitive Development, 6(4), 393-415. doi: 10.1016/0885-2014(91)90046-G

Hudson, J. A., Fivush, R., \& Kuebli, J. (1992). Scripts and episodes: The development of event memory. Applied Cognitive Psychology, 6(6), 483-505.

Hudson, J. A., \& Krackow, E. (1990, March). Preschool children's memory for deviations in a routine event. Paper presented at a Conference on Human Development, Richmond, VA. Abstract retrieved from http://eric.ed.gov/?id=ED338353

Hudson, J. A., \& Nelson, K. (1986). Repeated encounters of a similar kind: Effects of familiarity on children's autobiographic memory. Cognitive Development, 1(3), 253-271. doi: 10.1016/S0885-2014(86)80004-1

Kamins, M. L., \& Dweck, C. S. (1999). Person versus process praise and criticism: Implications for contingent self-worth and coping. Developmental Psychology, 35(3), 835-847. doi: 10.1037/0012-1649.35.3.835 
Kovacs, M. (1981). Rating scales to assess depression in school-aged children. Acta Paedopsychiatrica: International Journal of Child \& Adolescent Psychiatry, 46(5-6), $305-315$.

Krackow, E., \& Gordon, P. (1998). Are lions and tigers substitutes or associates? Evidence against slot filler accounts of children's early categorization. Child Development, 69(2), 347-354. doi: 10.1111/j.1467-8624.1998.tb06193.x

Krackow, E., \& Rudolph, K. D. (2008). Life stress and the accuracy of cognitive appraisals in depressed youth. Journal of Clinical Child \& Adolescent Psychology, 37(2), 376-385. doi:10.1080/15374410801955797

Kulkofsky, S. (2011). Characteristics of functional joint reminisce in early childhood. Memory, 19(1), 45-55. doi: 10.1080/09658211.2010.535542

Kulkofsky, S., Wang, Q., \& Koh, J. B. K. (2009). Functions of memory sharing and mother-child reminiscing behaviors: Individual and cultural variations. Journal of Cognition and Development, 10(1-2), 92-114. doi: 10.1080/15248370903041231

Laird, R. D., Pettit, G. S., Mize, J., Brown, E. G., \& Lindsey, E. (1994). Mother-child conversations about peers: Contributions to competence. Family Relations, 43(4), 425432. doi: $10.2307 / 585374$

Leaper, C. (2002). Part I: Parenting children and older people. In M. H. Bornstein (Ed.), Handbook of parenting: Vol. 1. Children and parenting (2nd ed., pp. 3-161). Mahwah, NJ: Erlbaum. 
Leckman-Westin, E., Cohen, P. R., \& Stueve, A. (2009). Maternal depression and mother-child interaction patterns: Association with toddler problems and continuity of effects to late childhood. Journal of Child Psychology and Psychiatry, 50(9), 1176-1184.

doi: $10.1111 / \mathrm{j} .1469-7610.2009 .02083 . x$

Lewin, A., Mitchell, S. J., \& Ronzio, C. R. (2013). Developmental differences in parenting behavior: Comparing adolescent, emerging adult, and adult mothers. Merrill-Palmer Quarterly, 59(1), 23-49.

Livingston, G., \& Cohn, D. (2010). The new demography of American motherhood. Retrieved from http://www.pewsocialtrends.org/2010/05/06/the-new-demography-of-americanmotherhood/

Lovejoy, M. C., Graczyk, P. A., O’Hare, E., \& Neuman, G. (2000). Maternal depression and parenting behavior: A meta-analytic review. Clinical Psychology Review, 20(5), 561-592. doi: 10.1016/S0272-7358(98)00100-7

Lucariello, J., \& Nelson, K. (1985). Slot-filler categories as memory organizers for young children. Developmental Psychology, 21(2), 272-282. doi: 10.1037/0012-1649.21.2.272

Marin, K. A., Bohanek, J. G., \& Fivush, R. (2008). Positive effects of talking about the negative: Family narratives of negative experiences and preadolescents' perceived competence. Journal of Research on Adolescence, 18(3), 573-593. doi: $10.1111 / \mathrm{j} .1532-7795.2008 .00572 . \mathrm{x}$

McCabe, A., \& Peterson, C. (1990). What makes a narrative memorable? Applied Psycholinguistics, 11(1), 73-82. doi: 10.1017/S0142716400008298 
McDowell, D. J., \& Parke, R. D. (2009). Parental correlates of children's peer relations: An empirical test of a tripartite model. Developmental Psychology, 45(1), 224-235. doi: $10.1037 / \mathrm{a} 0014305$

McDowell, D. J., Parke, R. D., \& Wang, S. J. (2003). Differences between mothers' and fathers' advice-giving style and content Relations with social competence and psychological functioning behavior in middle childhood. Merrill-Palmer Quarterly, 49(1), 55-76. doi: $10.1353 / \mathrm{mpq} .2003 .0004$

Miller, P. J., \& Fung, H. (2012). I. Introduction. Monographs of The Society for Research in Child Development, 77(1), 1-14. doi:10.1111/j.1540-5834.2011.00642.x

Miller, P. J., Fung, H., \& Mintz, J. (1996). Self-construction through narrative practices: A Chinese and American comparison of early socialization. Ethos, 24(2), 237-280.

Miller, P., \& Sperry, L. (1987). The socialization of anger and aggression. Merrill-Palmer Quarterly, 33, 1-31.

Miller, P. J., Wang, S., Sandel, T., \& Cho, G. E. (2002). Self-esteem as folk theory: A comparison of European American and Taiwanese mothers' beliefs. Parenting: Science and Practice, 2(3), 209-239. doi: 10.1207/S15327922PAR0203_02

Miller, P. J., Wiley, A. R., Fung, H., \& Wang, S. (1997). Personal storytelling as a medium of socialization in Chinese and American families. Child Development, 68(3), 557-568. doi: $10.2307 / 1131678$

Misailidi, P. (2006). Young children's display rule knowledge: Understanding the distinction between apparent and real emotions and the motives underlying the use of display rules. Social Behavior and Personality, 34(10), 1285-1296. 
Mize, J., \& Pettit, G. S. (1997). Mothers' social coaching, mother-child relationship style, and children's peer competence: Is the medium the message? Child Development, 68(2), 312332. doi: $10.2307 / 1131852$

Morris, A. S., Silk, J. S., Steinberg, L., Myers, S. S., \& Robsinson, L. R. (2007). The role of the family context in the development of emotion regulation. Social Development, 16(2), 361-388. doi: 10.1111/j.1467-9507.2007.00389.x

Nansel, T. R., Overpeck, M., Pilla, R. S., Ruan, W. J., Simons-Morton, B., \& Scheidt, P. (2008). Bullying behaviors among US youth: Prevalence and association with psychosocial adjustment. The Journal of the American Medical Association, 285(16), 2094-2100. doi: $10.1001 /$ jama.285.16.2094

Narvaez, D., Gleason, T., Mitchell, C., \& Bentley, J. (1999). Moral theme comprehension in children. Journal of Educational Psychology, 91(3), 477-487. doi: $10.1037 / 0022-0663.91 .3 .477$

Nelson, K. (1993). The psychological and social origins of autobiographical memory. Psychological Science, 4(1), 7-14. doi: 10.1111/j.1467-9280.1993.tb00548.x

Nolen-Hoeksema, S. (1990). Sex differences in depression. Stanford, CA: Stanford University Press.

Nolen-Hoeksema, S. (1991). Responses to depression and their effects on the duration of depressive episodes. Journal of Abnormal Psychology, 100, 569-582.

Orne, M. T. (1962). On the social psychology of the psychological experiment: With particular reference to demand characteristics and their implications. American Psychologist, 17, 776-783. doi: 10.1037/h0043424 
Peterson, C., \& Rideout, R. (1998). Memory for medical emergencies experienced by 1- and 2year-olds. Developmental Psychology, 34(5), 1059-1072.

doi: $10.1037 / 0012-1649.34 .5 .1059$

Peterson, C., Sales, J. M., Rees, M., \& Fivush, R. (2006). Parent-child talk and children’s memory for stressful events. Applied Cognitive Psychology, 21(8), 1057-1075. doi: $10.1002 /$ acp. 1314

Raikes, H. A., \& Thompson, R. A. (2008). Conversations about emotion in high-risk dyads. Attachment \& Human Development. 10(4), 359-377. doi: 10.1080/14616730802461367

Reese, E., Bird, A., \& Tripp, G. (2007). Children's self-esteem and moral self: Links to parentchild conversations regarding emotion. Social Development, 16(3), 460-478. doi: 10.1111/j.1467-9507.2007.00393.x

Reese, E., \& Brown, N. (2000). Reminiscing and recounting in the preschool years. Applied Cognitive Psychology, 14(1), 1-17. doi:10.1002/(SICI)1099-0720(200001)14:1<1::AID$\mathrm{ACP} 625>3.3 . \mathrm{CO} ; 2-7$

Reese, E., \& Newcombe, R. (2007). Training mothers in elaborative reminiscing enhances children's autobiographical memory and narrative. Child Development, 78(4), 1153 1170.

Rosenberg, M. (1965). Society and the adolescent self-image. Princeton, NJ: Princeton University Press.

Rothenberg, B. B. (1970). Children's social sensitivity and the relationship to interpersonal competence, intrapersonal comfort, and intellectual level. Developmental Psychology, 2(3), 335-350. doi:10.1037/h0029175 
Rudolph, K., \& Radey, M. (2011). Measuring parenting practices among parents of elementary school-age youth. Research on Social Work Practice, 21(1), 88-97. doi: $10.1177 / 1049731509353048$

Sales, J. M., Fivush, R., \& Peterson, C. (2003). Parental reminiscing about positive and negative events. Journal of Cognition \& Development, 4(2), 185-209. doi:10.1207/S15327647JCD0402_03

Smetana, J. G., Campione-Barr, N., \& Metzger, A. (2006). Adolescent development in interpersonal and societal contexts. Annual Review of Psychology, 57, 255-284. doi: 10.1146/annurev.psych.57.102904.190124

Suveg, C., Shaffer, A., Morelen, D., \& Thomassin, K. (2011). Links between maternal and child psychopathology symptoms: Mediation through child emotion regulation and moderation through maternal behavior. Child Psychiatry \& Human Development, 42(5), 507-520. doi: $10.1007 / \mathrm{s} 10578-011-0223-8$

Suveg, C., Zeman, J., Flannery-Schroeder, E., \& Cassano, M. (2005). Emotion socialization in families of children with an anxiety disorder. Journal of Abnormal Child Psychology, 33(2), 145-155. doi: 10.1007/s10802-005-1823-1

Thomson, S. B. (2011). Qualitative research: Validity. Journal of Administration \& Governance, $6(1), 77-82$.

Vygotsky, L. (1978). Interaction between learning and development. Mind and Society (pp. 7991). Cambridge, MA: Harvard University Press.

Wang, Q. (2001). "Did you have fun?: American and Chinese mother-child conversations about shared emotional experiences. Cognitive Development, 16(2), 693-715. doi: 10.1016/S0885-2014(01)00055-7 
Wang, Q., \& Fivush, R. (2005). Mother-child conversations of emotionally salient events: Exploring the functions of emotional reminiscing in European-American and Chinese families. Social Development, 14(3), 473-495. doi:10.1111/j.1467-9507.2005.00312.x

Wareham, P., \& Salmon, K. (2006). Mother-child reminiscing about everyday experiences: Implications for psychological interventions in the preschool years. Clinical Psychology Review, 26(5), 535-554. doi: 10.1016/j.cpr.2006.05.001

Watson, D., Clark, L. A., \& Tellegen, A. (1988). Development and validation of brief measures of positive and negative affect: The PANAS scales. Journal of Personality and Social Psychology, 54(6), 1063-1070. doi:10.1037/0022-3514.54.6.1063

Widen, S. C., \& Russell, J. A. (2010). Children's scripts for social emotions: Causes and consequences are more central than are facial expressions. British Journal of Developmental Psychology, 28(3), 565-581. doi: 10.1348/02615I OO9X457550d

Wiley, A. R., Rose, A. J., Burger, L. K., \& Miller, P. J. (1998). Constructing autonomous selves through narrative practices: A comparative study of working-class and middle-class families. Child Development, 69(3), 833-847.

Woolgar, M., Steele, H., Steele, M., Yabsley, S., \& Fonagy, P. (2001). Children's play narrative responses to hypothetical dilemmas and their awareness of moral emotions. British Journal of Developmental Psychology, 19(Pt1), 115-128. doi:10.1348/026151001165994 
Table 1

Descriptive characteristics of conversations

\begin{tabular}{|c|c|c|c|c|c|c|c|c|}
\hline & \multicolumn{2}{|c|}{ Happy } & \multicolumn{2}{|c|}{$\underline{\mathrm{Sad}}$} & \multicolumn{2}{|c|}{ Scared/Worried } & \multicolumn{2}{|c|}{ Angry } \\
\hline & $M$ & $S D$ & $M$ & $S D$ & $M$ & $S D$ & $M$ & $S D$ \\
\hline $\begin{array}{l}\text { Maternal } \\
\text { Exchanges }\end{array}$ & 22.4 & 13.4 & 15.0 & 8.5 & 24.0 & 18.4 & 16.6 & 11.5 \\
\hline Child Exchanges & 20.9 & 13.3 & 13.5 & 8.2 & 16.4 & 11.8 & 15.0 & 10.0 \\
\hline $\begin{array}{l}\text { Length of } \\
\text { Conversation } \\
\text { (Minutes) }\end{array}$ & 6.0 & - & 5.0 & - & 5.0 & - & 6.0 & - \\
\hline $\begin{array}{l}\text { Event Occurrence } \\
\text { prior to } \\
\text { Conversation } \\
\text { (Months) }\end{array}$ & 15.5 & 18.0 & 19.7 & 26.9 & 15.5 & 19.6 & 3.2 & 5.9 \\
\hline
\end{tabular}


Table 2

Coding system codes, definitions, and examples from this study

\begin{tabular}{|c|c|c|}
\hline Code & Definition & Example from this Study \\
\hline Content & The topic of the conversation & Severe weather \\
\hline Themes & $\begin{array}{l}\text { The meaningful grouping of } \\
\text { topics }\end{array}$ & Safety \\
\hline \multicolumn{3}{|l|}{ Maternal Processes } \\
\hline $\begin{array}{l}\text { Clarification on what the } \\
\text { emotion is }\end{array}$ & $\begin{array}{l}\text { Mention of emotion } \\
\text { words/behavior related to } \\
\text { child }\end{array}$ & $\begin{array}{l}\text { "How did that make you } \\
\text { feel?" }\end{array}$ \\
\hline $\begin{array}{l}\text { Clarification on why the } \\
\text { child's emotion occurred }\end{array}$ & $\begin{array}{l}\text { Attributes cause to or explains } \\
\text { child's emotion }\end{array}$ & "Why were you sad?" \\
\hline Eliciting of information & $\begin{array}{l}\text { Gets child to present new } \\
\text { information without } \\
\text { mentioning emotion }\end{array}$ & $\begin{array}{l}\text { "Was that the first time you } \\
\text { got to fly on an airplane?" }\end{array}$ \\
\hline Core issue & $\begin{array}{l}\text { Addresses main reason child } \\
\text { experienced emotion }\end{array}$ & $\begin{array}{l}\text { "And that's what really } \\
\text { bothered you?" }\end{array}$ \\
\hline Discussion of own emotion & Mentions mother's emotion & $\begin{array}{l}\text { "I was confused. I was } \\
\text { worried and I didn't know } \\
\text { what was going to happen } \\
\text { next." }\end{array}$ \\
\hline Shared reaction & $\begin{array}{l}\text { Mentions mother-child shared } \\
\text { emotion }\end{array}$ & "We cried and cried." \\
\hline Reduce negative emotion & $\begin{array}{l}\text { Attempts to resolve child's } \\
\text { negative emotions or ask } \\
\text { whether they're resolved }\end{array}$ & $\begin{array}{l}\text { "But that helped make it so it } \\
\text { wasn't so sad." }\end{array}$ \\
\hline Adding information & $\begin{array}{l}\text { Adds new details without } \\
\text { mentioning emotion }\end{array}$ & $\begin{array}{l}\text { "We had to figure out how to } \\
\text { get to the terminal." }\end{array}$ \\
\hline Lesson & $\begin{array}{l}\text { Conveys life lesson or gives } \\
\text { advice to child }\end{array}$ & $\begin{array}{l}\text { "If you can't stay where you } \\
\text { are, what should you do?" }\end{array}$ \\
\hline Negative comment & Reprimands or ridicules child & $\begin{array}{l}\text { "You're both bull-headed and } \\
\text { stubborn." }\end{array}$ \\
\hline
\end{tabular}


Exact Strategies

\section{Child Processes}

Clarification on what the emotion is

Clarification on why the child's emotion occurred

Eliciting of information

Eliciting of advice

Reduce negative emotion

Adding information

Lesson

Thanking the mother

Discussion of others' emotions

Negative comment

\section{Life lessons}

Exact questions mothers asked that fit under each process

Mention of child's own emotion

Attributes cause to or explains child's own emotion

Gets mother to present new information without mentioning emotion

Gets mother to give advice

Shows child's negative emotions have or have not been resolved or attempts to resolve child's own negative emotions

Contains new details without mentioning emotions - correct or confirm mother

Shows child has learned a lesson

Thanks the mother for support, advice, or compliment

Mention of others' emotions

Reprimands or ridicules others

Mentions proper behavior/rules/morals or gives or asks child to give solutions
"What is it that your sibling does that makes you angry?"

"Yes, I was very sad."

"I just thought our car was going to slide off the hill and crash. It was really dangerous."

"Downtown Disney, was it called?"

"Well what do you think I should do?"

"Still worried...scared."

"So it was really only just you and me when we came down."

"If somebody was being yucky to me, I'd tell."

"Thanks for giving me some advice."

"You were on the phone and you seemed really sad, so I asked why you seemed sad."

"I wanted to kill you."

"You have to talk about things that make you sad to deal with things." 
Self-Esteem Statements

Maternal Approach

Statements

Approach emotion

Approach emotion resolution

Approach event detail
Supports child's expression/evaluation of emotions, praises child/behavior, or recasts child's weakness as strength

Asking how a child feels, if a child feels a certain way, or summarizes/reflects on child's feelings - direct or indirect; or explains why child felt emotion

\section{Reduces child's negative} emotion or asks whether child's negative emotion is reduced

Either provides more information or obtains more information without mentioning emotion
"You were very good while you were there. You were well behaved and a good helper."

Direct- "It makes you upset?"

Indirect-"How'd that make your stomach feel?"

"Ok you got scared going through the water, but what did mommy do to help you get through that?"

"And then what would happen?" 
Table 3

Inter-rater reliability for the coding system, as calculated by Cohen's kappa

\begin{tabular}{|c|c|}
\hline Code & Cohen's Kappa (к) \\
\hline \multicolumn{2}{|l|}{ Maternal Processes } \\
\hline What and Why of Emotion & .97 \\
\hline Reduce Negative Emotion & .92 \\
\hline Shared Reaction & .84 \\
\hline Eliciting Information & .98 \\
\hline Core Issue & 1.0 \\
\hline Life Lesson & .82 \\
\hline \multicolumn{2}{|l|}{ Child Processes } \\
\hline What and Why of Emotion & .75 \\
\hline Reduce Negative Emotion & .60 \\
\hline Add Information & .72 \\
\hline Elicit Information & .74 \\
\hline Elicit Advice & .91 \\
\hline Discuss Others' Emotions & .66 \\
\hline Thank Mother & 1.0 \\
\hline Life Lessons & .95 \\
\hline Self-Esteem Statements & .90 \\
\hline \multicolumn{2}{|l|}{ Maternal Approach Statements } \\
\hline Approach Emotion & .83 \\
\hline Approach Emotion Resolution & .86 \\
\hline Approach Event Detail & .87 \\
\hline
\end{tabular}


Table 4

Name and number of topics discussed by mother-child dyads, per emotion conversation

\begin{tabular}{|c|c|c|c|c|}
\hline Content & $\begin{array}{c}\text { Happy } \\
\text { (n ) }\end{array}$ & $\begin{array}{l}\text { Sad } \\
(n)\end{array}$ & $\begin{array}{c}\text { Scared/ } \\
\text { Worried } \\
(n)\end{array}$ & $\begin{array}{c}\text { Angry } \\
\text { (n) }\end{array}$ \\
\hline Vacation/Trip & 9 & - & - & - \\
\hline Extracurricular Activities & 5 & - & - & - \\
\hline Feeling Good at Something & 2 & - & - & - \\
\hline New Friends & 2 & - & - & - \\
\hline Birth of Sibling & 2 & - & - & - \\
\hline New Pet & 1 & - & - & - \\
\hline Appropriate Behavior at School & 1 & - & - & - \\
\hline Religious Rite of Passage & 1 & - & - & - \\
\hline Going to Work with Parent & 1 & - & - & - \\
\hline Death/Lost Pet & - & 5 & 1 & - \\
\hline Separation from Loved One & - & 4 & - & - \\
\hline Moving & - & 3 & - & - \\
\hline Death of Loved One & - & 3 & - & - \\
\hline Losing Friends & - & 3 & - & - \\
\hline Getting Injured & - & 1 & 3 & 1 \\
\hline Performance in Sporting Event & - & 1 & 1 & 2 \\
\hline Losing/Breaking a Belonging & - & 1 & - & 2 \\
\hline Not Able to go Somewhere/do Something & - & 1 & - & 6 \\
\hline Not Wanting to Express Emotion & - & 1 & - & - \\
\hline TV Show Interrupted & - & 1 & - & - \\
\hline Parents' Well-Being & - & - & 2 & - \\
\hline Being Home Alone & - & - & 2 & - \\
\hline First Day of School & - & - & 1 & - \\
\hline Haunted House & - & - & 1 & - \\
\hline Sibling Lost & - & - & 1 & - \\
\hline Having Medical Procedure & - & - & 2 & - \\
\hline Riding Roller Coaster & - & - & 1 & - \\
\hline Not being Picked Up by Parent & - & - & 1 & - \\
\hline Almost Missing a Flight & - & - & 1 & - \\
\hline Argument with Friend & - & - & - & 8 \\
\hline Relationship Jealousy & - & - & - & 2 \\
\hline Broken Promise & - & - & - & 2 \\
\hline Blamed for Something did not do & - & - & - & 1 \\
\hline
\end{tabular}


Table 5

Name and number of themes discussed by mother-child dyads, per emotion conversation

\begin{tabular}{|c|c|c|c|c|}
\hline Themes & $\begin{array}{c}\text { Happy } \\
\text { (n) }\end{array}$ & $\begin{array}{l}\text { Sad } \\
(n) \\
\end{array}$ & $\begin{array}{c}\text { Scared/ } \\
\text { Worried } \\
(n) \\
\end{array}$ & $\begin{array}{c}\text { Angry } \\
(n) \\
\end{array}$ \\
\hline Novel Experiences & 19 & 2 & 1 & - \\
\hline Social Inclusion & 8 & - & - & - \\
\hline Talent & 5 & - & - & - \\
\hline Loving Someone & 3 & - & - & - \\
\hline Transitions & 2 & - & 1 & - \\
\hline Earning Privileges & 1 & - & - & - \\
\hline Mixed Feelings & 1 & - & 1 & - \\
\hline Rite of Passage & 1 & - & - & - \\
\hline Death/Loss of Loved One & - & 8 & 1 & - \\
\hline Separation from Loved One & - & 7 & - & - \\
\hline Negotiating Interpersonal Conflict & - & 5 & - & 19 \\
\hline Safety & - & 2 & 21 & - \\
\hline Losing at Something & - & 1 & - & - \\
\hline Losing/Breaking Belonging & - & 1 & - & 2 \\
\hline Restricted Privileges & - & 1 & - & 5 \\
\hline Reminiscing & - & 1 & - & - \\
\hline Identifying/Expressing Emotions & - & 1 & - & 1 \\
\hline Fun Interrupted & - & 1 & - & - \\
\hline Missing Out on Opportunity & - & - & 1 & - \\
\hline Pressure to Perform Well & - & - & 1 & - \\
\hline Fear of Letting Others Down & - & - & 1 & - \\
\hline Negotiating Scheduling & - & - & - & 1 \\
\hline Stressful Experiences & - & - & - & 1 \\
\hline
\end{tabular}


Table 6

Order of maternal processes used, per emotion conversation

\begin{tabular}{|c|c|c|c|c|}
\hline & Happy & Sad & Scared/Worried & Angry \\
\hline \multirow[t]{10}{*}{$\begin{array}{l}\text { Maternal } \\
\text { Processes }\end{array}$} & $\begin{array}{l}\text { Clarification of } \\
\text { what emotion is }\end{array}$ & $\begin{array}{c}\text { Elicit } \\
\text { information }\end{array}$ & $\begin{array}{c}\text { Elicit } \\
\text { information }\end{array}$ & $\begin{array}{c}\text { Elicit } \\
\text { information }\end{array}$ \\
\hline & $\begin{array}{c}\text { Clarification of } \\
\text { why emotion was } \\
\text { experienced }\end{array}$ & $\begin{array}{l}\text { Clarification of } \\
\text { what emotion is }\end{array}$ & $\begin{array}{l}\text { Clarification of } \\
\text { what emotion is }\end{array}$ & $\begin{array}{l}\text { Clarification of } \\
\text { what emotion is }\end{array}$ \\
\hline & $\begin{array}{c}\text { Elicit } \\
\text { information }\end{array}$ & $\begin{array}{c}\text { Clarification of } \\
\text { why emotion was } \\
\text { experienced }\end{array}$ & $\begin{array}{c}\text { Adding } \\
\text { information }\end{array}$ & $\begin{array}{c}\text { Clarification of } \\
\text { why emotion was } \\
\text { experienced }\end{array}$ \\
\hline & $\begin{array}{c}\text { Reduce negative } \\
\text { emotion }\end{array}$ & $\begin{array}{l}\text { Adding } \\
\text { information }\end{array}$ & $\begin{array}{c}\text { Reduce negative } \\
\text { emotion }\end{array}$ & $\begin{array}{c}\text { Reduce negative } \\
\text { emotion }\end{array}$ \\
\hline & $\begin{array}{c}\text { Adding } \\
\text { information }\end{array}$ & $\begin{array}{c}\text { Reduced } \\
\text { negative emotion }\end{array}$ & $\begin{array}{c}\text { Clarification of } \\
\text { why emotion was } \\
\text { experienced }\end{array}$ & $\begin{array}{c}\text { Adding } \\
\text { information }\end{array}$ \\
\hline & $\begin{array}{l}\text { Discussion of } \\
\text { own emotions }\end{array}$ & $\begin{array}{l}\text { Discussion of } \\
\text { own emotions }\end{array}$ & Core issue & Lesson \\
\hline & Shared reactions & Shared reactions & $\begin{array}{l}\text { Discussion of } \\
\text { own emotions }\end{array}$ & Core issue \\
\hline & - & Core issue & Shared reactions & $\begin{array}{l}\text { Negative } \\
\text { comment }\end{array}$ \\
\hline & - & Lesson & Lesson & - \\
\hline & - & - & $\begin{array}{l}\text { Negative } \\
\text { comment }\end{array}$ & - \\
\hline
\end{tabular}


Table 7

Mean use of maternal conversational processes by emotion event

\begin{tabular}{lcccccccc}
\hline \multicolumn{2}{l}{ Happy } & \multicolumn{2}{c}{$\underline{\text { Sad }}$} & \multicolumn{2}{c}{ Scared/Worried } & \multicolumn{2}{c}{ Angry } \\
Process & $M$ & $S D$ & $M$ & $S D$ & $M$ & $S D$ & $M$ & $S D$ \\
What emotion & 1.2 & 1.0 & 1.2 & 1.1 & 0.9 & 0.8 & 1.0 & 1.0 \\
Why emotion & 1.0 & 1.2 & 0.7 & 0.7 & 1.0 & 1.0 & 1.2 & 1.3 \\
Elicit information & 2.9 & 1.6 & 2.5 & 1.4 & 2.2 & 1.5 & 2.5 & 1.8 \\
Core issue & 0 & 0 & 0.1 & 0.3 & 0.2 & 0.2 & 0.1 & 0.3 \\
Own emotion & 0.5 & 0.7 & 0.2 & 0.4 & 0.3 & 0.5 & 0.1 & 0.4 \\
Shared reaction & 0.1 & 0.3 & 0.3 & 0.7 & 0.1 & 0.6 & 0 & 0 \\
Reduce negative & 0.6 & 1.0 & 1.5 & 1.6 & 1.8 & 1.1 & 1.2 & 1.3 \\
Add information & 1.4 & 1.6 & 1.4 & 1.7 & 1.7 & 1.5 & 1.3 & 1.9 \\
Lesson & 0 & 0.2 & 0.1 & 0.4 & 0.2 & 0.4 & 0.5 & 0.9 \\
Negative comment & 0 & 0 & 0 & 0.2 & 0 & 0.2 & 0 & 0.2 \\
\hline
\end{tabular}


Table 8

Order of children's processes, per emotion conversation

\begin{tabular}{|c|c|c|c|c|}
\hline & Happy & Sad & Scared/Worried & Angry \\
\hline \multirow{17}{*}{$\begin{array}{l}\text { Children's } \\
\text { Processes }\end{array}$} & Clarification of & Clarification of & Clarification of what & Clarification of \\
\hline & what emotion is & what emotion is & emotion is & what emotion is \\
\hline & Clarification of & Clarification of & Clarification of why & Clarification of \\
\hline & why emotion was & why emotion was & emotion was & why emotion was \\
\hline & experienced & experienced & experienced & experienced \\
\hline & Adding & Elicit information & Adding information & Adding \\
\hline & information & & & information \\
\hline & Elicit information & Adding & Reduce negative & Elicit information \\
\hline & & information & emotion & \\
\hline & Discussion of & Reduced negative & Elicit information & Elicit advice \\
\hline & other's emotions & emotion & & \\
\hline & Reduce negative & Elicit advice & Lesson & Reduce negative \\
\hline & emotion & & & emotion \\
\hline & Negative & Discussion of & Elicit advice & Discussion of \\
\hline & comment & others' emotions & & others' emotions \\
\hline & - & Lesson & Discussion of others' & Thank mother \\
\hline & - & - & Thank mother & - \\
\hline
\end{tabular}


Table 9

Mean use of children's conversational processes by emotion conversation

\begin{tabular}{lcccccccc}
\hline & \multicolumn{2}{c}{ Happy } & \multicolumn{2}{c}{ Sad } & & \multicolumn{2}{c}{ Scared/Worried } & \multicolumn{2}{c}{ Angry } \\
Process & $M$ & $S D$ & $M$ & $S D$ & $M$ & $S D$ & $M$ & $S D$ \\
\hline What emotion & 3.3 & 3.5 & 2.4 & 2.1 & 2.6 & 1.6 & 1.7 & 1.3 \\
Why emotion & 1.6 & 1.6 & 1.3 & 1.5 & 2.2 & 2.6 & 1.2 & 1.9 \\
Elicit information & 0.6 & 1.3 & 0.5 & 1.0 & 0.4 & 0.6 & 0.4 & 0.8 \\
Elicit advice & 0 & 0 & 0.1 & 0.3 & 0.1 & 0.6 & 0.3 & 1.3 \\
Reduce negative & 0 & 0.2 & 0.8 & 1.3 & 1.2 & 1.3 & 0.3 & 0.5 \\
Add information & 9.4 & 6.6 & 5.6 & 3.7 & 5.8 & 6.2 & 6.5 & 4.8 \\
Lesson & 0 & 0 & 0 & 0.2 & 0.5 & 1.6 & 0 & 0 \\
Thank mother & 0 & 0 & 0 & 0 & 0 & 0.2 & 0.1 & 0.4 \\
Others' Emotions & 0.1 & 0.5 & 0.1 & 0.3 & 0 & 0.2 & 0.1 & 0.6 \\
Negative comment & 0 & 0.2 & 0 & 0 & 0 & 0 & 0.2 & 0.8 \\
\hline
\end{tabular}


Table 10

Themes of life lessons mothers conveyed, per emotion conversation

\begin{tabular}{|c|c|c|c|c|}
\hline $\begin{array}{l}\text { Life Lesson } \\
\text { Themes }\end{array}$ & Happy & Sad & $\begin{array}{l}\text { Scared/ } \\
\text { Worried }\end{array}$ & Angry \\
\hline \multirow[t]{4}{*}{$\begin{array}{l}\text { Managing } \\
\text { Interpersonal } \\
\text { Relationships }\end{array}$} & $\begin{array}{l}\text { It is nice to be } \\
\text { helpful to others }\end{array}$ & $\begin{array}{l}\text { Give people the } \\
\text { benefit of the } \\
\text { doubt }\end{array}$ & $\begin{array}{l}\text { You can trust } \\
\text { your parents to } \\
\text { keep you safe }\end{array}$ & $\begin{array}{l}\text { Give people the } \\
\text { benefit of the } \\
\text { doubt }\end{array}$ \\
\hline & $\begin{array}{l}\text { Your emotions } \\
\text { can affect others }\end{array}$ & $\begin{array}{l}\text { Your emotions } \\
\text { can affect others }\end{array}$ & - & $\begin{array}{l}\text { It is important to } \\
\text { appropriately } \\
\text { handle conflict } \\
\text { with others }\end{array}$ \\
\hline & - & - & - & $\begin{array}{l}\text { It is important to } \\
\text { express your } \\
\text { emotions to } \\
\text { others }\end{array}$ \\
\hline & - & - & - & $\begin{array}{c}\text { There are } \\
\text { consequences for } \\
\text { aggression }\end{array}$ \\
\hline $\begin{array}{l}\text { Negotiating } \\
\text { Scheduling }\end{array}$ & - & - & - & $\begin{array}{c}\text { It is important to } \\
\text { adhere to } \\
\text { schedules }\end{array}$ \\
\hline \multirow[t]{3}{*}{$\begin{array}{l}\text { Managing } \\
\text { Mood }\end{array}$} & - & $\begin{array}{c}\text { It is important to } \\
\text { express your } \\
\text { emotions }\end{array}$ & $\begin{array}{c}\text { It is important to } \\
\text { express your } \\
\text { emotions }\end{array}$ & - \\
\hline & - & $\begin{array}{c}\text { Death has } \\
\text { different } \\
\text { circumstances }\end{array}$ & $\begin{array}{l}\text { It is normal to } \\
\text { experience some } \\
\text { worry }\end{array}$ & - \\
\hline & - & $\begin{array}{l}\text { There are } \\
\text { methods to } \\
\text { reduce your } \\
\text { sadness }\end{array}$ & $\begin{array}{l}\text { There are } \\
\text { methods to } \\
\text { reduce your fear }\end{array}$ & - \\
\hline
\end{tabular}




\begin{tabular}{|c|c|c|c|c|}
\hline & - & $\begin{array}{l}\text { It is acceptable to } \\
\text { grieve and honor } \\
\text { deceased } \\
\text { individuals }\end{array}$ & - & - \\
\hline $\begin{array}{l}\text { Promoting } \\
\text { Safety }\end{array}$ & - & - & $\begin{array}{l}\text { It is important to } \\
\text { take steps for } \\
\text { your safety }\end{array}$ & - \\
\hline \multirow[t]{2}{*}{$\begin{array}{l}\text { Persevering } \\
\text { through } \\
\text { Challenging } \\
\text { Times }\end{array}$} & $\begin{array}{c}\text { Difficult } \\
\text { situations can } \\
\text { improve }\end{array}$ & $\begin{array}{l}\text { Good things can } \\
\text { come from } \\
\text { difficult } \\
\text { situations }\end{array}$ & $\begin{array}{c}\text { Difficult } \\
\text { situations can } \\
\text { improve }\end{array}$ & $\begin{array}{c}\text { Difficult } \\
\text { situations can } \\
\text { improve }\end{array}$ \\
\hline & $\begin{array}{c}\text { Working hard } \\
\text { pays off }\end{array}$ & - & - & - \\
\hline
\end{tabular}


Table 11

Themes of statements mothers used that are related to improving children's self-esteem, per emotion conversation

\begin{tabular}{|c|c|c|c|c|}
\hline $\begin{array}{l}\text { Self-Esteem } \\
\text { Statement Codes }\end{array}$ & Нарру & Sad & $\begin{array}{l}\text { Scared/ } \\
\text { Worried }\end{array}$ & Angry \\
\hline $\begin{array}{l}\text { Support child's } \\
\text { expression/evaluation } \\
\text { of emotion }\end{array}$ & $\begin{array}{l}\text { Validating } \\
\text { emotions }\end{array}$ & - & $\begin{array}{l}\text { Validating } \\
\text { emotions }\end{array}$ & $\begin{array}{l}\text { Validating } \\
\text { emotions }\end{array}$ \\
\hline \multirow[t]{3}{*}{ Person Praise } & $\begin{array}{l}\text { Social inclusion } \\
\text { or competence }\end{array}$ & $\begin{array}{l}\text { Social inclusion } \\
\text { or competence }\end{array}$ & Personality & - \\
\hline & Personality & - & - & - \\
\hline & $\begin{array}{l}\text { Memory and } \\
\text { description of } \\
\text { an event }\end{array}$ & - & - & - \\
\hline \multirow[t]{4}{*}{ Process Praise } & $\begin{array}{c}\text { Talent at } \\
\text { sporting event }\end{array}$ & Perseverance & Perseverance & $\begin{array}{c}\text { Talent at } \\
\text { sporting event }\end{array}$ \\
\hline & $\begin{array}{c}\text { Religious rite of } \\
\text { passage }\end{array}$ & - & Bravery & - \\
\hline & $\begin{array}{l}\text { Appropriate } \\
\text { behavior }\end{array}$ & - & $\begin{array}{l}\text { Appropriate } \\
\text { behavior }\end{array}$ & - \\
\hline & $\begin{array}{c}\text { Good grades in } \\
\text { school }\end{array}$ & - & - & - \\
\hline $\begin{array}{l}\text { Recasting Weakness } \\
\text { as Strength }\end{array}$ & Strengths & - & - & $\begin{array}{l}\text { Reducing } \\
\text { blame }\end{array}$ \\
\hline
\end{tabular}


Table 12

Mean use of maternal approach statements, per emotion conversation

\begin{tabular}{|c|c|c|c|c|c|c|c|c|}
\hline \multirow[b]{2}{*}{ Approach Statements } & \multicolumn{2}{|c|}{ Happy } & \multicolumn{2}{|c|}{$\underline{\mathrm{Sad}}$} & \multicolumn{2}{|c|}{$\underline{\text { Scared/Worried }}$} & \multicolumn{2}{|c|}{$\underline{\text { Angry }}$} \\
\hline & $M$ & $S D$ & $M$ & $S D$ & $M$ & $S D$ & $M$ & $S D$ \\
\hline Approach Emotion & 6.3 & 5.4 & 4.8 & 2.9 & 4.5 & 3.3 & 4.2 & 3.8 \\
\hline Approach Emotion Resolution & 0.1 & 0.4 & 1.5 & 2.0 & 2.8 & 2.7 & 1.7 & 2.5 \\
\hline Approach Event Detail & 14.1 & 9.5 & 8.3 & 6.3 & 10.2 & 9.6 & 9.5 & 9.2 \\
\hline
\end{tabular}


Table 13

Correlations among negative affect (NA) and positive affect (PA) on the PANAS and use of approach statements, per emotion

\begin{tabular}{|c|c|c|c|c|c|c|c|c|c|c|c|c|c|c|}
\hline Variable & 1 & 2 & 3 & 4 & 5 & 6 & 7 & 8 & 9 & 10 & 11 & 12 & 13 & 14 \\
\hline 1. NA, In General & 1 & & & & & & & & & & & & & \\
\hline 2. PA, In General & -.25 & 1 & & & & & & & & & & & & \\
\hline 3. Approach Emotion, Happy & -.02 & -.35 & 1 & & & & & & & & & & & \\
\hline 4. Approach Emotion Resolution, Happy & -.15 & 0 & .29 & $\mathbf{1}$ & & & & & & & & & & \\
\hline 5. Approach Event Detail, Happy & -.39 & -.21 & .26 & .29 & $\mathbf{1}$ & & & & & & & & & \\
\hline 6. Approach Emotion, Sad & .27 & -.40 & .29 & -.33 & .18 & 1 & & & & & & & & \\
\hline 7. Approach Emotion Resolution, Sad & .18 & -.32 & .16 & -.24 & .09 & .18 & 1 & & & & & & & \\
\hline 8. Approach Event Detail, Sad & -.13 & -.27 & -.01 & -.30 & .34 & $.60 * *$ & .06 & 1 & & & & & & \\
\hline 9. Approach Emotion, Worried & .12 & -.02 & .38 & .12 & -.04 & .20 & .15 & -.35 & 1 & & & & & \\
\hline 10. Approach Emotion Resolution, Worried & .11 & -.34 & .29 & -.03 & -.06 & 0 & $.54 * *$ & $-.45 *$ & $.52 * *$ & 1 & & & & \\
\hline 11. Approach Event Detail, Worried & $-.59 * *$ & .19 & .15 & -.06 & $.59 * *$ & .15 & .14 & .34 & -.03 & -.05 & 1 & & & \\
\hline 12. Approach Emotion, Angry & .08 & -.17 & .27 & -.03 & .17 & .23 & .11 & .01 & -.06 & .14 & .31 & 1 & & \\
\hline 13. Approach Emotion Resolution, Angry & .07 & -.13 & .15 & .34 & .33 & -.03 & .37 & -.08 & .16 & .09 & .02 & -.06 & 1 & \\
\hline 14. Approach Event Detail, Angry & $-.56 * *$ & -.15 & 0 & -.17 & $.58 * *$ & .24 & .07 & $.46^{*}$ & -.17 & .02 & $.62 * *$ & .05 & -.16 & 1 \\
\hline
\end{tabular}




\section{Table 14}

Correlations among negative affect (NA) and positive affect (PA) on the PANAS, and number of maternal conversational exchanges, per emotion

\begin{tabular}{|c|c|c|c|c|c|c|}
\hline Variable & 1 & 2 & 3 & 4 & 5 & 6 \\
\hline 1. NA, In General & 1 & & & & & \\
\hline 2. PA, In General & -.25 & 1 & & & & \\
\hline 3. Maternal Exchanges, Happy & -.22 & $-.41 *$ & 1 & & & \\
\hline 4. Maternal Exchanges, Sad & -.07 & -.35 & .30 & 1 & & \\
\hline 5. Maternal Exchanges, Worried/Scared & -.34 & -.09 & $.42 *$ & .05 & 1 & \\
\hline 6. Maternal Exchanges, Angry & -.24 & -.28 & $.63 * *$ & .36 & $.53 * *$ & 1 \\
\hline
\end{tabular}

$* * p<.01 ; * p<.05$ 
Figure 1. Mean Maternal Exchanges by Emotion Conversation

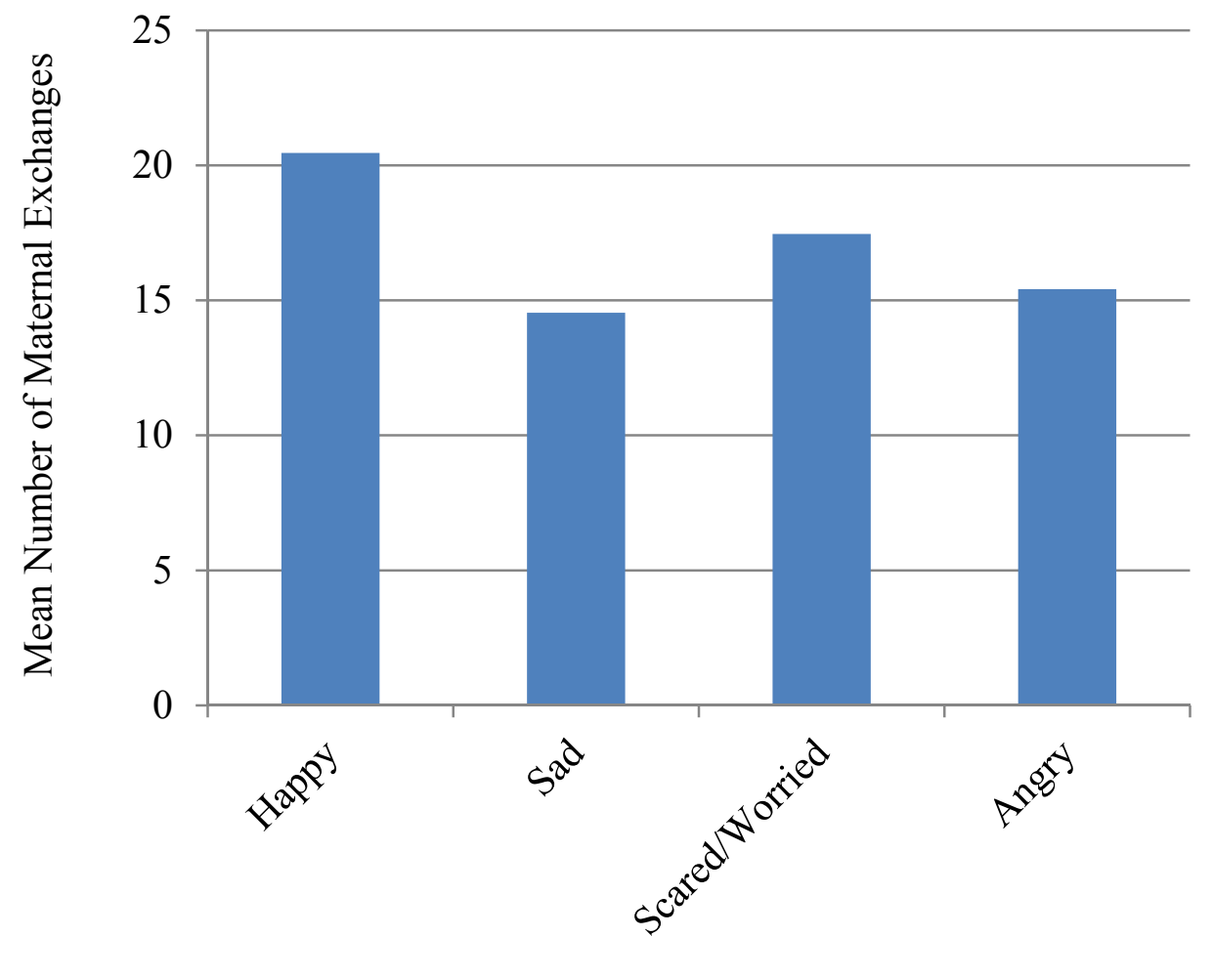

Emotion Conversation

Figure 1. Means for number of maternal exchanges by emotion conversation (i.e., happy, sad, scared/worried, angry). Mothers engaged in the highest number of maternal exchanges during happy conversations. 
Figure 2. Mothers' Use of Statements that Approach Emotion, Emotion Resolution, and Event Detail during Happy Conversations.

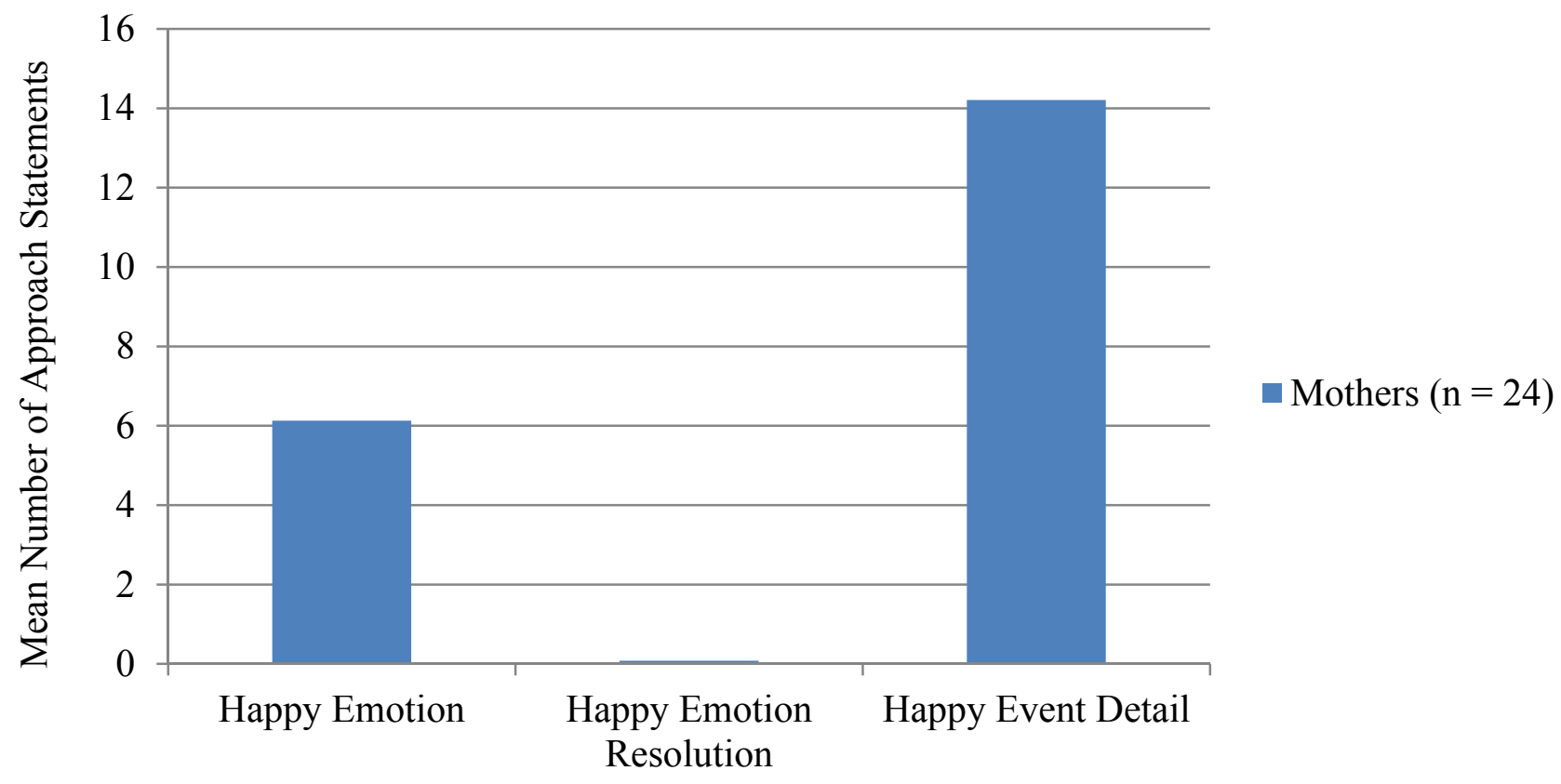

Approach Statement Type

Figure 2. Means for number of maternal statements that approach emotion, emotion resolution, and event detail statements during happy emotion conversations. Mothers approached event details most frequently and emotion resolution least frequently during happy conversations. 
Figure 3. Mothers' Use of Statements that Approach Emotion, Emotion Resolution, and Event Detail during Sad Conversations.

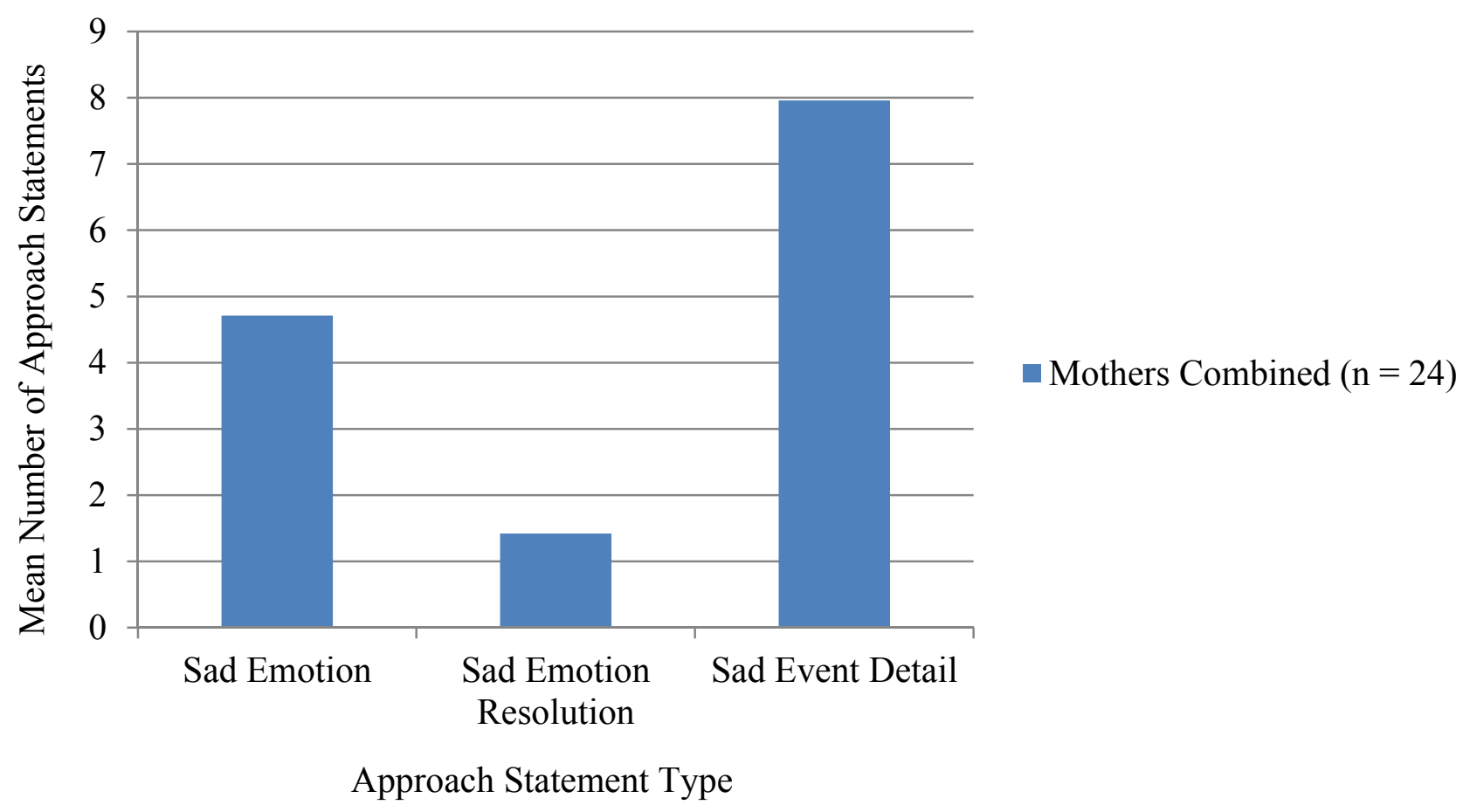

Figure 3. Means for number of maternal emotion, emotion resolution, and event detail statements for sad emotion conversations. Mothers approached event details most frequently and emotion resolution least frequently during sad conversations. 
Figure 4. Mothers' Use of Statements that Approach Emotion, Emotion Resolution, and Event Detail during Scared/Worried Conversations.

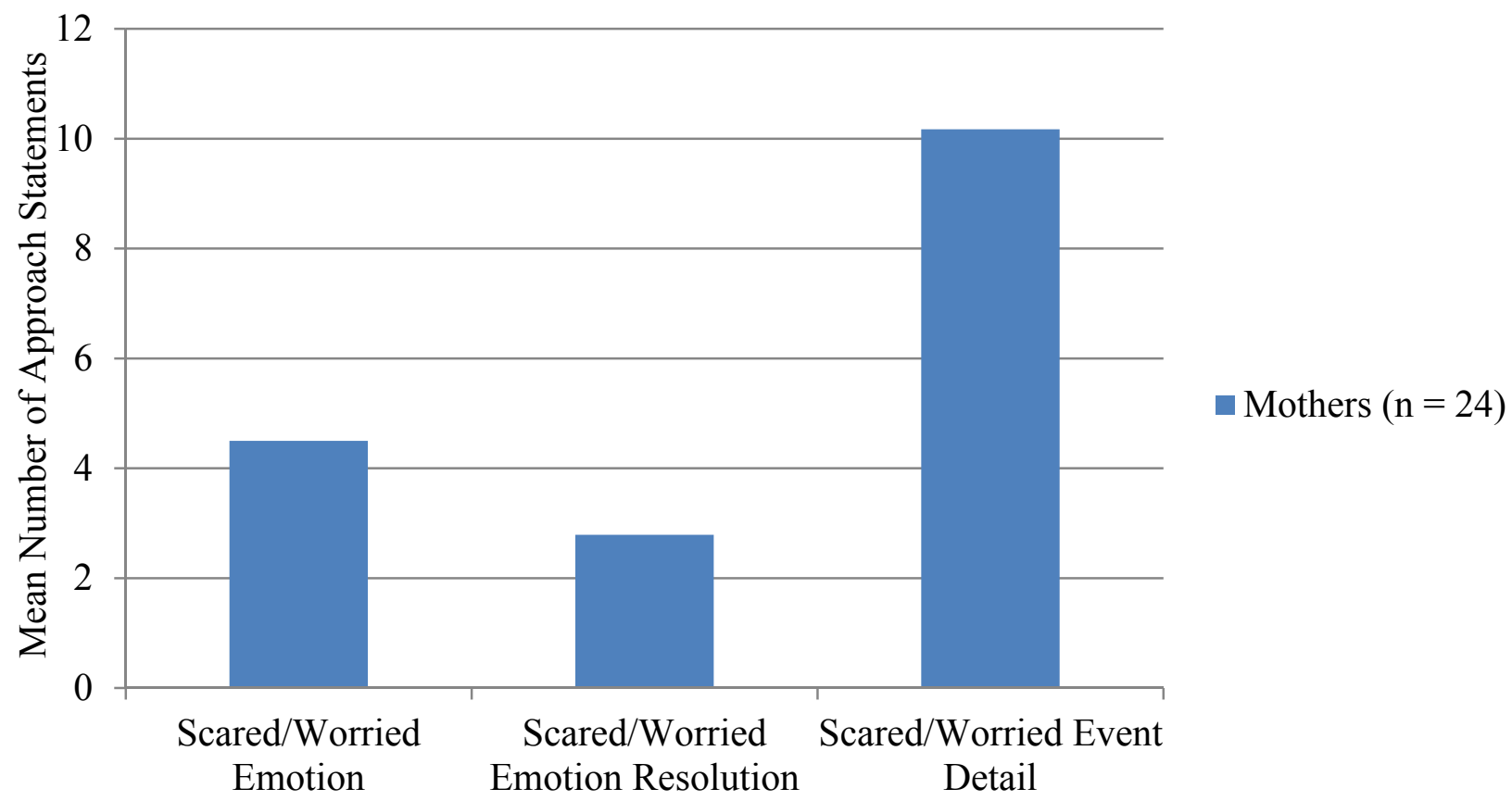

Approach Statement Type

Figure 4. Means for number of maternal emotion, emotion resolution, and event detail statements for scared/worried emotion conversations. Mothers approached event details most frequently and emotion resolution least frequently during scared/worried conversations. 
Figure 5. Mothers' Use of Statements that Approach Emotion, Emotion Resolution, and Event Detail during Angry Conversations.

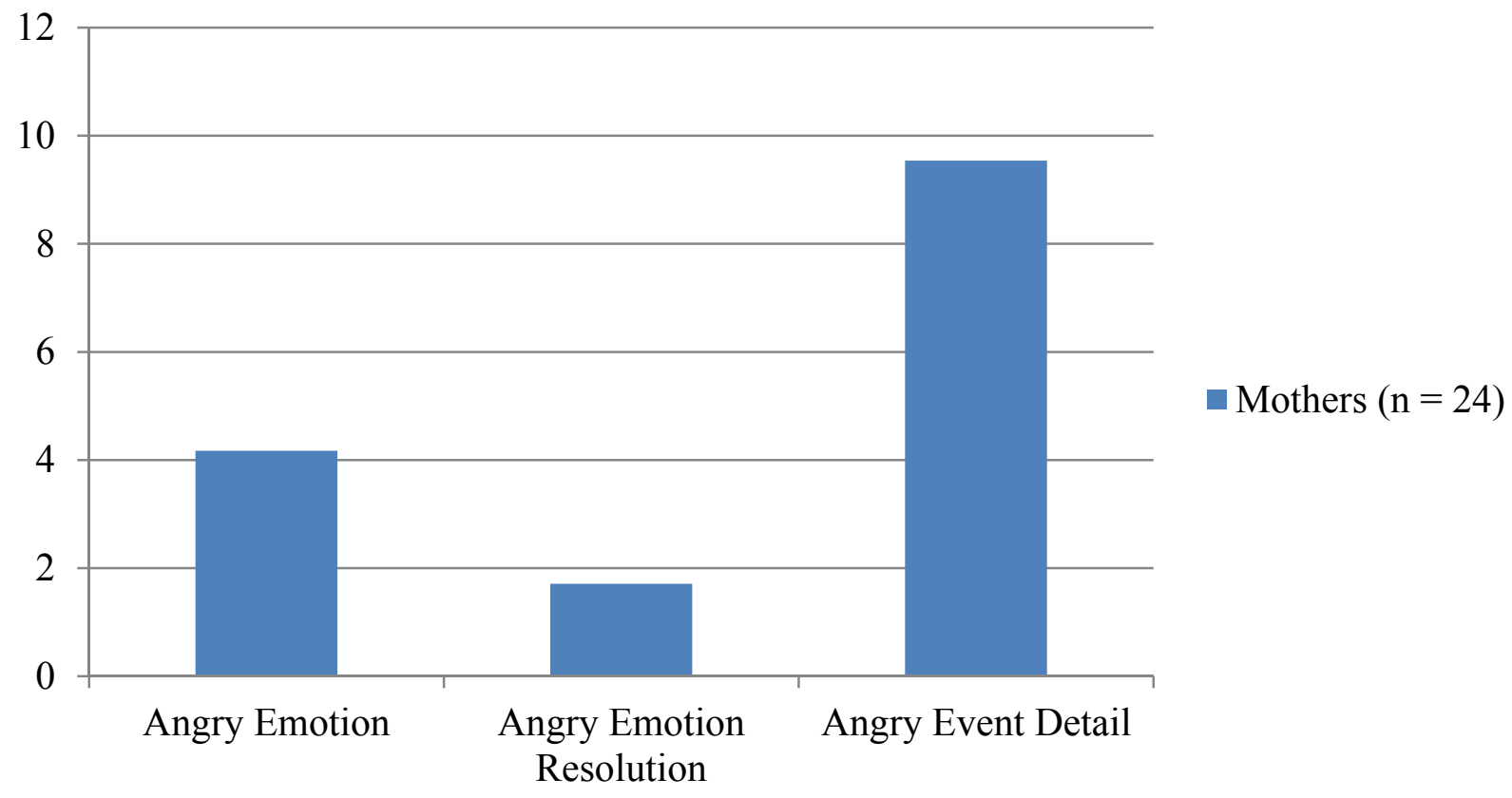

Approach Statement Type

Figure 5. Means for number of maternal emotion, emotion resolution, and event detail statements for angry emotion conversations. Mothers approached event details most frequently and emotion resolution least frequently during angry conversations. 